\title{
Advanced Neutron Source (ANS) Project Progress Report FY 1993
}

\author{
Principal Authors \\ D. L. Selby R. M. Harrington \\ Oak Ridge National Laboratory \\ P. B. Thompson \\ Engineering Division \\ Martin Marietta Energy Systems, Inc.
}

Editor

J. H. Campbell

Oak Ridge National Laboratory

Electronic Publishers

L. W. Davis

S. C. Lyttle

Oak Ridge National Laboratory

Date Published-January 1994

Prepared by the

Oak Ridge National Laboratory

Oak Ridge, Tennessee 37831-6285

managed by

Martin Marietta Energy Systems, Inc.

for the

U.S. DEPARTMENT OF ENERGY

under Contract No. DE-AC05-84OR21400

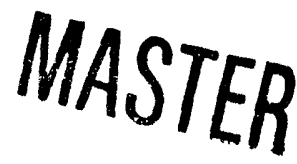




\section{Contributing Authors}

$\begin{array}{lll}\text { D. J. Alexander } & \text { A. W. Longest } & \text { W. K. Sartory } \\ \text { J. L. Anderson } & \text { A. T. Lucas } & \text { H. B. Shapira } \\ \text { R. L. Battiste } & \text { C. R. Luttrell } & \text { M. Siman Tov } \\ \text { R. E. Battle } & \text { M. F. Marchbanks } & \text { H. G. Smith } \\ \text { N. C. J. Chen } & \text { J. A. March-Leuba } & \text { T. K. Stovall } \\ \text { G. L. Copeland } & \text { J. T. Mihalczo } & \text { W. F. Swinson } \\ \text { W. W. Engle } & \text { H. A. Mook } & \text { R. P. Taleyarkhan } \\ \text { D. K. Felde } & \text { R. M. Moon } & \text { M. W. Wendel } \\ \text { J. C. Gehin } & \text { D. G. Morris } & \text { C. D. West } \\ \text { M. L. Gildner } & \text { R. E. Pawel } & \text { B. A. Worley } \\ \text { W. A. Hamilton } & \text { C. T. Ramsey } & \text { G. T. Yahr } \\ \text { W. R. Hendrich } & \text { J. P. Renier } & \text { G. L. Yoder, Jr. }\end{array}$

R. A. Lillie

Oak Ridge National Laboratory

R. R. Allen

J. R. DeVore

F. J. Peretz

R. S. Booth

C. C. Eberle

C. C. Queen

W. W. Bowman

T. J. McManamy

J. P. Schubert

R. A. Brown

G. R. McNutt

B. R. Smith

P. F. Cento

T. F. Orlin

D. W. Theisen

K. K. Chipley

H. R. Payne

D. M. Williams

J. E. Cleaves

Engineering Division, Martin Marietta Energy Systems, Inc.
R. C. Birtcher
J. L. Snelgrove
G. L. Hofman
T. C. Wiencek
J. Rest
Argonne National Laboratory
C. D. Fletcher
J. M. Ryskamp
L. S. Ghan
C. A. Wemple
A. M. Ougouag
Idaho National Engineering Laboratory
H. N. Goldstein $\quad$ P. J. Shipper
W. E. Meek P. T. Talarico
Gilbert/Commonwealth, Inc.

L. Crow

A. Steyerl

University of Rhode Island

G. K. Carlough

DRS/Hundley Kling Gmitter

C. F. Majkrzak

National Institute of Standards and Technology
C. R. Bass

H. G. Wood, III

University of Virginia

M. Ibn-Khayat

Oak Ridge Associated Universities

M. Kaminaga

Japan Atomic Energy Research Institute 


\section{CONTENTS}

Page

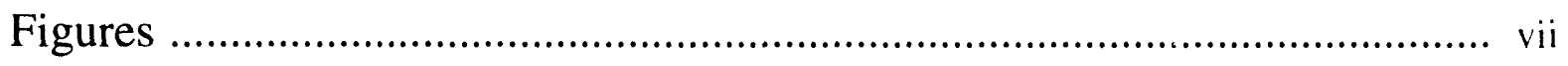

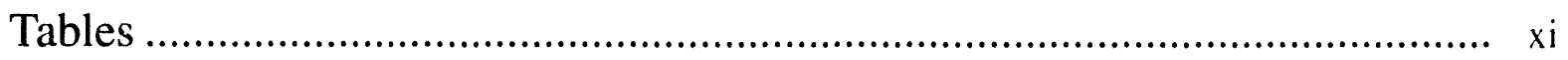

Acronyms .............................................................................. xiii

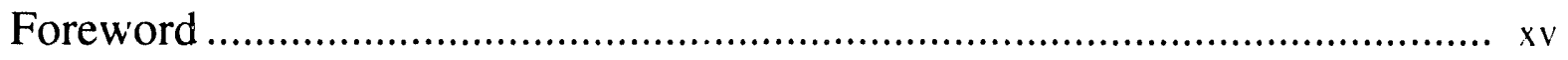

1. Project Management .................................................................. ।

1.1 ANS Project Quality Program ............................................................. 2

2. Research and Development ................................................... 3

2.1 Reactor Core Development ................................................................... 3

2.1.1 Development of New Fuel Grading ................................................ 3

2.1.2 Analysis of the FOEHN Criticals ........................................................ 4

2.1 .3 Treatment of Uncertainties .............................................................. 5

2.1.4 Impact of Photoneutron Production on Neutron

Spectrum in the Reflector ............................................................. 6

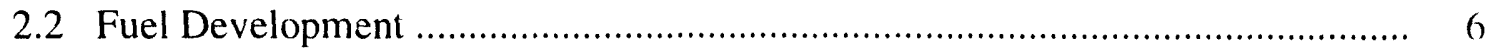

2.2.1 Irradiation of Fuel Capsules ......................................................... 7

2.2.2 Fuel Performance Studies and Modeling …...................................... 7

2.2.3 Fabrication Development ......................................................... 9

2.3 Corrosion Loop Tests and Analyses ......................................................

2.4 Thermal-Hydraulic Loop Tests ................................................................ 10

2.4.1 Test Loop Facility ...................................................................... 10

2.4.2 Data Reduction, Results, and Analysis .......................................... 12

2.4.3 Future Plans ........................................................................... 16

2.5 Reactor Control and Shutdown Concepts ........................................... 17

2.6 Critical and Subcritical Experiments ................................................. 17 
2.7 Material Data, Structural Tests, and Analyses …………............................... 18

2.7.1 Code Case for 6061-T6 Aluminum …………….............................. 18

2.7.2 Fracture Toughness of Irradiated 6061-T6 Aluminum ........................... 18

2.7.3 Core Pressure Boundary Tube Fracture Evaluation ................................. 19

2.7.4 Advanced Neutron Source Materials Information System ..................... 20

2.7.5 Fuel Plate Stability Tests and Analysis .................................................... 20

2.7.5.1 Experimental Studies of the Structural Response of the Fuel Plates to Coolant Flow ............................................ 20

2.7.5.2 Fuel Plate Thermal Deflection .............................................. 21

2.7.6 Inner Control Element Structural Stability ………………………...... 21

2.7.6.1 Flow-Induced Vibrations ..................................................... 22

2.7.6.2 Scram Performance Studies ................................................... 22

2.7.6.3 Control Element Test Facility ................................................ 22

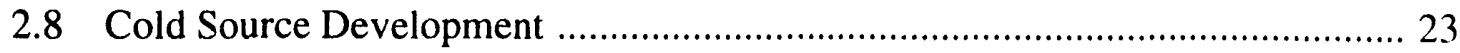

2.8.1 Design Principles of the Moderator Unit ........................................... 25

2.8.2 Cold Source Neutronics ...................................................................... 26

2.8.3 Liquid Deuterium Loop Design ....................................................... 26

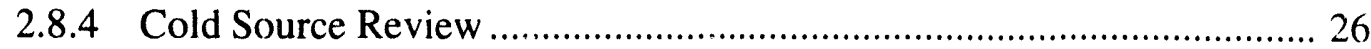

2.8.5 General Design Parameters .................................................................. 27

2.9 Beam Tube, Guide, and Instrument Development …………………............. 27

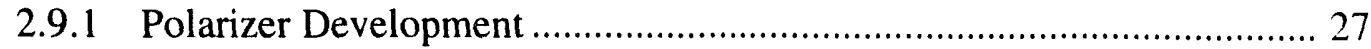

2.9.2 Neutron and Gamma Filters for Straight Neutron Guides ..................... 28

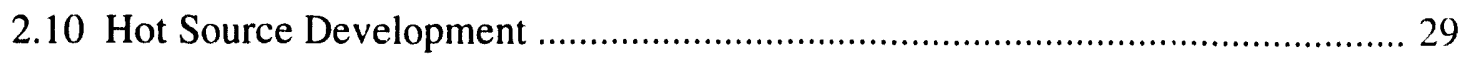

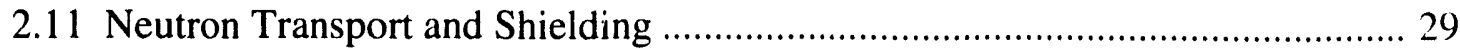

2.11.1 Cold Neutron Guide Tube Tunnel Shielding ........................................ 29

2.11.2 Shielding Cross-Section Library ......................................................... 30

2.11.3 Flux Characterization in the Heavy Water Vessel ................................. 30

2.11.4 Analysis of Beam Tube Shield Plugs ................................................... 30

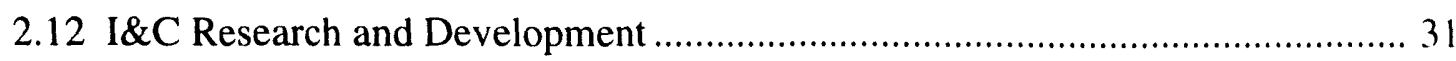

2.12.1 Neutron Kinetics Modeling ................................................................ 31

2.12.2 ANSDM, PRSDYN, RELAP5/ANS Benchmark ................................. 31

2.12.3 Reactor Inlet Temperature Control .................................................... 31

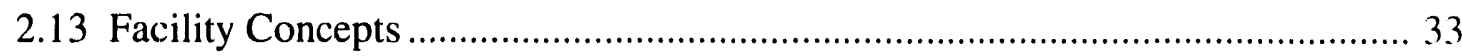

2.13.1 Test Plan Development ………………………............................... 33

2.13.2 Inner Control and Shutdown Rod Tests .............................................. 34

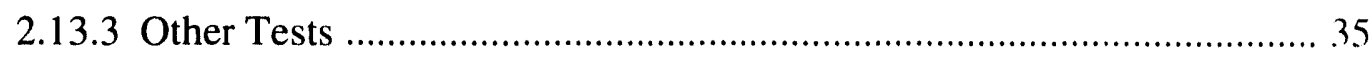

iv Advanced Neutron Source (ANS) Progress Report 


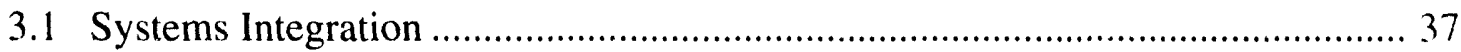

3.1.1 Configuration Management Philosophy ……………........................... 37

3.1.2 Configuration Management Experience ……………………………...... 37

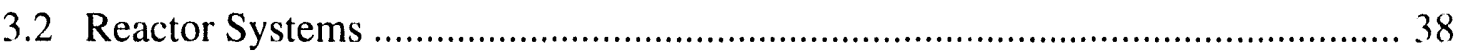

3.2.1 Reactor Primary Pressure Boundary Design ........................................ 38

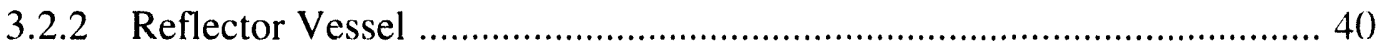

3.2.3 Control and Shutdown Rod Assembly ................................................ 41

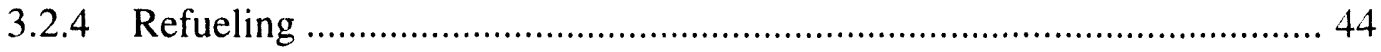

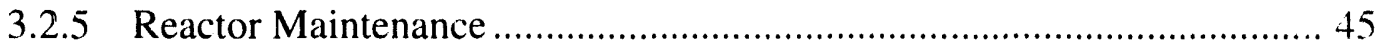

3.2.6 Modeling of the Reactor Assembly ...................................................... 45

3.2.7 Thimbles and Light Water Transition Assemblies ................................... 46

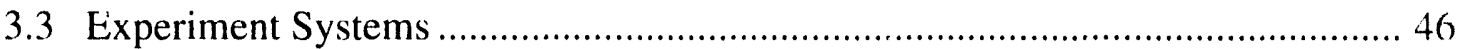

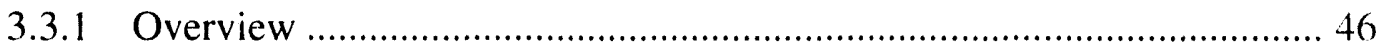

3.3.2 Neutron Beam Transport .................................................................. 46

3.3.3 Neutron Scattering and Physic, Instruments ........................................... 48

3.3.4 Irradiation and Isotope Production Facilities ......................................... 49

3.3.5 Hot Source ............................................................................... 49

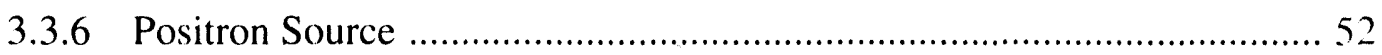

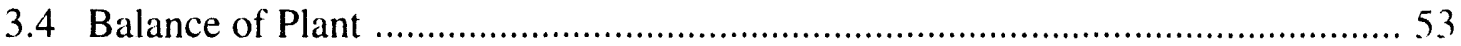

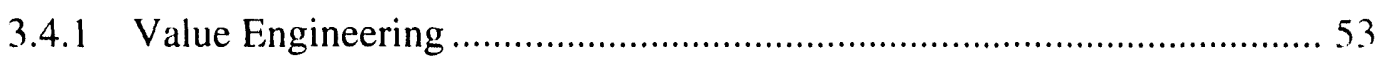

3.4.1.1 Value Engineering Proposals Adopted .................................... 53

3.4.1.2 Value Engineering Proposals Not Adopted .............................. 54

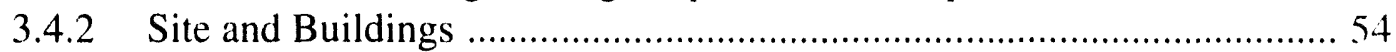

3.4.2.1 Site Characterization .............................................................. 54

3.4.2.2 Buildings and Site Arrangement .............................................. 54

3.4.2.3 Maintenance, Operation, Radiation Zone-

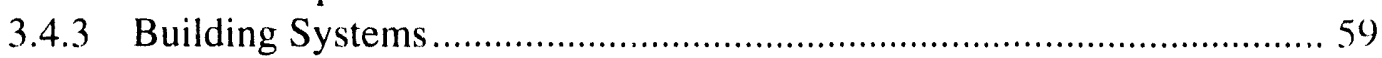

3.4.3.1 Reactor Primary Cooling System Study ................................ 59

3.4.3.2 Building Heating System ................................................... 59

3.4.3.3 Cryogenic Helium System ......................................................

3.4.3.4 Plant Fire Protection System ....................................................... (6)

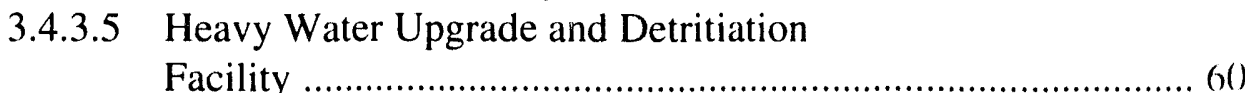

3.4.3.6 Instrumentation, Computing, and Electrical Systems ................ 62 


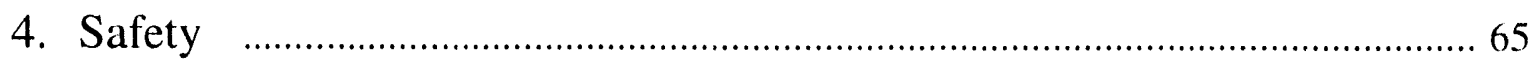

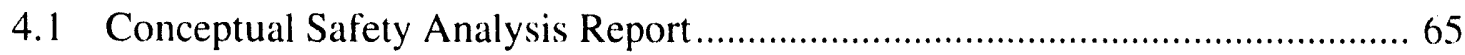

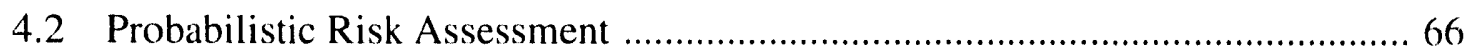

4.2.1 Level I Probabilistic Risk Assessment ....................................................66 66

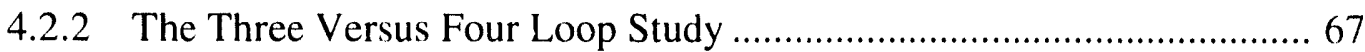

4.2.3 The Cold Source Availability Study ........................................................ 67

4.2.4 Flow Blockage Risk Mitigation Plans ...................................................... 67

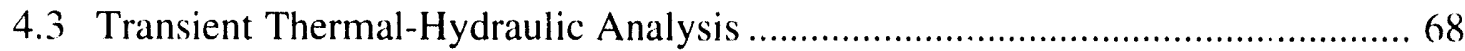

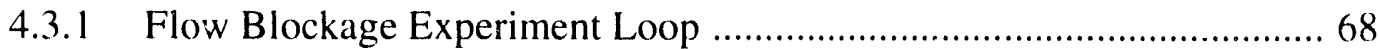

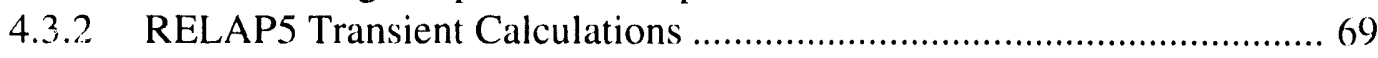

4.3.2.1 RELAP5 Code and Model Modifications ................................... 69

4.3.2.2 RELAP5 Transient Analysis …………................................. 70

4.3.2.3 RELAP5 Verification and Validation ...................................... 73

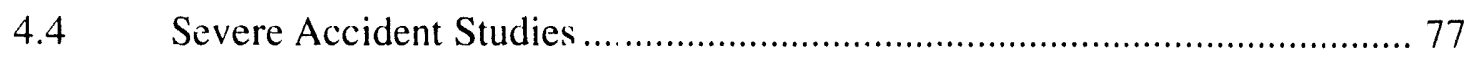

4.4.1 Performance Calculations for Alternate Containment Configuration Concepts.................................................................. 77

4.4.2 Pressure Wave Calculations for Hypothetical Local

$\mathrm{D}_{2}$-Air Detonation Events ............................................................. 80

4.4.3 Fission Product Chemistry Scoping Study ...................................... 82

4.4.4 Severe Accident Experimentation and Related Analysis ................... 84

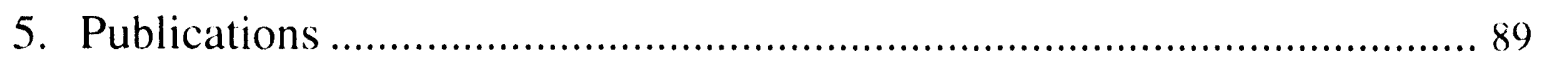

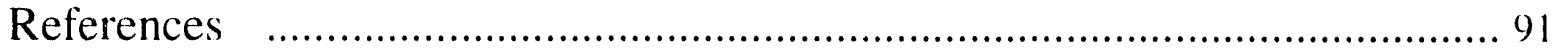




\section{FIGURES}

Figure

2.1 Comparison of measured and calculated data for three typical power distribution profiles

2.2 Microstructure of $\mathrm{U}_{3} \mathrm{Si}_{2}-\mathrm{Al}$ dispersion fuel irradiated to $90 \%$ burnup in the High Flux Isotope Reactor at Advanced Neutron Source conditions

2.3 Schematic interpretation of excursive instability 11

2.4 Flow excursion data from thermal-hydraulic test loop experiments 14

2.5 Comparison of flow excursion data from thermal-hydraulic test loop experiments

2.6 Destructive critical heat flux and flow excursion tests in the thermal-hydraulic test loop

2.7 The prompt-neutron lifetime and effective delayed-neutron fraction (including photoneutrons) during the Advanced Neutron Source fuel cycle

2.8 Fracture toughness results from Phases I and II from the HANSAL-T1 capsule

2.9 Schematic of the control element test facility flow loop

2.10 Relative positions of the components in the deuterium loop..... 24

2.11 The operational envelope of the cold source system 25

2.12 Polarizing supermirror response as a function of scattering angle 28

2.13 Time delay in sensing power changes as a function of distance from core 32

2.14 Comparison of transfer functions and point-kinetics theory 3.3 
2.15 Advanced Neutron Source latch magnet test facility

2.16 Block diagram of reactor components tests ...................................................... 36

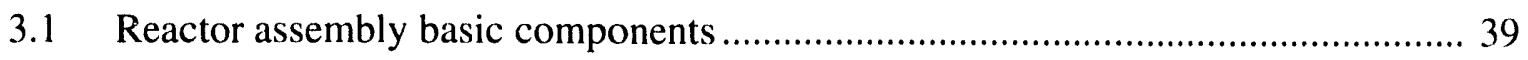

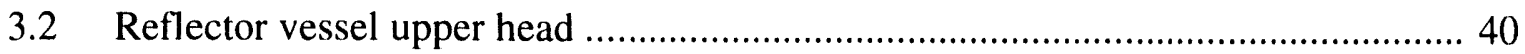

3.3 Cross section through reflector vessel lower head .............................................. 41

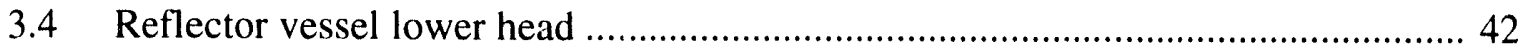

3.5 Inner control rod with hafnium inside an inconel tube ....................................... 43

3.6 Basic concept of stack and tunnel structures for refueling system ......................... 44

3.7 Advanced Neutron Source reactor assembly_-IGRIP model .................................. 45

3.8 Beam line and hot source configuration ..................................................... 47

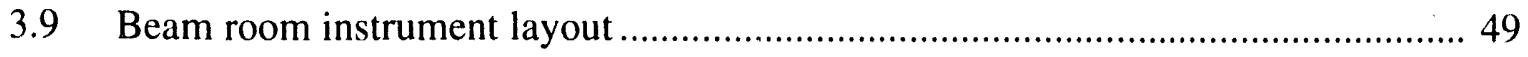

3.10 Advanced Neutron Source monochromator shielding ….................................... 50

3.11 Second floor isotope separation on-line facility .............................................. 50

3.12 Hot source and biological shield penetration assembly (HB-4) ………….............. 51

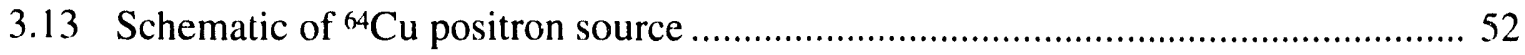

3.14 Revised building arrangement on the site overlaid on the identified wetlands

3.15 Revised core building configuration with experiment and equipment locations-main levels

3.16 Revised core building configuration with experiment and equipment

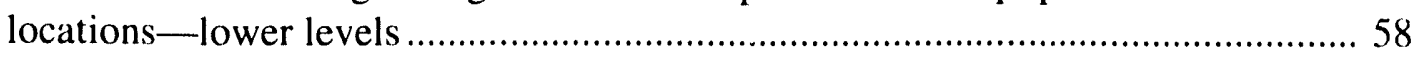

3.17 A three-dimensional sketch of the reactor control complex ...................................62 62

3.18 Single parameter signal flow for an ASIC-based reactor protection system …….... 63

4.1 Flow chart for planned tasks for assessing flow blockage hazards ....................... 68

viii Advanced Neutron Source (ANS) Progress Report 
4.2 FE thermal limit ratio during 1.1-s primary system vessel adaptor weldment double-ended guillotine break with $0.065-\mathrm{m}^{3}$ accumulator bubble

4.3 Second pressure wave propagation test case: reflections and transmissions .......... $7+$

4.4 Calculated and measured axial pressure profiles for Costa test $258 \ldots \ldots \ldots \ldots \ldots \ldots \ldots . . . \ldots \ldots$

4.5 Ccinparison in pressures at the lower core inlet and outlet during the double-ended guillotine break with 1100-ms opening time

4.6 Variation of whole-body dose for single and dual containments vs distance zone at various percentiles

4.7 Schematic representation of Advanced Neutron Source containment 81

4.8 Variation of pressure with time during hydrogen detonations in Advanced Neutron Source containment 


\section{TABLES}

Table

2.1 Comparison of new G693 and the previous L7 fuel gradings

4

2.2 Parameter ranges for flow excursion tests in the thermal-hydraulic test loop 13

2.3 Calculated dose rates above removable concrete roof sections .............................. 30

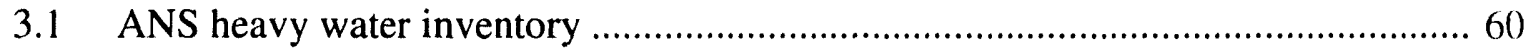

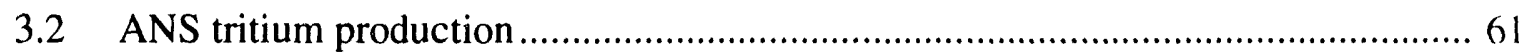

4.1 Maximum survivable breaks in the ANSR determined by RELAP5 ................... 72

4.2 Containment performance for the reference conceptual design and three alternatives

4.3 Matrix of severe accident studies-related experiments under study 84 


\section{ACRONYMS}

\begin{tabular}{|c|c|}
\hline AECL & Atomic Energy of Canada, Ltd. \\
\hline AMBK & ANS materials databook \\
\hline AMIS & ANS materials information system \\
\hline ANL & Argonne National Laboratory \\
\hline ANS & Advanced Neutron Source \\
\hline ANSR & Advanced Neutron Source reactor \\
\hline ASIC & application-specific integrated circuits \\
\hline ASME & American Society of Mechanical Engineers \\
\hline $\mathrm{B} \& \mathrm{PV}$ & Boiler \& Pressure Vessel \\
\hline $\mathrm{B} \& W$ & Babcock and Wilcox Company \\
\hline BESAC & Basic Energy Sciences Advisory Committee \\
\hline BPR & bypass ratio \\
\hline $\mathrm{B} / \mathrm{R}$ & Bergles/Rohsenow \\
\hline $\mathrm{CBCF}$ & carbon-bonded carbon fiber \\
\hline $\mathrm{CCB}$ & Configuration Control Board \\
\hline $\mathrm{CCI}$ & core-concrete interaction \\
\hline CDR & conceptual design report \\
\hline CECE & combined electrolysis and catalytic exchange \\
\hline CETF & control element test facility \\
\hline CFD & computational fluid dynamics \\
\hline $\mathrm{CHF}$ & critical heat flux \\
\hline C-J & Chapman-Jouquet \\
\hline CPBT & core pressure boundary tube \\
\hline CSAR & conceptual safety analysis report \\
\hline DEG & double-ended guillotine \\
\hline $\mathrm{DOE}$ & Department of Energy \\
\hline ER & environmental report \\
\hline FBTF & flow blockage test facility \\
\hline $\mathrm{FE}$ & flow excursion \\
\hline HFIR & High Flux Isotope Reactor \\
\hline HWUDF & heavy water upgrade and detritiation facility \\
\hline $\mathrm{I} \& \mathrm{C}$ & instrumentation and controls \\
\hline IB & incipient boiling \\
\hline ILL & Institut Laue-Langevin \\
\hline INEL & Idaho National Engineering Laboratory \\
\hline ISDD & integrating system design description \\
\hline ISOL & isotope separation on-line \\
\hline JAERI & Japan Atomic Energy Research Institute \\
\hline LEFM & linear elastic fracture mechanics \\
\hline LOCA & loss-of-coolant accident \\
\hline
\end{tabular}




$\begin{array}{ll}\text { LWTA } & \text { light water transition assemblies } \\ \text { MMES } & \text { Martin Marietta Energy Systems, Inc. } \\ \text { NAAF } & \text { neutron activation analysis facility } \\ \text { NDE } & \text { nondestructive examination } \\ \text { NPR-HWR } & \text { New Production Reactor-Heavy-Water Reactor } \\ \text { NSRR } & \text { Nuclear Safety Research Reactor } \\ \text { OFI } & \text { onset of flow instability } \\ \text { ORNL } & \text { Oak Ridge National Laboratory } \\ \text { ORR } & \text { Oak Ridge Research Reactor } \\ \text { PCDAS } & \text { plant control and data acquisition system } \\ \text { PCO } & \text { project change order } \\ \text { PDR } & \text { Plant Design Requirements } \\ \text { PIDAS } & \text { plant intrusion, detection, and security } \\ \text { POD } & \text { probability of detection } \\ \text { PRA } & \text { probabilistic risk assessment } \\ \text { PSS } & \text { pulsed spallation source } \\ \text { PSVA } & \text { primary supply vessel adaptor } \\ \text { PSVAW } & \text { primary system vessel adaptor weldment } \\ \text { QA } & \text { quality assurance } \\ \text { R\&D } & \text { research and development } \\ \text { RV } & \text { reflector vessel } \\ \text { RVCS } & \text { reflector vessel cooling system } \\ \text { S\&Z } & \text { Saha and Zuber } \\ \text { SDD } & \text { system design description } \\ \text { SST } & \text { stainless steel } \\ \text { THTL } & \text { thermal-hydraulic test loop } \\ \text { TRF } & \text { tritium removal facility } \\ \text { UCN } & \text { ultracold neutron } \\ \text { VCN } & \text { very cold neutron } \\ \text { W\&R } & \text { Whittle and Forgan } \\ \text { WBS } & \text { work breakdown structure } \\ & \end{array}$




\section{FOREWORD}

A major review by the Department of Energy (DOE), involving more than 75 reviewers, accepted the Advanced Neutron Source (ANS) conceptual design report, published last year, as the basis for future work. A number of recommendations from that review, along with the results of value engineering studies, have since been incorporated into the project's baseline. The value engineering studies-that is, the search for design changes that reduce costs without reduction of scope or capabilities-identified project cost savings of almost $\$ 200$ million (as-spent dollars).

DOE commissioned a study, through their Basic Energy Sciences Advisory Committee, of the applications and priorities for new neutron sources based upon a reactor, on a spallation source, or on both. The study panel, chaired by Prof. Walter Kohn, recommended that DOE complete the design and construction of the ANS according to the schedule proposed by the project and immediately authorize the development of competitive proposals for the design of a 1-MW pulsed spallation source, leading to a construction timetable that does not interfere with rapid completion of the ANS.

Colin D. West

ANS Project Director 


\section{PROJECT MANAGEMENT}

A major Department of Energy (DOE) review of the project's conceptual design, carried out by more than 75 people, was completed in December 1992. The reviewers found no insuperable technical problems and accepted the conceptual design as the basis for future work on the project.

A further review of the scientific applications for reactor and spallation neutron sources, and of the relative priorities for their construction, was commissioned by DOE. The task was assigned to a special committee under the Basic Energy Sciences Committee. The following is an excerpt from their report Neutron Sources for America's Future, ${ }^{\prime}$ published in January 1993.

After reviewing different alternatives for capability and cost-effectiveness, the Panel concluded that the nation has a critical need for a complementary pair of sources: a new reactor, the Advanced Neutron Source (ANS), which will be the world's leading neutron source; and a 1-MW pulsed spallation source (PSS), more powerful than any existing PSS and providing crucial additional capabilities, particularly at higher neutron energies. The ANS is the Panel's highest priority for rapid construction. In the Panel's view, any plan that does not include a new, full-performance, highflux reactor is unsatisfactory because of a number of essential functions that can be best or only performed by such a reactor.

Recommendation 1: $\quad$ Complete the design and construction of the ANS according to the schedule proposed by the project.
Recommendation 2: $\quad$ Immediately authorize the development of competitive proposals for the cost effective design and construction of a 1-MW pulsed spallation source. Evaluation of these proposals should be done as soon as possible, leading to a construction timetable that does not interfere with rapid completion of the ANS.

These new sources must be firmly dedicated to neutron science and technology as their principal mission. Predictability and reliability are of the essence.

The ANS was included in President Clinton's budget as a construction project to begin in fiscal year 1994. However, the budget bill passed by Congress, and signed by the president, does not authorize construction of the ANS and appropriates only operating money for the continuation of the project in 1994.

Much work has been devoted, during this reporting period, to preparing the project for the next phase of work: configuration controls, an appropriate accounting and work reporting system, and necessary procedures have been put in place. All the preparatory work has been completed for selection of a firm with nuclear industry experience to join the team for the design and construction phase, and we are ready, when authorized, to seek bids for these tasks. The results of value 
engineering and other studies are being incorporated into an updated set of conceptual design documents and will be available to bidders.

\subsection{ANS PROJECT QUALITY PROGRAM}

The project's quality program has continued to be refined during FY 1993. The program was revised to address the requirements of DOE Order $5700.6 \mathrm{C} .{ }^{2}$ The implementation of its provisions has been the focus of the program development efforts this year. Of primary concern has been the development of project activity control schemes in preparation for Title I. This has been especially challenging because of the unknown involvement of the yet-to-be-selected industry support team. The schemes need to permit a maximum of variation in the actual implementation details to accommodate the currently unknown internal practices of the industry team and yet achieve the desired control of process to ensure valid results.

A system of quality assurance (QA) specifications has been developed as the basis for grading the QA requirements for subcontractor supporting organizations, based on their respective scopes of work.

Project procedures have been reviewed for consistency with upper tier requirements and with Martin Marietta Energy Systems, Inc. (MMES) policies and practices. These procedures are being revised to address identified inconsistencies and to allow for subsequent industry team involvement in the processes.

Followup audits of Gilbert/Commonwealth, Inc., and of the Oak Ridge National Laboratory (ORNL) Engineering Physics and Mathematics Division were conducted to verify completion of corrective actions from the initial audits performed last year.

The project's quality assurance group has been reviewing processes and documents in preparation for the next phase of the project. The quality assurance program, the implementing procedures, and the field technical procedures of the geophysical subcontractor have been reviewed and, following resolution of comments, have been accepted for use on the project site characterization activities.

Processes have been established to control, document, track, and verify project change orders, providing an integrated control over changes to the project requirements, scope, design, or documentation. Additional areas of support have addressed the relevant issues of maintenance of project records and the obtaining of an American Society of Mechanical Engineers (ASME) Owner's Certificate for components requiring Boiler \& Pressure Vessel ( $B \& P V)$ Code certification of design and fabrication. 


\section{RESEARCH AND DEVELOPMENT}

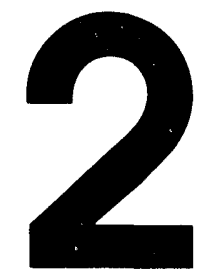

Research and development (R\&D) activities in thirteen areas have been identified as essential to the ANS Project. These R\&D activities are required to address feasibility issues, to produce the data necessary to make a rational decision when alternative design concepts are identified, and to examine and demonstrate the applicability of technological advances. This chapter summarizes progress on these activities for the reporting period and includes tasks performed by Argonne National Laboratory (ANL), Babcock and Wilcox Company (B\&W), Battelle Pacific Northwest Laboratory, Brookhaven National Laboratory, Idaho National Engineering Laboratory (INEL), Martin Marietta Engineering, the Massachusetts Institute of Technology, the McGill University, the National Institute of Standards and Technology (NIST), ORNL, Ovonic Synthetic Materials Company, the Tennessee Technological University, the Texas A\&I University, the University of California at Santa Barbara, the University of Florida, the University of Rhode Island, the University of Tennessee, and the University of Virginia.

\subsection{REACTOR CORE DEVELOPMENT}

The reactor core development task provides the neutronic and thermal-hydraulic analyses needed to support the reactor core design. A significant amount of work has been performed under this work breakdown structure (WBS) during this report period, but four specific tasks stand out as having particular importance:

(1) development of new fuel grading, (2) analysis of FOEHN critical experiments, (3) treatment of uncertainties, and (4) evaluation of the impact of photoneutron production on neutron spectrum in the reflector region.

\subsubsection{Development of New Fuel Grading}

In the conceptual design, it was determined that five thermal-hydraulic criteria must be met to ensure adequate cooling of the reactor core during normal operation and anticipated events: (1) heat flux from the fuel plates must not exceed (with a $99.9 \%$ or greater probability level) the critical heat flux $(\mathrm{CHF})$, beyond which steam blanketing is possible; (2) heat flux from the fuel plates must not exceed (with a $99.9 \%$ or greater probability limit) conditions that would lead to flow excursion (FE); (3) the maximum fuel temperature for normal operation must remain below $400^{\circ} \mathrm{C}$ with a $95 \%$ probability; (4) the temperature drop across the oxide film formed on the fuel plates must remain below $119^{\circ} \mathrm{C}$ with a 95\% probability to prevent oxide spallation; and (5) for normal operating conditions, the heat flux from the fuel plates must not exceed (with a $95 \%$ or greater probability level) the onset of incipient boiling (IB).

Analysis of the conceptual core at the proposed 303-MW $\mathrm{MW}_{\mathrm{t}}$ power level indicated that the above criteria were met with the exception of the temperature drop across the oxide film, which 
reached the maximum permissible level at a power level of $295 \mathrm{MW}_{\mathrm{t}}$. Because previous fuel-grading optimization studies had not included the oxide temperature drop as a constraint, it was known that some reduction in the oxide effects could be obtained by changing the fuel grading. Therefore, a study was initiated to improve the fuel grading and thus the power distribution within the core region, and a new fuel grading (designated G693) with significant performance improvement was developed. Table 2.1 provides a comparison of the performance characteristics of the new grading and the conceptual design baseline grading (designated L7). As seen from this table, all five criteria are now more than satisfied at the $303-\mathrm{MW}_{\mathrm{t}}$ power level with appropriate uncertainties allowed for. determined that data from the FOEHN criticals ${ }^{3}$ [Institut Laue-Langevin (ILL) critical experiments performed in the late 1960s] could be applied to check the ANS physics analysis methods in a realistic geometry very similar to ANS and could be used as the basis for the majority of the phase- 2 validation process.

A total of 24 configurations included in the FOEHN critical test program were modeled and analyzed using the $\mathrm{MCNP}^{4}$ computer code. The detailed calculations and their comparison with the measured data are documented in a separate report. ${ }^{5}$ The average deviation in $\mathrm{k}_{\mathrm{eff}}$ was $0.64 \%$ with the largest variation being $1.27 \%$. This agreement with measured data is very good. Nineteen of the 24 configurations studied gave agreement in $\mathrm{k}_{\mathrm{eff}}$ within the three-sigma statistical

Table 2.1. Comparison of new G693 and the previous L7 fuel gradings

\begin{tabular}{|c|c|c|c|}
\hline Parameter & $\begin{array}{l}\text { Maximum power } \\
\text { for } L 7 \text { core } \\
\left(\mathrm{MW}_{\mathrm{t}}\right)\end{array}$ & $\begin{array}{c}\text { Maximum power } \\
\text { for } \mathrm{G693} \text { core } \\
\left(\mathrm{MW}_{\mathrm{t}}\right)\end{array}$ & Improvement \\
\hline CHF limitation at $99.9 \%$ probability & 358 & 375 & $+5 \%$ \\
\hline FE limitation at $99.9 \%$ probability & 355 & 369 & $+4 \%$ \\
\hline Oxide temperature drop & 295 & 388 & $+32 \%$ \\
\hline Centerline fuel temperature & 308 & 402 & $+31 \%$ \\
\hline Onset of incipient boiling at $95 \%$ probability & 332 & 346 & $+4 \%$ \\
\hline
\end{tabular}

${ }^{a}$ Note that the maximum power for CHF and FE limitations is based on the temperature, the pressure, and the flow parameters being set at their safety set point (scram) limit. This results in a 9 to $13 \%$ reduction in the allowable power.

\subsubsection{Analysis of the FOEHN Criticals}

The physics data and analysis methods used tc evaluate the ANS reactor core are being validated in three phases: (1) benchmark with heavy water solution criticals during the preconceptual design phase (work now completed), (2) benchmark with existing heavy water critical experiment data, and (3) benchmark with data from a series of dedicated ANS critical experiments. Last year it was uncertainty band of the Monte Carlo calculation. Of the five remaining configurations, two are covered by four-sigma, two are covered by fivesigma, and the peak deviation case (the $1.27 \%$ deviation) represented a 5.5-sigma deviation from the measured value.

Power distributions and thermal flux values were also calculated and compared with measured data. Less than $2 \%$ of the several hundred points of comparison did not have overlap between the 
error bars of the experimental data and a 2-sigma statistical uncertainty on the calculated values. A comparison of measured and calculated data for three typical power distribution profiles is shown in Fig. 2.1. In all cases, the total core power is normalized to the value reported in the FOEHN report. ${ }^{3.5}$

This evaluation is a good validation of the MCNP analysis method, and the remaining physics codes will, in turn, be benchmarked against the MCNP code. This validation is sufficient to justify the use of our present analysis methods during the Title I design phase. Therefore, with the possible exception of some neutron and gamma heating validation studies, no additional base physics validation efforts are expected to be performed until the ANS dedicated critical experiments in the 1997-1998 time frame.

\subsubsection{Treatment of Uncertainties}

Efforts to characterize key ANS analytical, process, and manufacturing parameter uncertainties and to incorporate them into the thermal-hydraulic analysis continued during FY 1993. These efforts have focused on two main areas: (1) further development of the data base upon which parameter uncertainties are based and the refinement of these uncertainties, in either a deterministic or probabilistic manner; and (2) the refinement of tools for combining uncertainties.

In the area of uncertainty data base development and analysis, significant progress was made. Evaluation of thermal-hydraulic correlations and their statistical uncertainties continued. Additional data were extracted from the literature and incorporated into the general ANS data base. The uncertainty parameters (mean

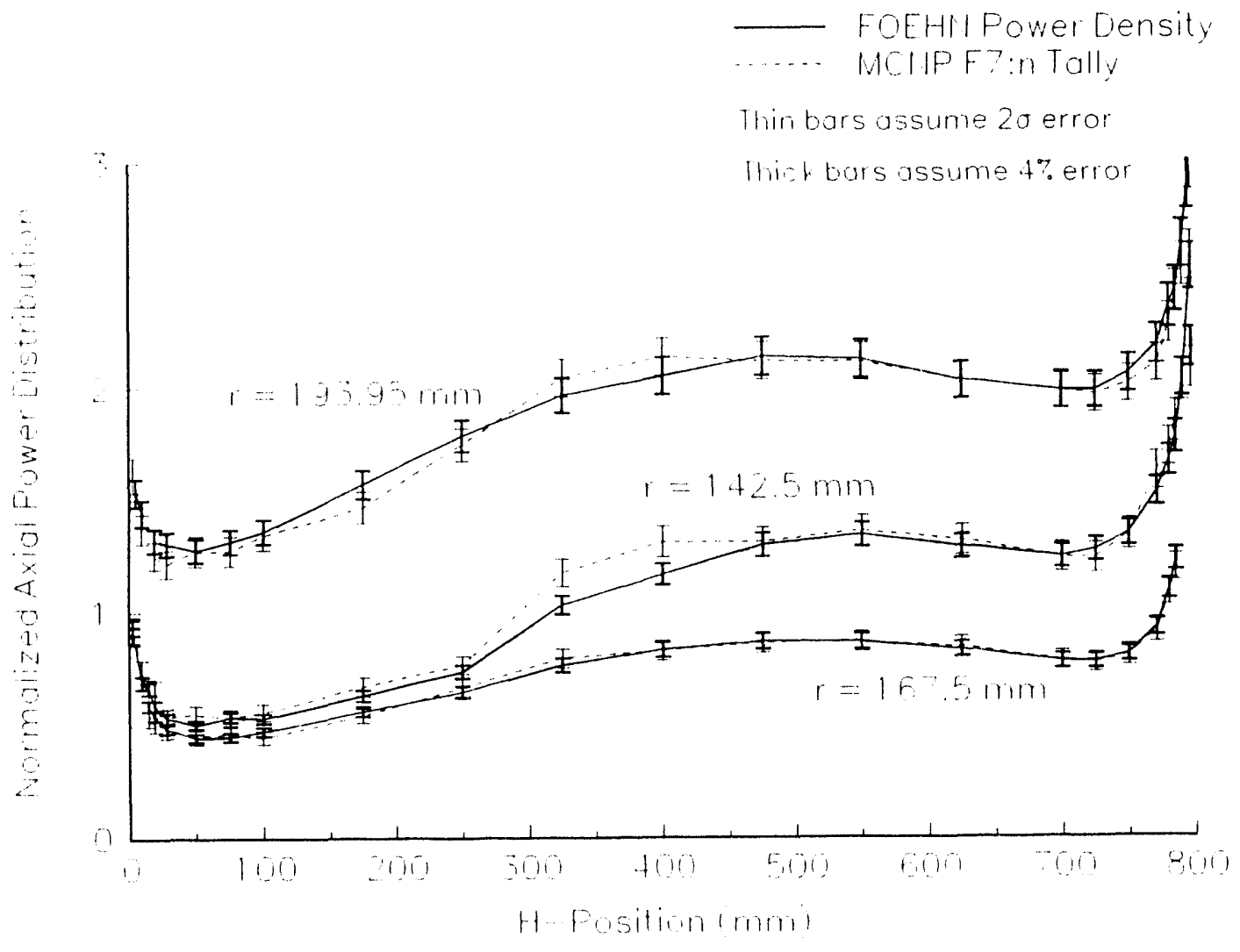

Fig. 2.1. Comparison of measured and calculated data for three typical power distribution profiles. 
and standard deviation) for the IB correlations have been revised. As a result, the statistical evaluation of the IB correlations has improved considerably. The evaluation also shows that of the four correlations we have compared, the Bergles/Rohsenow (B/R) correlation has the best agreement with the data, providing a mean of 1.02 and a standard deviation of $23 \%$ (in terms of the ratio of the experimental to correlation predicted values). In addition, a sensitivity analysis was performed to determine the effect of uncertainties in the $B / R$ correlation (or similar IB correlations) on the resulting $I B$ heat flux for various subcooling levels. The analysis showed that the IB heat flux is not very sensitive to these uncertainties.

Further development and analysis of the fuel plate manufacturing uncertainty data base was accomplished. Detailed fuel homogeneity data was obtained for several High Flux Isotope Reactor (HFIR) and prototype ANS fuel plates. These data were examined graphically, and initial statistical analysis was performed. In addition, the thermal models used to analyze the impact of fuel nonhomogeneity and nonbonds on thermal parameters have been greatly enhanced to reduce unwarranted conservatism present in previous analyses.

The ANS steady-state statistical thermal analysis code was recently revised. The revision entailed updating to include the latest thermalhydraulic correlations package and the capability to evaluate the arcuate fuel plate design, which is currently being considered as an option to enhance plate stability. Using similar input parameter uncertainties, results obtained with the revised statistical thermal analysis code were compared to those obtained with the statistical peaking factor methodology that was employed for the ANS conceptual design studies. It was found that the maximum operating power levels at a probability/confidence of $95 / 95 \%$ calculated with the two approaches were in close agreement, with the former indicating a slightly higher power level. It was concluded that the two approaches have been implemented successfully in ANS statistical analysis.

\subsubsection{Impact of Photoneutron Production on Neutron Spectrum in the Reflector}

In the early stages of the design of the ANS, it was recognized that a large heavy water reflector region coupled with a high gamma flux would lead to photoneutron (gamma-n reaction) production that must be included in kinetic evaluations. As a result, special delayed neutron groups were developed to account for the photoneutrons in the heavy water. However, the impact of this neutron production on the neutron spectrum in the reflector was not considered at that time. During this report period, a study was completed to quantify the photoneutron production and its effect on the neutron spectrum in the reflector. The results indicated that the impact on the thermal flux magnitude was insignificant, but the magnitude of the fast flux $(\mathrm{E}>0.1 \mathrm{MeV})$ in the outer heavy water reflector regions was greatly increased by photoneutron production. We now calculate a fast flux of about $10^{11)} \mathrm{m}^{-2} \cdot \mathrm{s}^{-1}$ at the reflector vessel wall that, although still fairly small, is about five orders of magnitude higher than that calculated if the photoneutrons are not included. Because the thermal flux in the same location is eight orders of magnitude higher than the fast flux, the spectrum change is not believed to be important, but all aspects of this new information have not been considered yet. It should be noted that at the beam tube mouth location, the changes in both the fast and thermal fluxes are insignificant, resulting in no change in the thermal-to-fast ratio for the beam tube current or damage rates for the beam tube.

\subsection{FUEL, DEVELOPMENT}

Work continued in support of a $\mathrm{U}_{3} \mathrm{Si}_{2}-\mathrm{Al}$ dispersion as the reference fuel for the ANS. The work was concentrated in the areas of irradiation of fuel specimens, fuel performance modeling, and fuel fabrication. Irradiation specimens of backup candidate fuels were also irradiated in the same capsules as a prudent and economical measure. 


\subsubsection{Irradiation of Fuel Capsules}

The HANS- 1 samples were transferred to ANL in order to complete their postirradiation examination using high-resolution electron beam instruments. Detailed postirradiation examinations of the $\mathrm{U}_{3} \mathrm{Si}_{2}$ particles in the HANS-1 experiment have greatly increased our understanding of the irradiation behavior of $\mathrm{U}_{3} \mathrm{Si}_{2}$ under ANS operating conditions. All previous data had been obtained from specimens irradiated in the Oak Ridge Research Reactor (ORR), with much lower temperatures and fission rates and to a lower burnup. Optical metallography, scanning electron microcopy, and electron microprobe analysis lead to the following conclusions: aluminum diffusion into the fuel particle is much more extensive because of the higher fission rate, a thermal fission-enhanced diffusion, and the highertemperature thermally activated diffusion. This results in a transformation of a major part of the fuel particles to an aluminide-type component, basically $\mathrm{U}(\mathrm{AISi})_{3}$, as shown in Fig. 2.2. The central part of the fuel particle remains essentially silicide, but because of the high uranium burnup, the center enters a phase field that was not reached in the ORR irradiations, the peritectoid phase $\mathrm{USi}_{2}$. The large gas bubbles in the center are explained by amorphization of the high-silicon phase, in analogy with $\mathrm{U}_{3} \mathrm{Si}$. A most important result is the direct observation of grain refinement, also shown in Fig. 2.2. The occurrence of this phenomenon has been a key element in our model, but until now it was only indirectly supported by the observed bubble morphology in $\mathrm{U}_{3} \mathrm{Si}_{2}$ and by observation of its occurrence in oxide fuel, which displays a very similar bubble morphology. Serial grinding through the fuel particles in one specimen showed that the bubble morphology pictured in Fig. 2.2 is typical. Much larger, interconnecting bubbles, such as those shown in last year's report, form in the oxidized regions of the fuel particle, but such regions are expected to be much less extensive in typical roll-bonded fuel.

The HANS-2 capsule, which contains additional $\mathrm{U}_{3} \mathrm{Si}_{2}$ samples as well as samples of the backup candidate fuels $\mathrm{UAI}_{\mathrm{x}}, \mathrm{UAl}_{2}$, and $\mathrm{U}_{3} \mathrm{O}_{8}$, was irradiated during January and February. The 18 fuel holders have been shipped to ANL for postirradiation examination during FY 1994. Fabrication of fuel specimens for HANS-3 is in progress. The HANS-3 fuel specimens are punched from hot-rolled fuel plates and, therefore, are more typical than the cold-compacted fuel specimens in HANS- 1 and HANS-2.

\subsubsection{Fuel Performance Studies and Modeling}

The fuel performance model, DART, ${ }^{7}$ has continued to evolve in response to information gained from the measured irradiation behavio $r$. The DART analysis of the evolution and swelling of the complex microstructure described above is based on the following scenario: during irradiation, aluminum diffuses into the $\mathrm{U}_{3} \mathrm{Si}_{2}$ fuel particle, converting the outer layer to a $\mathrm{UAl}_{3}$-type material. Based on observation, it is conjectured that the aluminide material is stable against amorphization and recrystallization. However, when the fission density has become sufficiently high, the silicide material inside the aluminum diffusion front does undergo recrystallization, or grain refinement. Aluminum continues to diffuse inward, converting the recrystallized material to aluminide. If the particle is large enough. the interior of the fuel particle will move into the unstable USi, phase field before the aluminum front reaches it. The DART analyses show that the outer aluminide shell acts as a restraint on the swelling of the inner fuel material. Because the outer (unrestructured) aluminide shell contains predominantly small (not visible by scanning electron microscope) intragranular bubbles, it has a relatively low swelling rate as compared to the recrystallized and/ or amorphized material in the interior regions and appears "hard," or stiff, in comparison to the relatively "soft," or ductile, interior. DART calculations show that if the outer aluminide shell did not form (e.g., for fuel particles irradiated in the absence of aluminum), fuel particle swelling rates would increase significantly. In order for DART to predict an aluminide outer shell and 


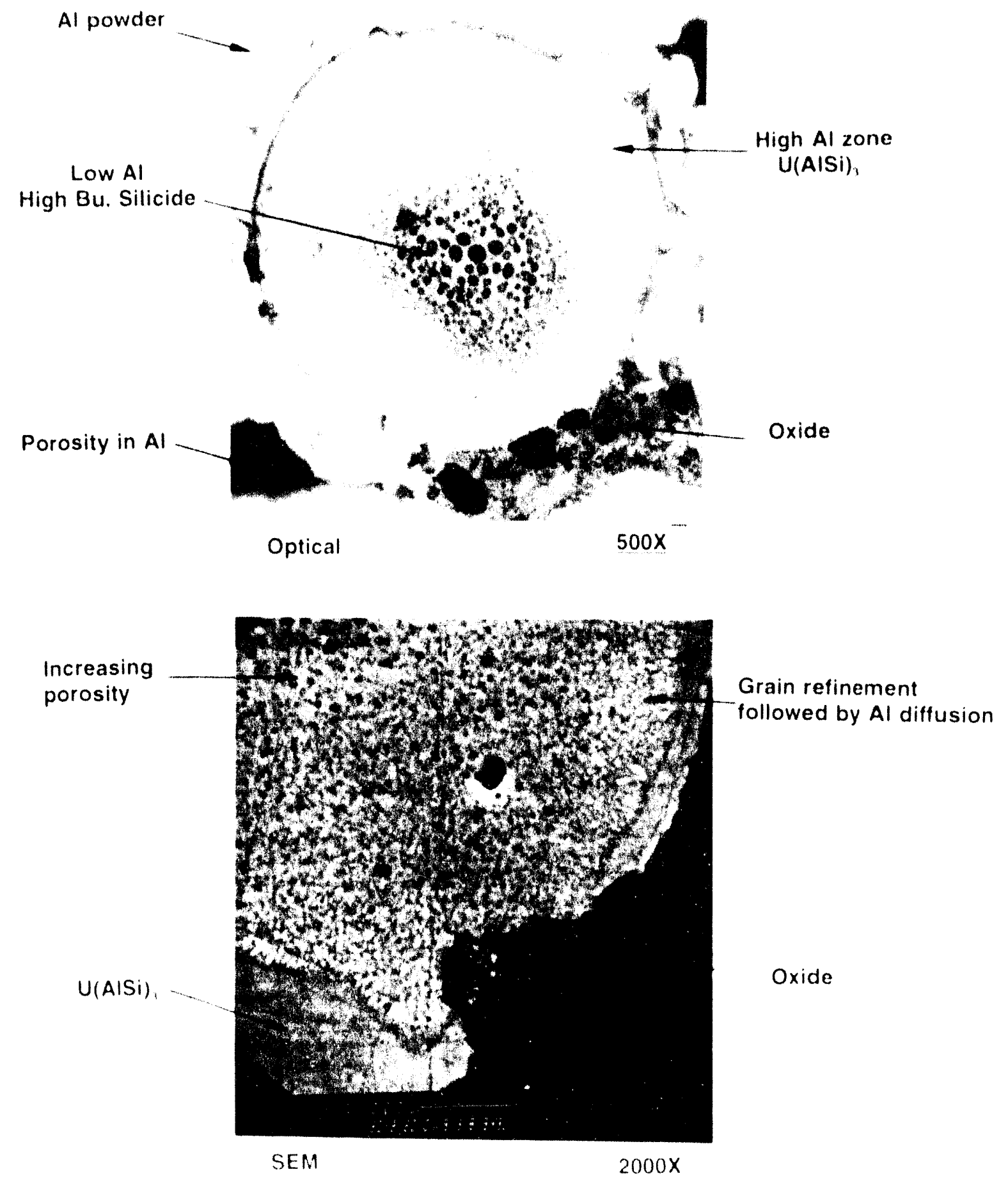

Fig. 2.2. Microstructure of $\mathrm{U}_{3} \mathrm{Si}_{2}$-Al dispersion fuel irradiated to $90 \%$ burnup in the High Flux Isotope Reactor at Advanced Neutron Source conditions.

8 Advanced Neutron Source (ANS) Progress Report 
therefore low particle swelling rates, aluminum diffusion through the outer fuel ring defined in the calculation's multinode configuration into the material must occur before the recrystallization model predicts grain refinement in that node. The inner nodes recrystallize prior to aluminum penetration, leading to an aluminide annulus having a refined grain structure when compared to the outer aluminide shell. Because of enhanced bubble growth on grain boundaries and "dead-end nodes," swelling rates in a recrystallized annulus would be much higher than in the aluminide outer shell. Although higher, the swelling rate retains its linearity with burnup. Subsequent to recrystallization, aluminum penetration of this inner annulus occurs, converting the material to a refined grain structure aluminide region. Subsequently, as the simulation moves across the uranium-silicon phase diagram, the code tests whether the calculation has entered the unstable $\mathrm{USi}_{2}$ phase. If so, models for the behavior of fission gas bubbles in irradiated amorphous $\mathrm{USi}_{2}$ are invoked. Swelling rates in the amorphous inner core are higher than in the outer crystalline regions because of the plastic nature of amorphous material in the presence of irradiation. The outer, relatively hard, crystalline regions constrain the swelling of the inner, relatively soft, amorphous core.

\subsubsection{Fabrication Development}

Fabrication efforts at ANL continued to be focused on improving the fuel distribution. Fuel plates were rolled using different size distributions of $\mathrm{U}_{3} \mathrm{Si}_{2}$ powder, and it was found that smaller fuel particles produce a more homogeneous distribution.

During this report period, the homogeneity scanner at B\&W was modified to provide digital data and was qualified for use. The HFIR outer element plates made with $\mathrm{U}_{3} \mathrm{Si}_{2}$ mentioned in last year's report were scanned with the digital system, and the results compared to production oxide HFIR plates. The results from three different silicide powder lots were essentially identical to the HFIR production plates in regard to standard deviation of the fuel distribution. Future ANS development plates will use a finer particle size distribution in an attempt further to improve the fuel homogeneity.

Several different methods of obtaining the dual fuel gradients planned for ANS are being investigated at $B \& W$ to demonstrate the feasibility of this concept. All of these techniques maintain a constant volume fraction of fuel in the meat and use varying methods of tapering the meat in the axial and radial directions to obtain the gradients.

During the year, two lots of miniplates were fabricated at B\&W for safety tests in the Nuclear Safety Research Reactor (NSRR) at the Japanese Atomic Energy Research Institute (JAERI). The first lot was the first produced at $B \& W$ for a long time, and homogeneity was poor with only three of the nine produced meeting the specification. Improvements in the blending, primarily the size of the blending jar, produced excellent homogeneity in the second lot of plates, and all twelve of the second lot were well within the homogeneity specification. Meat configuration, cladding thickness, and other attributes were also within the required range.

\subsection{CORROSION LOOP TESTS AND ANALYSES}

The exposure of aluminum alloys to high velocity water under heat transfer conditions is known to produce a thin, adherent corrosion product film having low thermal conductivity. In principle, the growth of such films on the surface of aluminum fuel cladding in typical research reactors could influence core performance through increases in cladding and fuel temperatures, as well as increases in coolant turbidity and other effects should spallation occur. Thus, a characterization of oxide growth and its impact for the expected thermal-hydraulic parameters is considered to be a necessary element in the design of the ANS core.

For several years, the ANS Project has supported an experimental program wherein aluminum alloy specimens were exposed at high 
heat fluxes to high velocity coolant in a corrosion test loop system. Recent results and the growing data base have been reported in previous ANS progress reports, ${ }^{8-11}$ ORNL reports, ${ }^{12,13}$ and openliterature publications. ${ }^{14-18}$ The corrosion results to date sugrest that minimal film growth will occur under "iverage" ANS core thermal-hydraulic conditions. Only when hot spots, hot streaks, and uncertainties are included will potential problems arise because of the temperature increases associated with high heat flux through lowconductivity oxide. Of particular interest and importance has been the observation that both the kinetics and morphology of the corrosion process under these conditions are highly sensitive to water chemistry, in addition to the influence of temperature and heat flux.

In this period, we have completed the testing of the 8001 aluminum alloy specimens under thermal-hydraulic and water chemistry conditions particularly important to the New Production Reactor-Heavy Water Reactor (NPR-HWR) project that cosponsored this phase of the effort. The results of these tests are important to the ANS data base, and they will be expanded in the next fiscal year as we examine the corrosion behavior of 8001 aluminum and other alloys under high heat fluxes for possible ANS usage. The NPR closeout report ${ }^{13}$ discusses the corrosion results of the 8001 alloy in the context of the ANS data base and our previous observations on the corrosion behavior of 6061 aluminum, the basis material for fuel cladding in the ANS core.

Following the corrosion test series with the 8001 alloy, the corrosion test loop was returned to its former configuration to continue the 6061 aluminum testing. During the initial period of reestablishing conditions, the test loop produced some erratic results, presumably as a result of the sensitivity of the corrosion reaction to differences in water chemistry. We believe that the control of the coolant $\mathrm{pH}$, as well as the interaction of the stainless steel components of the loop with the coolant, contributes to the changing water properties and its influence on corrosion. Extended downtime for the loop while repairs of several components were completed has slowed our resolution of this issue. However, the reasonable success of our correlation procedure for corrosion product growth on 6061 aluminum fuel cladding when water chemistry conditions were carefully controlled (Correlation II, as discussed in ref. 17 and in the preceding progress report ${ }^{11}$ ) has continued to serve as a basis for data comparisons. We anticipate undertaking an additional effort to interpret and explain the phenomena involved in the observed sensitivity of film growth to $\mathrm{pH}$ variations in the general range of $\mathrm{pH} 5$. This is a particularly important issue since corrosion-related results from the thermal-hydraulic test loop (THTL), discussed in the next section of this report, should be shown to be consistent with those from the corrosion test loop prior to conducting tests in heavy water.

\subsection{THERMAL-HYDRAULIC LOOP TESTS}

The thermal-hydraulic performance of the ANS reactor will directly influence both its normal operational limits and its off-normal behavior. Experiments are planned to allow development and validation of models used in the thermalhydraulic analysis. This plan incorporates experimentation to examine phenomena that are critical to characterizing the thermal-hydraulic behavior of the ANS and to evaluate more integral type phenomena that must ultimately be determined using codes and models. The plan attempts to isolate the important phenomena and to provide specific experimentation in order to define the phenomena correctly as well as, under some circumstances, to collect data to support statistical analysis of the reactor performance.

\subsubsection{Test Loop Facility}

The THTL facility was designed and built to provide known thermal-hydraulic conditions for a simulated full-length coolant subchannel of the ANS reactor core, thus facilitating experimental determination of $\mathrm{FE}$ and $\mathrm{CHF}$ thermal limits under expected ANS reactor (ANSR) conditions.

Determination of these two thermal limits and the relationship between them is the main objective of the THTL facility. However, it is also designed to 
examine other phenomena, including onset of incipient boiling, single-phase heat-transfer coefficients and friction factors, and two-phase heat-transfer and pressure-drop characteristics. Although the facility's primary aim is to develop correlations at the ANSR nominal conditions for normal operation and safety margin analysis, tests will also be conducted that are representative of decay heat levels at both high pressure (e.g., loss of off-site power) and low pressure [e.g., a loss-ofcoolant accident (LOCA)], as well as other quasiequilibrium conditions encountered during transients.
This year the experiments focused on the FE phenomenon at ANS nominal conditions, as well as a few true $\mathrm{CHF}$ experiments for comparison. The cooling channels in the ANSR fuel assembly are all parallel and share common inlet and outlet plenums, effectively imposing a common pressure drop across all the channels. Such a configuration is subject to FE and/or flow instability ${ }^{19,20}$ that may occur once boiling is initiated in any one of the channels. Figure 2.3 presents a typical plot of the pressure drop vs flow rate relationship under various conditions. In the case of many parallel channels between large common headers, as in the

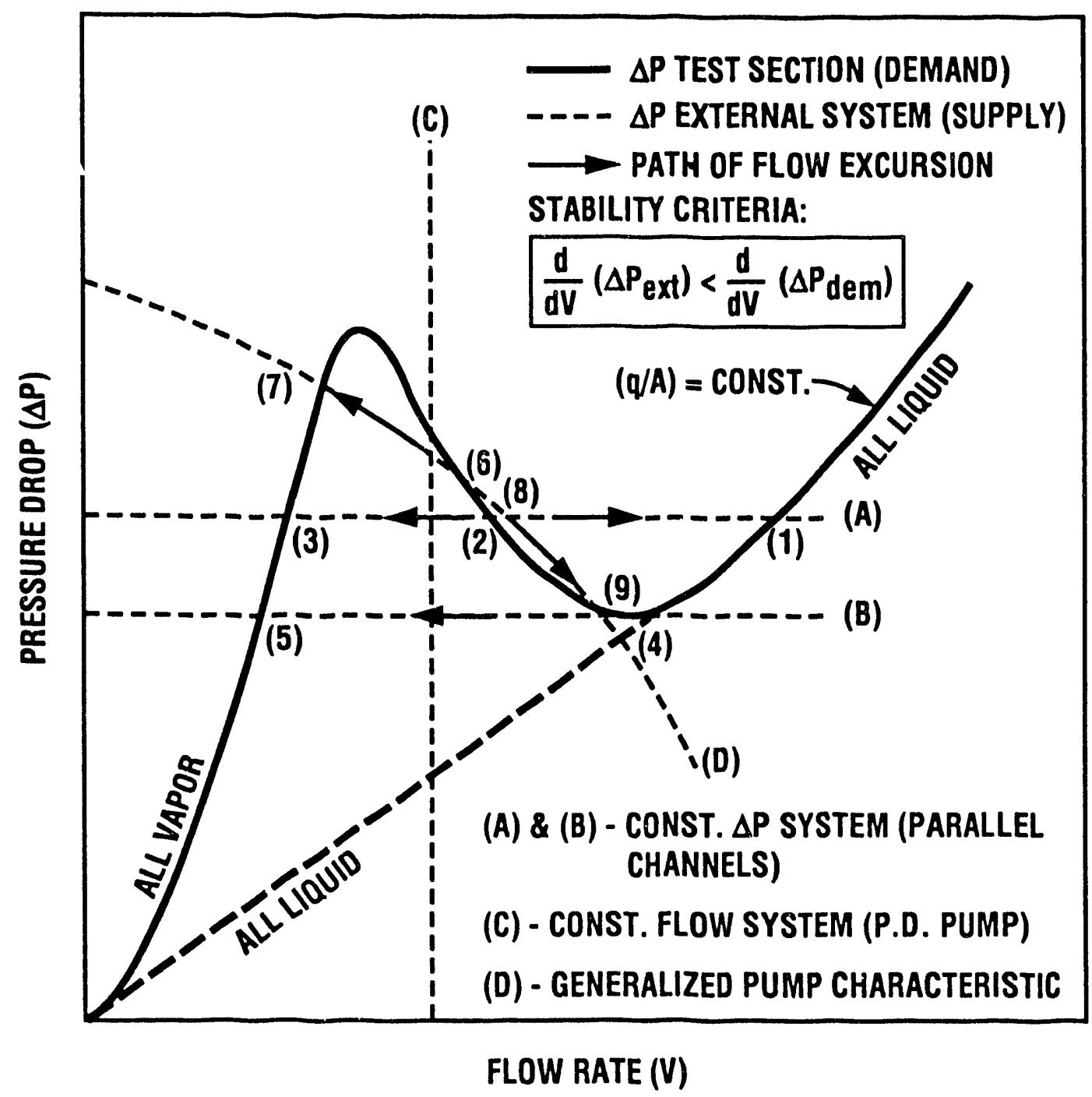

Fig. 2.3. Schematic interpretation of excursive instability. 
ANSR, the slope of the external supply system is practically zero and is represented in Fig. 2.3 by horizontal lines (A and B). Based on this observation, $\mathrm{FE}$ or onset of flow instability (OFI) conditions were determined in most of the THTL FE experiments by detection of the test section pressure-drop minimum as the flow to the test section was reduced under a constant heat flux. This method allowed for repetition of many tests without experiencing an actual FE that normally causes test section failure. For confirmation and comparison, limited experineuts were performed with an actual FE burnout, and some experiments were run with true $\mathrm{CHF}$ burnout under constant flow. One of the main goals of these tests is to determine the relationship between $\mathrm{CHF}$ and FE under ANSR conditions. To accommodate all these experimental needs, the design of the THTL system had to respond to three separate modes of operation as enumerated below.

1. A "soft" system was used to perform actual FE tests with burnout. In this mode, a large bypass around the test section is fully open to maintain an almost constant common pressure drop across both.

2. A "stiff" system was used to perform true $\mathrm{CHF}$ tests with actual burnout at constant and known flow rates. In this mode, the bypass around the test section was completely closed to maintain a constant flow through the test section. In addition, a near positive-displacement pump was used in the primary loop.

3. A "modified stiff" system was used to perform simulated FE tests without experiencing actual FE. In this mode, a closed or minimal bypass configuration, along with a significant pressure drop across the flow control valve upstream of the test section, was used to prevent actual FE or other flow instability. In this case, the potential for FE was determined by detecting the minimum pressure drop in a plot of pressure drop vs flow rate (which coincides with the OFI point).
The test section simulated a single subchannel in the ANS reactor core with a cross section that had a full prototypic length $(507 \mathrm{~mm})$, the same flow-channel gap $(1.27 \mathrm{~mm})$ but with a reduced span $(12.7 \mathrm{~mm})$, and the same material (aluminum 6061-T6) with a surface roughness $(\sim 0.5 \mu \mathrm{m})$ reasonably close to that expected in the ANSR fuel plates. A detailed description of the test facility and the test section design are given elsewhere. ${ }^{11,21,22}$

\subsubsection{Data Reduction, Results, and Analysis}

A model for reduction of the experimental data was developed for single-phase forcedconvection flow, focusing on the flat portion of the test channel. Local heat flux on the flats was calculated based on temperature-dependent resistivity of the aluminum test section and the average heat flux on the flat. The model also includes a single-phase pressure-drop calculation model. Internal lateral and axial heat redistribution by thermal conduction were considered in a preliminary way in determining the local heat flux but are being reconsidered in more detail through the use of a three-dimensional conduction model.

The THTL experimentation for the ANSR thermal-hydraulic correlations is still in its initial stages. The current THTL and test section design are the result of a number of initial shakedown and benchmark tests, which led to successive modifications both in the loop and the test section design. The initial emphasis was placed on the FE phenomena at nominal conditions. The major experiments completed so far have used water as the coolant, a rectangular test channel $(1.27 \times 12.7 \times 507 \mathrm{~mm})$, and an inlet water temperature of $45^{\circ} \mathrm{C}$.

The data ranges from the sequences performed for each case are summarized in Table 2.2. Figure 2.4 shows a typical pressure drop vs velocity plot for the six powered cases tested and the one nonpowered case. It is worth emphasizing that the heat fluxes indicated for each curve are nominal average values. The actual local heat fluxes close 
Table 2.2. Parameter ranges for flow excursion tests in the thermal-hydraulic test loop

\begin{tabular}{|c|c|c|c|c|}
\hline Test case & $\begin{array}{c}\text { Q"av,c } \\
\left(\mathrm{MW} / \mathrm{m}^{2}\right)\end{array}$ & $\begin{array}{l}\mathrm{V} \mathrm{c} \\
(\mathrm{m} / \mathrm{s}) \\
\end{array}$ & $\begin{array}{l}\text { P ex,c } \\
(\mathrm{MPa}) \\
\end{array}$ & $\begin{array}{c}\text { Tb ex,c } \\
\left({ }^{\circ} \mathrm{C}\right)\end{array}$ \\
\hline FE817C & 5.865 & 8.065 & 1.653 & 182.5 \\
\hline FE904A & 5.768 & 8.063 & 1.702 & 190.1 \\
\hline FE904B & 8.794 & 12.488 & 1.697 & 188.0 \\
\hline FE904C & 11.076 & 16.556 & 1.713 & 178.3 \\
\hline FE904D & 12.411 & 17.503 & 1.690 & 182.3 \\
\hline FEN 17B & 7.627 & 12.491 & 1.721 & 182.5 \\
\hline FEN17C & 10.625 & 17.407 & 1.693 & 178.1 \\
\hline FEN20A & 11.979 & 19.034 & 1.725 & 178.6 \\
\hline FEN20B & 13.658 & 20.460 & 1.712 & 180.0 \\
\hline FEN30A & 13.628 & 20.467 & 1.709 & 180.7 \\
\hline FED 15B & 11.524 & 17.059 & 1.706 & 181.9 \\
\hline FED 15C & 13.020 & 18.554 & 1.719 & 181.3 \\
\hline FED 17A & 14.412 & 20.514 & 1.685 & 176.8 \\
\hline FED28B & 14.612 & 19.972 & 1.723 & 181.1 \\
\hline FE105B & 9.030 & 13.470 & 1.721 & 173.6 \\
\hline FE105C & 12.737 & 17.476 & 1.722 & 179.1 \\
\hline FEI05D & 14.760 & 19.987 & 1.707 & 182.5 \\
\hline FEII4B & 10.841 & 17.471 & 1.713 & 181.9 \\
\hline CF115B & 11.771 & 17.044 & 1.709 & 186.1 \\
\hline FE2 $10 B$ & 11.422 & 17.495 & 1.718 & 178.2 \\
\hline FE212A & 12.146 & 16.674 & 1.708 & 185.2 \\
\hline FE318B & 1.886 & 4.520 & 0.445 & 132.7 \\
\hline FE330A & 12.009 & 18.502 & 1.709 & 174.7 \\
\hline FE331A & 11.996 & 17.029 & 1.698 & 178.4 \\
\hline FE712B & 1.668 & 2.503 & 1.695 & 183.1 \\
\hline FE713B & 0.679 & 2.654 & 0.175 & 100.1 \\
\hline FE714B & 4.333 & 7.507 & 1.700 & 174.3 \\
\hline FE714C & 6.396 & 10.017 & 1.701 & 182.3 \\
\hline FE715B & 9.195 & 14.472 & 1.709 & 177.0 \\
\hline FE719B & 11.675 & 17.549 & 1.673 & 176.8 \\
\hline
\end{tabular}

In all cases, the inlet temperature is equal to $45^{\circ} \mathrm{C}$. Q" av = average nominal heat flux. $\mathrm{V} \mathrm{c}=$ average coolant velocity at the minimum pressure drop point. $\mathrm{P}$ ex, $\mathrm{c}=$ pressure at the exit of the test section. $\mathrm{Tb}$ ex, $\mathrm{c}=$ exit bulk coolant temperature.

to the exit (where the FE phenomena is supposed to start) are actually higher than the average in all cases as a result of the aluminum resistivity change with temperature. As illustrated in Fig. 2.4, the minimum points are clearly identifiable, and the true CHF (or the subsequent expected burnout) was not encountered before that minimum (the point where FE would occur) in any of the experiments. Acquiring FE data at this level of heat fluxes and velocities is of significance for two reasons. First, to the best of our knowledge, no data are available for velocities higher than $10 \mathrm{~m} / \mathrm{s},{ }^{23-25}$ except those reported by Waters ${ }^{26}$ at $16 \mathrm{~m} / \mathrm{s}$ in experiments supporting the Advanced Test Reactor. Second, the heat flux achieved is beyond the ANS nominal peak heat flux of $12 \mathrm{MW} / \mathrm{m}^{2}$. The measured limiting velocity is about $18 \mathrm{~m} / \mathrm{s}$, comfortably below the actual ANS nominal velocity of $25 \mathrm{~m} / \mathrm{s}$; even at the highest local heat flux tested $\left(14.7 \mathrm{MW} / \mathrm{m}^{2}\right.$ average and $16.3 \mathrm{MW} / \mathrm{m}^{2}$ at the exit), the ANSR nominal operating velocity is still well above the measured 


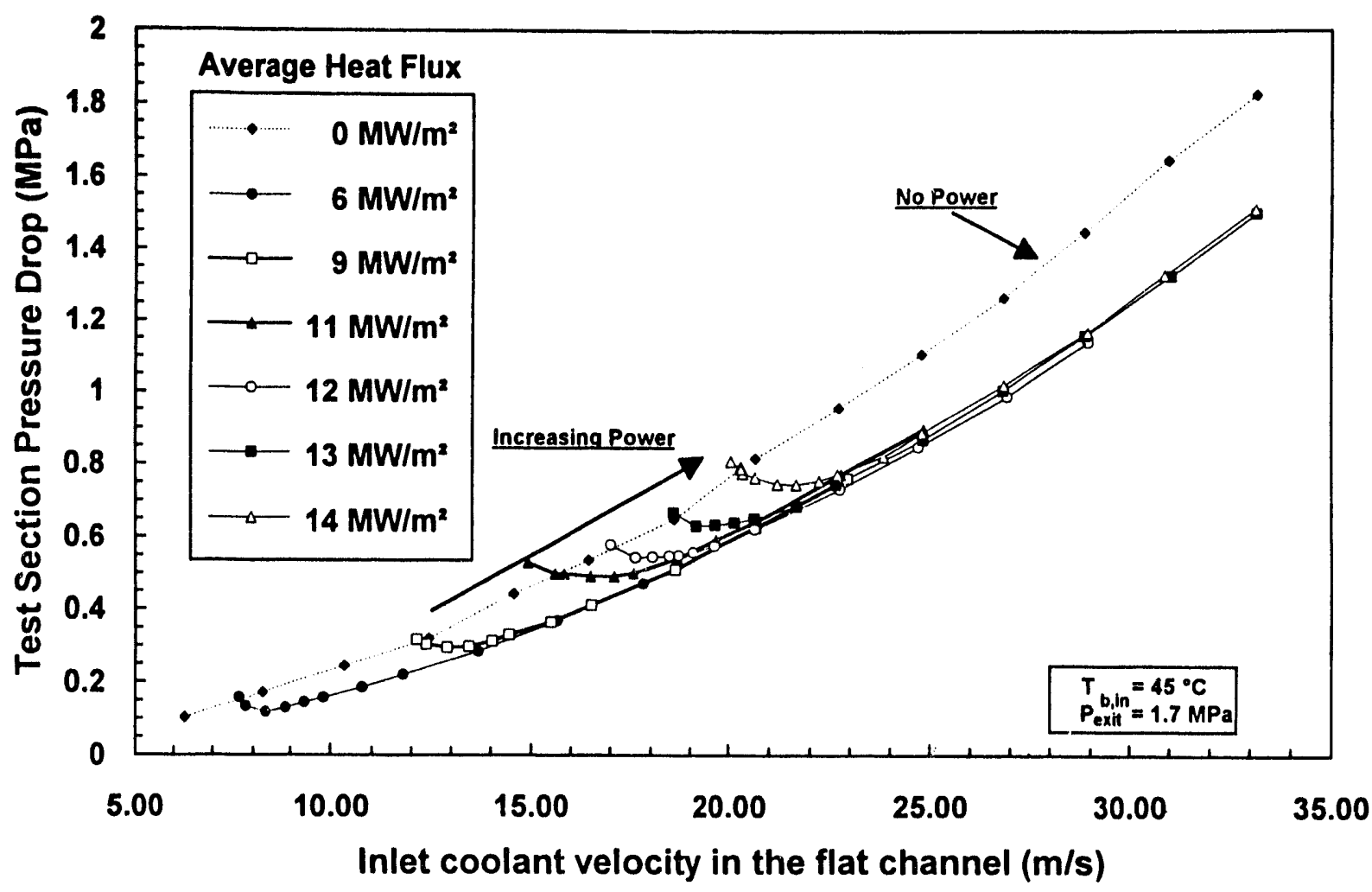

Fig. 2.4. Flow excursion data from thermal-hydraulic test loop experiments.

limiting velocity of $20 \mathrm{~m} / \mathrm{s}$. This implies, on a preliminary basis, that a good safety margin exists in the ANSR operating velocity.

Although final correlation of the FE data will be postponed until the remainder of the experiments are performed, the data collected so far were plotted in Fig. 2.5, and comparisons were made with correlations by Costa, ${ }^{27}$ Whittle and Forgan (W\&F), ${ }^{28}$ and Saha and Zuber (S\&Z) ${ }^{29}$ The Costa correlation is the one currently being used for the conceptual ANSR thermal-hydraulic design and analysis. W\&F and S\&Z correlations are widely used in the United States with the S\&Z correlation being well established in many computer codes for nuclear safety analysis. For a given coolant (water), physical properties, and geometry $(\mathrm{L} / \mathrm{D}=199.6)$, all three correlations can be rearranged and simplified to the same general formulation as

$$
Q_{f e} /\left(T_{s}-T_{b}\right)_{f e}=C V^{n},
$$

where

$$
\begin{aligned}
Q & =\text { heat rate } \\
f e & =\text { flow excursion point } \\
T_{s} & =\text { saturated temperature, } \\
T_{b} & =\text { bulk coolant temperature, } \\
V & =\text { coolant velocity, } \\
C & =1 / 0.0128 \text { and } n=0.5(\text { Costa }) \\
C & =1 / 0.0382 \text { and } n=1.0(\mathrm{~S} \& \mathrm{Z}) \\
C & =1 / 0.0427 \text { and } n=1.0(\mathrm{~W} \& \mathrm{~F}) .
\end{aligned}
$$

In the Costa correlation, the FE heat flux is proportional to the square root of velocity, whereas both $\mathrm{W} \& \mathrm{~F}$ and $\mathrm{S} \& \mathrm{Z}$ (as well as most other FE correlations) show a linear dependence. Based on this formulation, the Costa correlation will be too optimistic (predicting a higher safe heat 


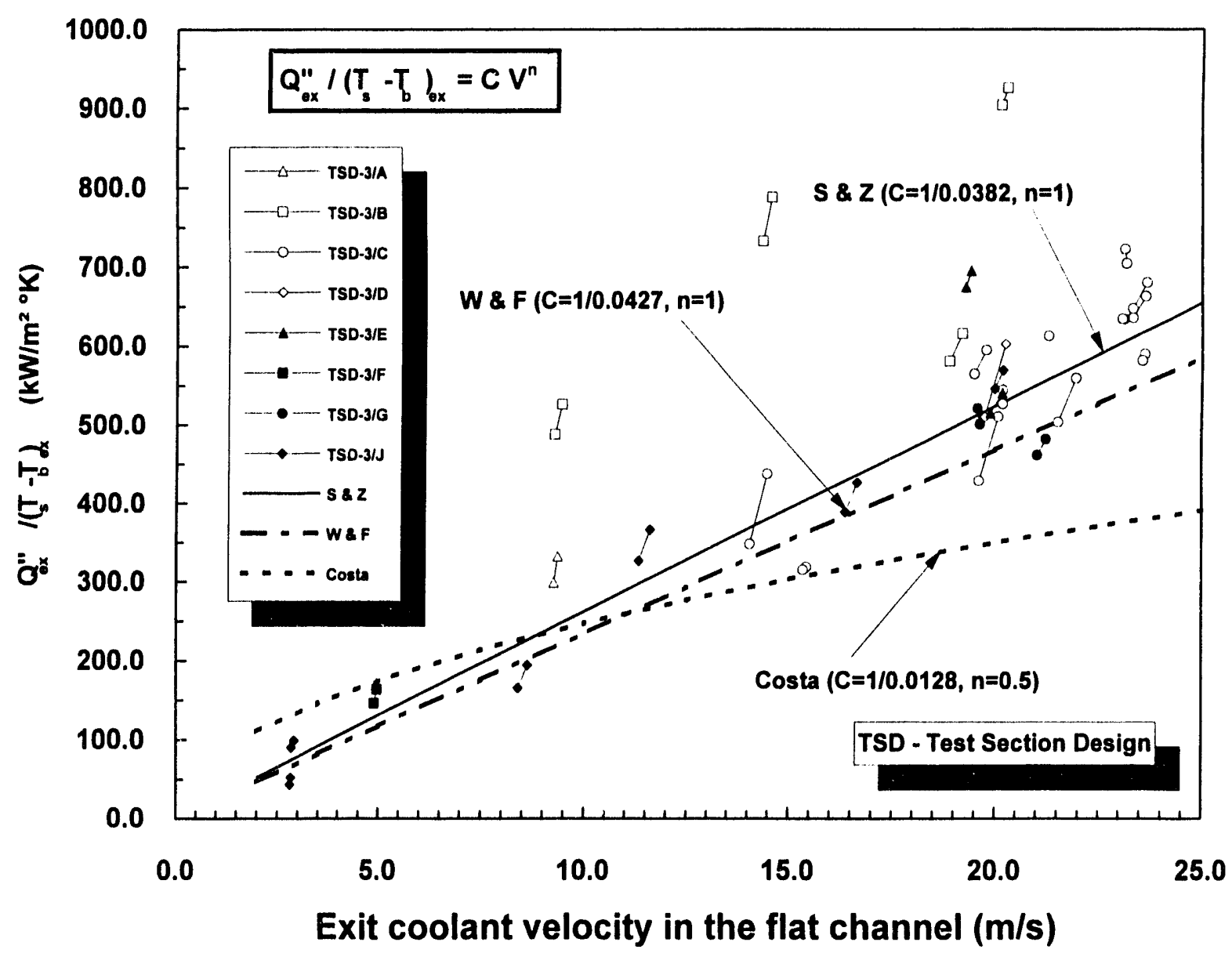

Fig. 2.5. Comparison of flow excursion data from thermal-hydraulic test loop experiments.

flux than the reality) at lower velocities and too conservative at higher velocities in comparison with W\&F and S\&Z (33\% more conservative than W\&F and $\sim 40 \%$ more conservative than $S \& Z$ at the ANSR nominal velocity of $25 \mathrm{~m} / \mathrm{s}$ ).

All three correlations seem to be conservative when compared to the measured data, with $S \& Z$ being in the closest agreement. Excluding three of the four data points taken with test section TSD 3/B (a possible anomaly was observed with tests using this section), the agreement with $S \& Z$ is quite good, with the correlation skirting the lower bound of the data. The FE heat flux dependence on velocity seems to be between 0.5 power (Costa) and 1.0 (S\&Z and W\&F), more nearly in the $0.8-0.9$ range. As indicated before, the actual correlation of the ANSR FE data is postponed to a later stage. In addition to the above FE experiments that are based on the minimum pressure drop (nondestructive tests), three destructive FE experiments and one true $\mathrm{CHF}$ experiment were performed. The results are presented in Fig. 2.6. The CHF experiment was performed at $12 \mathrm{MW} / \mathrm{m}^{2}$ in a stiff system with a practically closed bypass line. It shows a $30 \%$ additional margin in velocity CHF not revealed until the coolant velocity had fallen to only $12.3 \mathrm{~m} / \mathrm{s}$, compared to the FE velocity of $17.0 \mathrm{~m} / \mathrm{s}$ at the minimum pressure drop, which is clearly identifiable in Fig. 2.6 and which shows a factor of two margin to the ANS nominal velocity of $25 \mathrm{~m} / \mathrm{s}$. The three destructive FE experiments were performed in a soft system, but each with a different bypass ratio (BPR) as indicated in the 


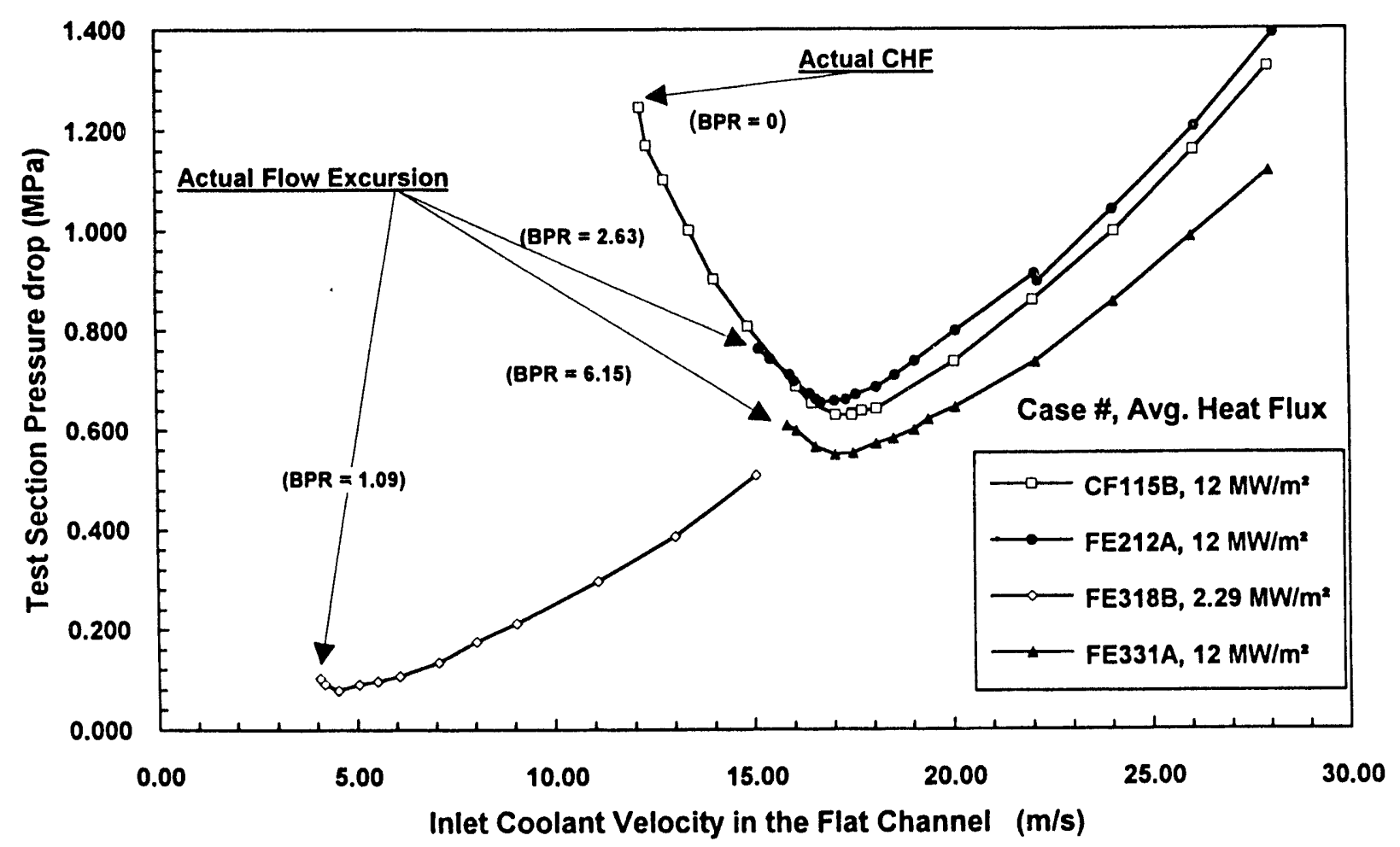

Fig. 2.6. Destructive critical heat flux and flow excursion tests in the thermal-hydraulic test loop.

figure. As can be seen in the two tests performed at $12 \mathrm{MW} / \mathrm{m}^{2}$ heat flux and $1.7 \mathrm{MPa}$ exit pressure, the one with the larger BPR (6.15) had a burnout critical velocity much closer to the minimum than the one with the lower BPR (2.63), again demonstrating the effect of BPR. The third destructive FE was performed at conditions as close to Costa's (1969) as possible. The heat flux $\left(2.29 \mathrm{MW} / \mathrm{m}^{2}\right)$ used is the same as in Costa, but the pressure $(0.38 \mathrm{MPa})$ was higher than in Costa $(0.17 \mathrm{MPa})$ because of loop limitations, and the inlet temperature $\left(40^{\circ} \mathrm{C}\right)$ was set to be lower than in Costa $\left(74.2^{\circ} \mathrm{C}\right)$ in order to achieve the same exit subcooling $\left(4.3^{\circ} \mathrm{C}\right)$. As can be seen in the figure, the minimum pressure drop point was achieved at a velocity of $4.7 \mathrm{~m} / \mathrm{s}$ as compared to $5.4 \mathrm{~m} / \mathrm{s}$ in Costa. When an attempt was made to reduce the velocity a little further, an actual destructive flow excursion occurred at a velocity of $4.2 \mathrm{~m} / \mathrm{s}$ in spite of the fact that the system was relatively stiff with a BPR of about 1.0. In this case, the destructive FE occurred much closer to the minimum in spite of a lower BPR of about 1.0. The higher sensitivity of those conditions to $\mathrm{FE}$ is also reflected in the larger negative slope of the $\mathrm{dP} / \mathrm{dV}$ curve on the left-hand side of the minimum in test THTL-09 (similar to Costa conditions) as seen on the left side of the minimum point in this figure, as compared to the slopes of the other two FE tests. Another difference between the two tests is the closer agreement of the flow excursion heat flux data with the Costa correlation. The measured heat flux in case FE318B was about $12 \%$ higher than the Costa correlation, whereas in cases FE212A and FE331A, it was about $50 \%$ and $60 \%$ higher, respectively. This is in agreement with our previous conclusion that the Costa correlation may be more conservative at higher velocities (and pressures). In addition, a number of tests were performed at decay heat removal conditions represented in Table 2.2 and Fig. 2.5. A more detailed discussion of the experiments and results are given in Siman-Tov et al. ${ }^{22}$

\subsubsection{Future Plans}

The initial focus of the THTL experimentation for the ANSR is the determination of thermal 
limits under ANS nominal conditions using water as coolant. Future plans include additional experiments to be performed with the existing facility and the basic test section design to capture the onset of incipient boiling, single-phase heat transfer coefficients and friction factors, and twophase heat transfer and pressure-drop characteristics.

Also included are plans for off-nominal conditions including low-flow tests simulating shutdown and refueling conditions, low pressure conditions simulating LOCA and other selective quasi-equilibrium conditions encountered during some transients, the effects of oxide buildup (on the aluminum), the effects of material and its surface roughness, and the effects of heavy water on the thermal limits (CHF, FE, and IB).

Other experiments will require upgrading the THTL facility and adding new test section designs to accommodate additional requirements. This includes a full-span single-sided heated channel to determine the level of lateral flow-mixing in the channel and to confirm the effects (or lack thereof) of channel span, a two-sided half-length heated channel to test the effects of lateral and axial heat flux distributions, and a full span single-sided heated channel to test the effects of hot spots and hot streaks on CHF and FE thermal limits, respectively.

\subsection{REACTOR CONTROL AND SHUTDOWN CONCEPTS}

The use of the point-kinetics method requires an accurate knowledge of the point-kinetics parameters, including the reactivity, the promptneutron lifetime, and the effective delayed-neutron fractions. The most crucial parameter is the reactivity, which is commonly obtained by performing static calculations (referred to as the adiabatic method). The prompt-neutron lifetime and the delayed-neutron fractions generally change much more slowly and, for most cases, can be assumed to be constant.

The prompt-neutron lifetime and the effective delayed-neutron fractions were evaluated for the
ANS. The calculations are based upon a diffusiontheory model, and the effect of photoneutron production in $\mathrm{D}_{2} \mathrm{O}$ was considered. An approximation for the transport of the gamma rays was used until a more rigorous transport calculation can be performed. The prompt-neutron lifetime and the effective delayed-neutron fractions were computed at each depletion step throughout the cycle.

The computation of the point-kinetics parameters requires knowledge of the shape function, adjoint weight function, cross sections, group speeds, and delayed-neutron parameters. The shape function and adjoint weight function were obtained throughout the cycle using four energy-group VENTURE ${ }^{31)}$ calculations. Routines from the CONQUEST ${ }^{31}$ nodal kinetics code were used to evaluate the point-kinetics parameters.

The prompt-neutron lifetime and the effective delayed-neutron fractions at beginning-of-cycle, including the effects of photoneutrons, were calculated to be $1.305 \mathrm{~ms}$ and 0.00774 , respectively. The photoneutrons result in a significant contribution to the fraction of delayed neutrons. Calculations were also performed at each VENTURE depletion step to obtain the prompt-neutron lifetime and delayed-neutron fractions throughout the entire cycle. The results are presented in Fig. 2.7. The quantities show only minor variations throughout the cycle.

\subsection{CRITICAL AND SUBCRITICAL EXPERIMENTS}

Various facilities are under consideration for performing the ANS critical experiments. Five potential sites for these experiments were identified during this report period. All five sites have expressed interest in performing the experiments and were visited by ANS staff during the year in preparation for a site selection activity. However, before a formal selection process could be initiated, DOE put a hold on this selection process pending results of the low-enrichment study. A resumption of this activity in FY 1994 is expected. 


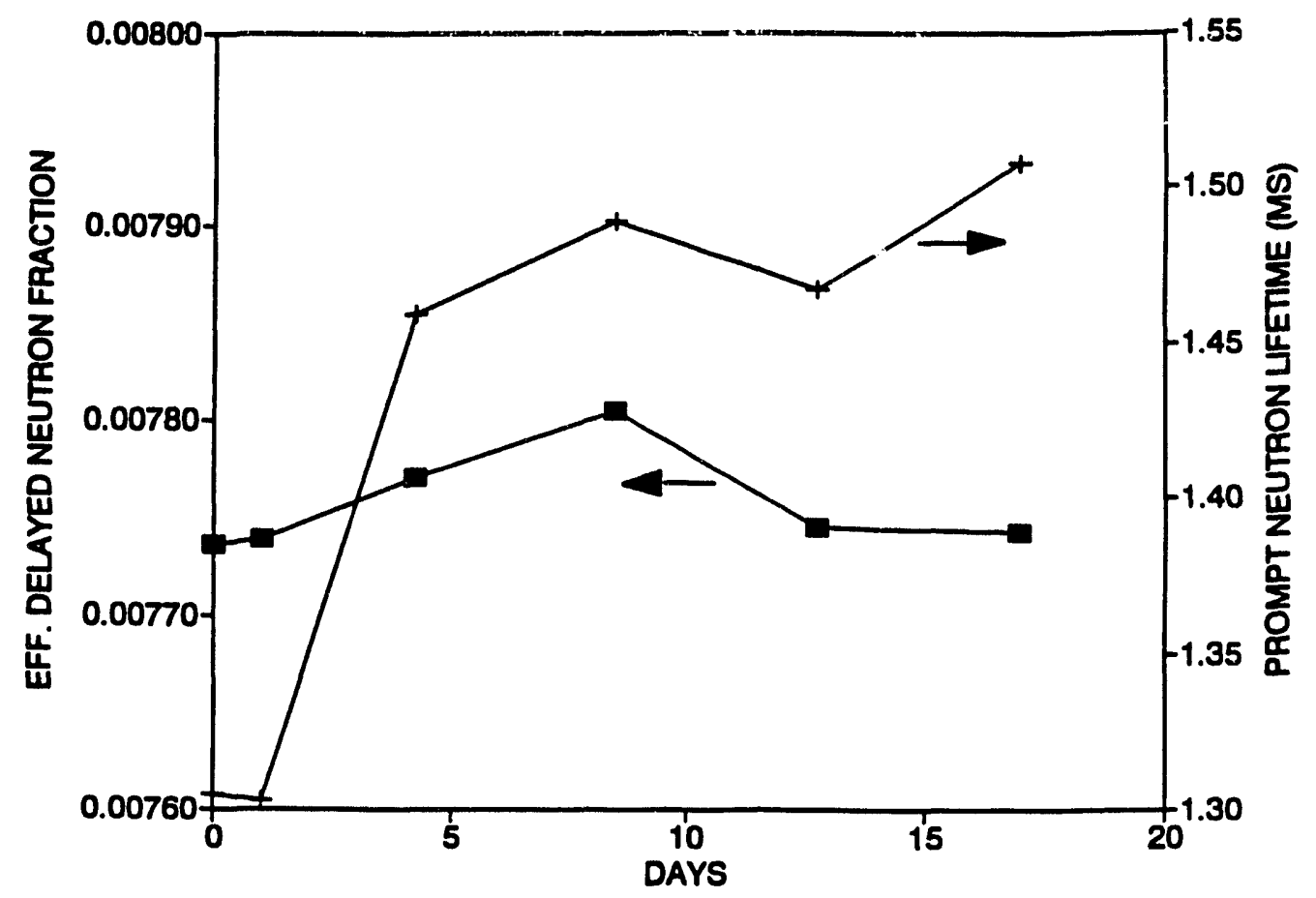

Fig. 2.7. The prompt-neutron lifetime and effective delayed-neutron fraction (including photoneutrons) during the Advanced Neutron Source fuel cycle.

\subsection{MATERIAL DATA, STRUCTURAL TESTS, AND ANALYSES}

\subsubsection{Code Case for 6061-T6 Aluminum}

After careful consideration of candidate materials, 6061-T6 aluminum has been selected as the reference core pressure boundary tube (CPBT) structural material. Although used in previous research reactors, 6061-T6 aluminum has not been included in the $A S M E B \& P V$ Code for Class 1 nuclear construction. The project has formally requested the $A S M E B \& P V$ Code Committee to include 6061-T6 aluminum as an acceptable material for Class 1 components. That request has been considered and approved by a series of Code committees up through the ASME B\&PV Code Main Committee. Code Case N-519: Use of 6061T6 and 6061-T651 Aluminum for Class 1 Nuclear Components, Section III, Division 1 has been approved by voice vote by the Main Committee after resolution of the single Main Committee negative letter ballot. Unless a negative vote is cast in a letter ballot of the revised Code Case, it will be passed directly to the ASME Board on Nuclear Codes and Standards for final approval.

\subsubsection{Fracture Toughness of Irradiated 6061-T6 Aluminum}

The extremely high neutron flux is expected eventually to cause significant embrittlement as aluminum nuclei are transmuted to silicon by capture of thermal neutrons. An extensive irradiation testing program and a surveillance program are planned to determine more precisely the irradiation embrittlement of 6061-T6 aluminum. The first capsule assembly, HANSAL$\mathrm{T} 1$, was irradiated at $95^{\circ} \mathrm{C}$ in the HFIR to a peak thermal neutron fluence of $1.12 \times 10^{26} \mathrm{~m}^{-2}$ $(\mathrm{E}<0.5 \mathrm{eV})$. Tests of fracture toughness specimens from the HANSAL-T1 capsule have been completed, and the results are shown in Fig. 2.8. These specimens confirmed the earlier data (Phase 1) and showed that irradiation at 


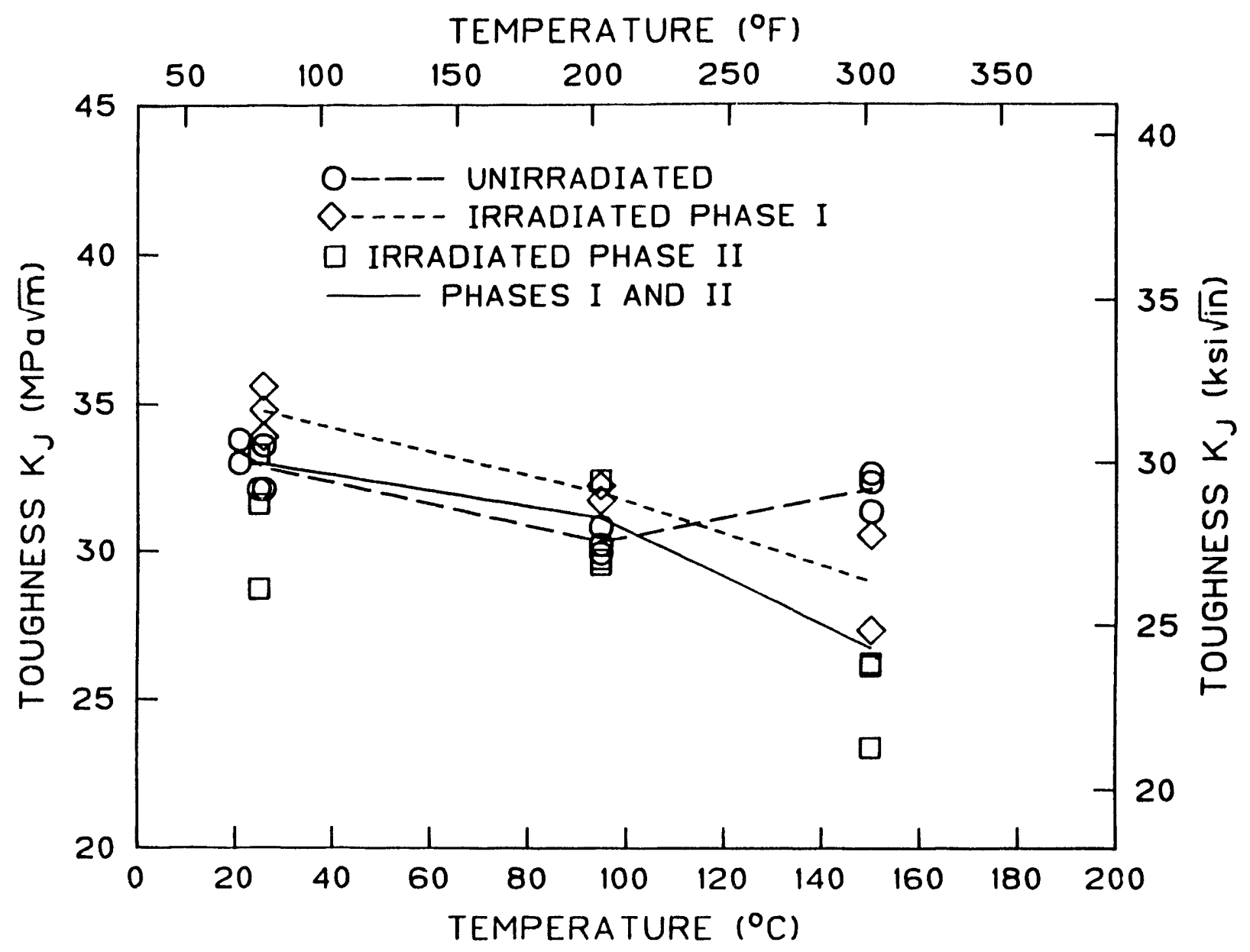

Fig. 2.8. Fracture toughness results from Phases I and II from the HANSAL-T1 capsule.

approximately $95^{\circ} \mathrm{C}$ to a thermal fluence of $\sim 10^{26} \mathrm{~m}^{-2}$ had little, if any, effect on the fracture toughness at test temperatures of 25 or $95^{\circ} \mathrm{C}$. However, this irradiation did result in a measurable decrease (approximately $15 \%$ ) in the fracture toughness at a test temperature of $150^{\circ} \mathrm{C}$. These tests have provided critically important information that shows that the fracture roughness of the candidate aluminum alloy 6061-T651 will not be significantly degraded after a fluence of $10^{26} \mathrm{~m}^{-2}$. At the CPBT location, this fluence is reached after one ANS cycle. Therefore, it is clear that the ANS can operate for at least one cycle without a loss in toughness of the CPBT material. Additional data are needed for higher fluences. This information will be provided by the HANSAL-T2 experiment, which has completed 20 of its planned 21 cycles of irradiation in HFIR and that will be removed and the specimens tested during FY 1994.

Seven weldments were fabricated from the reference plate material. These weldments, made by the gas tungsten arc method with 4043 aluminum alloy filler metal, were used to fabricate compact and tensile specimens for the HANSAL-T3 and -T4 capsules. These capsules will contain weld specimens for comparison with the base metal material previously irradiated in HANSAL-T1 and -T2, respectively.

\subsubsection{Core Pressure Boundary Tube Fracture Evaluation}

A methodology was developed for ensuring the prevention of nonductile fracture of the CPBT 
in the ANS reactor. Since 6061-T6 aluminum is known to be relatively brittle, the linear elastic fracture mechanics (LEFM) approach was utilized to determine allowable flaw sizes for the CPBT. A $\mathrm{J}$-analysis following the procedure developed by the Electric Power Research Institute, San Jose, was conducted as a check; the results matched those for the LEFM analysis for the cases analyzed. Since 6061-T6 is known to embrittle when irradiated, the reduction in the static crack initiation fracture-toughness value $\left(\mathrm{K}_{\mathrm{IC}}\right)$ because of irradiation was considered in the analysis. In anticipation of probable requirements on ensuring maximum flaw size, nondestructive inspection capabilities were surveyed.

\subsubsection{Advanced Neutron Source Materials Information System}

The ANS materials information system (AMIS) is providing hard copy and electronic versions of materials information for the ANS program. Initial efforts are providing data for those activities demanding immediate estimates of material properties. Future work will provide reviewed and approved versions to support final design and safety reviews.

An AMIS general operating guide was drafted to provide a description of the AMIS project and as an aid to those involved in administrative and data-input activities for the project.

An initial draft of an ANS materials databook (AMBK) was prepared. The AMBK includes (1) as-received information with no analysis or review and (2) draft analysis and summary versions of the as-received information. Approximately 100 pages of as-received information have been prepared to date.

\subsubsection{Fuel Plate Stability Tests and Analysis}

Closely spaced arrays of fuel plates cooled by water flowing through the channels between the plates have long been used in research reactors.
Since the work of Stromquist and Sisman in 1948,32 it has been known that very high flow velocities past fuel plates can cause the plates to deform, buckle, and eventually collapse.

Obviously, the fuel plates must not deflect to an extent that will impede the flow of coolant through the core. Therefore, fuel plate stability tests and analytical model analysis will be performed to ensure that adequate margins exist between the coolant flow velocity and the plate collapse velocity.

\subsubsection{Experimental Studies of the Structural Response of the Fuel Plates to Coolant Flow}

Using epoxy models, experimental studies and the resulting analyses of the structural response of the ANS fuel plates to coolant flow have been concluded. Two test models of the upper element fuel plates and two test models of the lower element fuel plates were tested. Each model contained five active plates and six flow channels. Because of the boundary conditions involved, the response of the three central plates and the pressure data were taken from the four channels surrounding these plates, all as a function of flow velocity. The data were taken and related to the prototype plates through model laws.

The data showed no plate stability problems in the test velocity range, which included velocities equivalent to twice the operating velocity of the ANS. The data showed deflections to be less than $6 \%$ of the channel thickness at the equivalent operating velocity of the ANS.

The data showed that the pressure difference between adjacent flow channels was the most significant variable in determining the structural response of a plate. This pressure difference was put in equation form as

$$
\Delta p=0.03620 \rho v^{2}(\rho v / h / \mu)^{0.167} \text {. }
$$

where

$\rho=$ mass density of the fluid,

$r=$ average flow velocity, 
$h=$ channel thickness,

$\mu=$ dynamic coefficient of viscosity.

It has been observed that for both spheres and cylinders, the effects of Reynolds' number saturate at high values of the number. In Eq. (2), the Reynolds' number has no more than a $20 \%$ effect on pressure over the entire relevant range (from $18,000$ to 52.000$)$ ). Therefore, the effect of Reynolds' number can be neglected without significant loss of accuracy, and Eq. (2) can be simplified to

$$
\Delta p=0.204 \rho r^{2} .
$$

An analytical solution was developed for the plate response to the pressure load given by Eq. (2). In addition to the plate response because of a pressure load, the analytical solution was also used to predict plate response to average temperature differences between the plates and side walls. Structural results of the plate response to the pressure load at the ANS operating flow velocity of $25 \mathrm{~m} / \mathrm{s}$ and to the thermal load are summarized below:

1. Maximum plate deflections as a percentage of the channel thickness for the upper and lower elements are $4 \%$ and $6 \%$, respectively.

2. Maximum principal stresses in the transverse direction (along the plate arc length) because of the channel pressure difference for the upper and lower plates are $31.7 \mathrm{MPa}$ and 59.0 MPa. These stresses are primarily because of bending, and the maximum occurs at the intersection of the plates with the inside support cylinder. Theoretically, the radius of curvature at this point is zero, which would produce infinite stresses. For a more realistic stress value, the radius of curvature at this point is assumed to be equal to the plate thickness; however, if the radius of curvature were fabricated even smaller than this, higher stresses would occur.

3. Maximum principal stresses in the transverse direction because of an average temperature difference between the side walls and the upper and lower plates are $25.5 \mathrm{MPa}$ and 8.6 MPa, respectively. These stress values would be superimposed on the stress values from the pressure load. The average temperature differences of $167^{\circ} \mathrm{C}$ and $103^{\circ} \mathrm{C}$ are taken from projected operating temperatures calculated by the ANS thermal-hydraulics staff.

4. Maximum principal stresses in the longitudinal direction because of the same average temperature differences, as noted above between the side walls and the upper and lower plates, are $-84.8 \mathrm{MPa}$ and $-49.0 \mathrm{MPa}$.

Since the yield strength of the 6061-T0 aluminum that the fuel plates are made of is only $55 \mathrm{MPa}$ at room temperature, design modifications to lower the stress levels may be required.

\subsubsection{Fuel Plate Thermal Deflection}

Finite element analyses have been performed on the proposed ANS involute fuel plates to determine the hypothetical worst-case change in gap between the statistical hottest and statistical coldest fuel plates at the location of maximum plate deflection because of temperature variations in the plates. The results of the analyses for the lower fuel plates show that the gap between the cold and hot plates changes by $0.15 \mathrm{~mm}$. The analyses of the upper fuel plates show that the gap between the cold and hot upper fuel plates changes by $0.21 \mathrm{~mm}$. The gap between the undeflected plates is $1.27 \mathrm{~mm}$; therefore, the gap between the upper fuel plates could change about $17 \%$ at the location of maximum deflection.

\subsubsection{Inner Control Element Structural Stability}

The inner control elements are very flexibie because of their long unsupported spans and small diameter. Therefore, turbulent axial and cross flow 
around them could result in vibration amplitudes that cause concern about the safe operation of the reactor. The cross flow has been minimized by the inherent design, but several portions of the control elements will be exposed to turbulent axial flow. Large vibrations of the control elements could cause contact with the core inner cylinder, which would result in wear and a failure to scram. In addition, large vibrations could cause oscillations in the response of the nuclear monitoring devices, which could cause difficulty in the control system or result in false scram signals. Thus, control element stability tests and analytical model analysis must be performed to ensure that unacceptable vibrations will not occur.

\subsubsection{Flow-Induced Vibrations}

The three inner control elements are cylindrical rods that are confined to a very small space inside the core. Flow-induced vibration of these long slender cylinders is a concern because of the large unsupported length immersed in turbulent flow.

Considerable analytical effort has led to several major design modifications. In order to increase the very low fundamental frequencies computed for the baseline conceptual design configuration, a revised configuration (MOD B) 3.9- $\mathrm{m}$ shorter than the baseline was developed and evaluated. A series of three-dimensional beam models of the MOD B three-element system that included the added mass of the fluid and alternate suspension system designs led to the conclusion that a second set of upper support rollers is necessary.

This control element model was analyzed at McGill University using existing computer codes that can better account for the fluid coupling between the control elements under flowing conditions. Correlation between ORNL and McGill University analyses was good. A semiempirical equation predicted a peak flowinduced vibration response of $5 \mathrm{~mm}$ at the control element tip compared to a clearance of $8 \mathrm{~mm}$. The critical flow velocity for instability was found to be much larger than the operating velocity of 5 to $15 \mathrm{~m} / \mathrm{s}$.

\subsubsection{Scram Performance Studies}

All three of the inner control elements are extracted from the core until criticality is reached (moved upward about 600 to $700 \mathrm{~mm}$ ) and then used for shim control. The rods are rapidly accelerated downward by springs and gravity forces when a reactor scram is required, and the rods are then stopped by a deceleration spring and a piston that acts as damper.

A dynamic simulation of this process was developed and is being improved that will provide the time history response of the control element insertion. Since the fluid mass in the piston is not constant and the forces produced moving the $\mathrm{D}_{2} \mathrm{O}$ are proportional to velocity squared, the system equations are highly nonlinear and must be solved by step-wise integration. Most of the important fluid inertial and shear force terms have been included in the simulation, and a prototypic set of springs and damper profile has been developed.

The deceleration to stop the rods has the potential to buckle the long slender control elements. The preliminary scram performance criteria have been met with a peak deceleration of only about $3 \mathrm{~g}$. Since scram performance is closely tied to thermal, neutronics, and safety requirements of the reactor, the scram simulation will be updated as those requirements are better defined.

\subsubsection{Control Element Test Facility}

The control element test facility (CETF) will be used to benchmark analytical models and to provide final confirmation of control element flowinduced vibration characteristics. The facility will also be used to establish assembly/disassembly procedures, to determine operational characteristics, and to determine operational reliability. Figure 2.9 shows a schematic of the CETF based on the conceptual design configuration. 


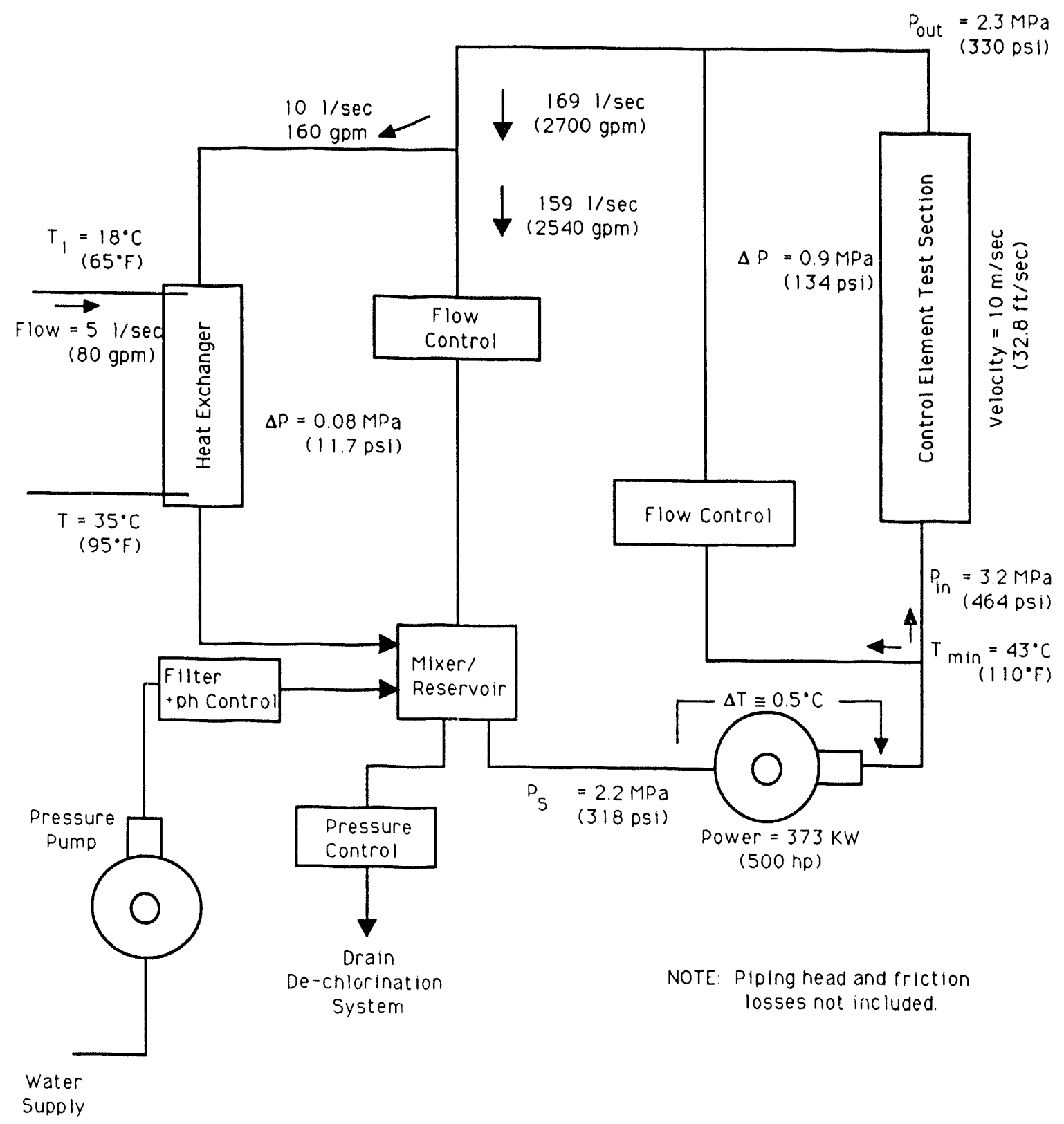

Fig. 2.9. Schematic of the control element test facility flow loop.

Recent calculations have indicated a major revision may be needed to the baseline design in order to prevent the possibility that a broken rod would be rejected from the core because of flow forces. The $0.9 \mathrm{MPa}$ (134 psi) pressure drop across the control element test section must be reduced to as low as $0.3 \mathrm{MPa}$ (43.5 psi), or the drag effect of the flow on the rod correspondingly reduced, or the rod mass increased. Consequently, further study of the control element performance requirements will be carried out prior to detailed design of the CETF.

\subsection{COLD SOURCE DEVEIOPMENT}

Over the past year, a major effort has been directed to establishing an overall baseline design 
of a complete cold source system. This has helped define interfaces and identify specific problems. Figure $>10$ is a sketch of the main equipment showing the relative elevation of the main deuterium components. The equipment is laid out as follows:
1. Refrigerator compressors are housed in a building adjoining the esst wall of the reactor containment building.

2. Cryogenic refrigerator equipment is situated on the third floor of the containment building.
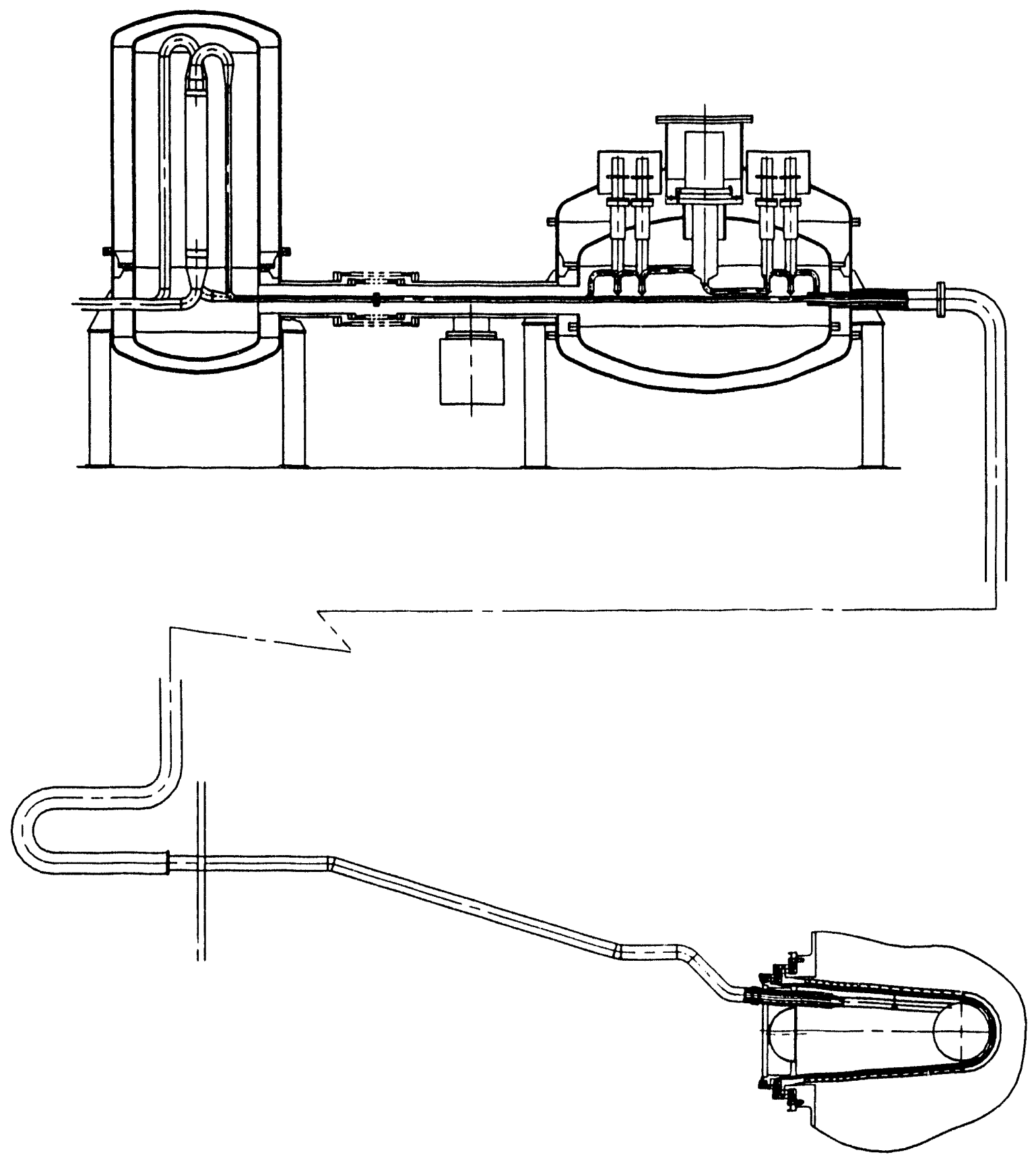

Fig. 2.10. Relative positions of the components in the deuterium loop. 
3. Cold helium gas transfer lines link the cold boxes to a cryogenic plant room on the second floor of the containment building.

4. The cryogenic plant room contains both pumping modules and other items associated with the deuterium loop. It is a designated hazardous gas area and is equipped to contain and to inert possible leaks.

5. Liquid deuterium transfer lines run from the cryogenic plant room to the biological shield face at a point adjacent to each cold source transfer line.

6. Each cold source thimble assembly is fabricated as a welded assembly and includes a rigid transfer line that allows the first cryogenic coupling to be located in a personnel access area.

\subsubsection{Design Principles of the Moderator Unit}

The moderator vessel is a spherical shell 410-mm diam containing subcooled liquid deuterium. The liquid is pressure controlled between 0.25 and $0.4 \mathrm{MPa}$ to keep it below saturation temperature at all times. Figure 2.11 shows the operating envelope. The closest approach to saturation is at the point of inlet to the heat exchanger. At this point of the envelope, it would require an increase of $9 \mathrm{~kW}$ in heat load to cause boiling at the designed thow rate of $1 \mathrm{~kg} / \mathrm{s}$. The combined neutronic heat load of the liquid deuterium and the vessel is $32 \mathrm{~kW}$, causing a net temperature rise within the liquid of $5 \mathrm{~K}$. The suspension of the vessel within its vacuum thimble

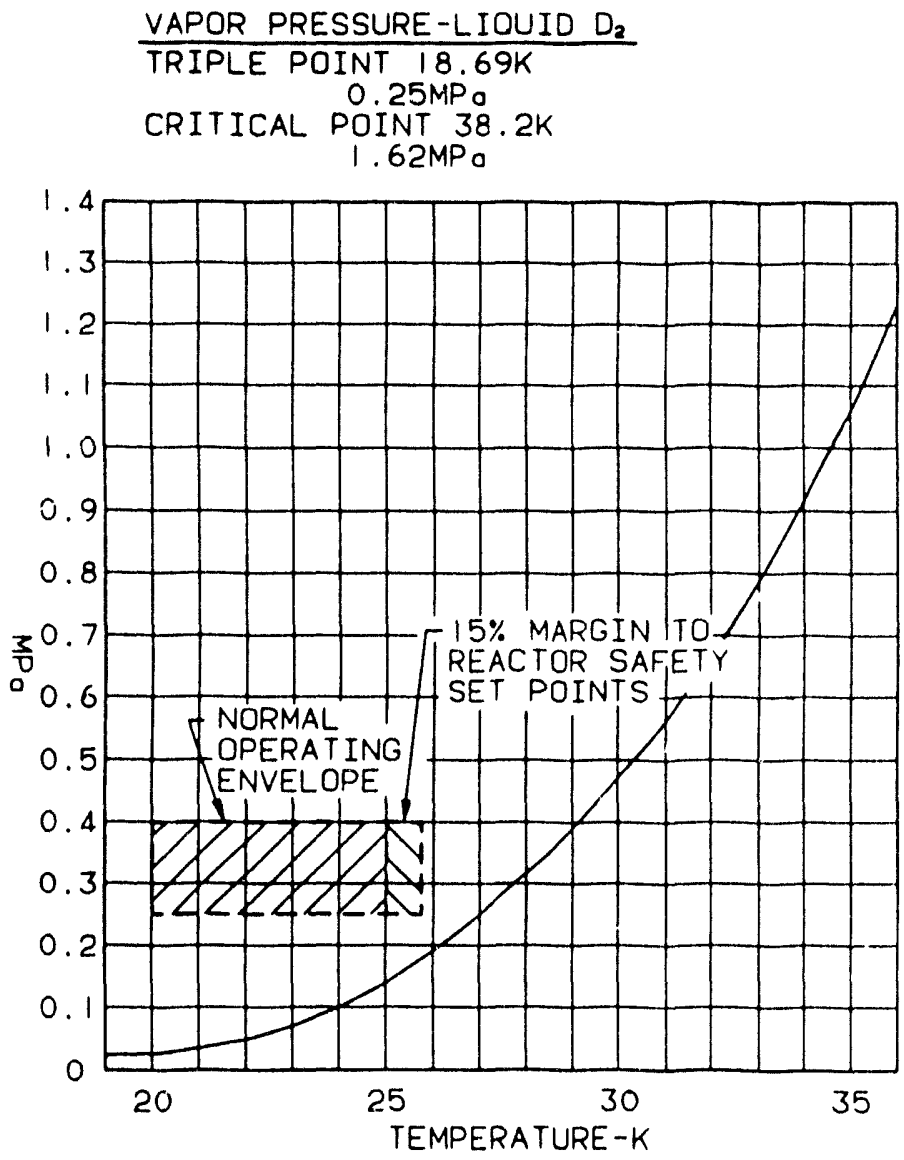

Fig. 2.11. The operational envelope of the cold source system. 
is designed to restrict vertical and horizontal movement while allowing some axial movement to accommodate shrinkage of the feed pipes during cooldown. The thimble is closed by a thin window to minimize the loss of cold neutrons being transported to the beam lines. The transfer line section of the assembly is added to the main thimble body as a final operation, prior to fullscale testing. Remotely operated equipment used for installation of the thimble assembly will include the capability of locking and sealing this assembly in place.

\subsubsection{Cold Source Neutronics}

A three-dimensional model of the ILL cold source has been developed from data provided by INEL. This model is being used to benchmark data used for the design of the ANS cold source.

Heating calculations have been made to assess the induced heat load distribution in the liquid deuterium and vessel wall using alternative combinations of vessel and vacuum thimble materials. Further calculations have compared the neutronic properties of a low-density liquid hydrogen mist with liquid deuterium; this confirmed that deuterium is superior for moderators of the size required for the ANS.

\subsubsection{Liquid Deuterium Loop Design}

Two liquid deuterium circulators have been ordered to investigate their operational characteristics and long-term reliability. A flow test stand using liquid nitrogen has been designed to run a circulator over an extended period.

Authentic rotational speed and shaft loading are essential for a realistic test program, and to compensate for the increased density of liquid nitrogen, a modified impeller will be used. The flow loop will be pressurized to maintain subcooling throughout, and a remotely operated valve will create a realistic system pressure drop. A spherical vessel with viewing ports will be fitted to allow visual observation of any tendency toward cavitation. While this is not expected to be a problem in normal operation, it could occur in unusual circumstances, and the test loop will help develop ways to minimize its effects and restore the impeller to normal operation.

The actual cold source systems will include a redundant circulator that can be brought on-line without stopping the cryogenic loop. Replacement of an off-line circulator during operation will also be possible. The cryogenic isolation valves required for this operation have been studied and a baseline design evolved. Main transfer lines in the conceptual design have concentric multitube configuration in conjunction with long-nosed couplings. The overall plan of the pumping module and associated components shows all major items of the systems situated within the containment building, allowing appropriate floor space to be allocated.

\subsubsection{Cold Source Review}

A second cold source review was held in July. Two members of the committee who served on the first review were joined by two new members, and all four had background and experience directly related to the needs of the review.

The most significant issue recognized was the difficulty of ensuring adequate heat transfer from the inner walls of the moderator vessel to the liquid deuterium. This is a function of the hydraulic behavior of the liquid under operational conditions. The review committee recommended, as their highest priority, that available resources be diverted to this problem to minimize the effects of possible modifications later. An aggressive investigation into available three-dimensional computer codes and relevant expertise is currently being pursued. In parallel with this, physical model work will be performed to allow visual flow pattern tests to be conducted with a surrogate fluid. These tests will support and help benchmark the computational modeling. Final testing will be carried out by NIST at Boulder, Colorado, using liquid hydrogen.

The committee also recommended a preliminary safety report for the cold source, founded on realistic accident possibilities with 
consideration of diffuse faults where the true location of a leak could be difficult to determine. They recommended a detailed plan for routine replacement of cold source thimbles, with the attendant movement of peripheral equipment, and that further consideration be given to cold source control functions and their relation to reactor operation

\subsubsection{General Design Parameters}

The safety strategy of the cold source systems will rest heavily on isolating the deuterium from oxygen under all circumstances. To this end, both the deuterium loops will be surrounded by an inert gas blanket. Each cold source will operate in closed loop configuration with a buffer vessel of sufficient volume to limit its pressure to $0.4 \mathrm{MPa}$ at ambient temperature. This will reduce gas handling to a minimum. All primary and secondary deuterium containment is protected from overpressure by rupture discs venting to a storage tank capable of holding a cold source inventory at room temperature at a pressure of only $0.13 \mathrm{MPa}$. Gas from the tank would then be removed by portable metal hydride units and transported to the detritiation facility. The inventory of both cold sources will be routinely replaced biannually to control the tritium content.

\subsection{BEAM TUBE, GUIDE, AND INSTRUMENT DEVELOPMENT}

The beam tube, guide, and instrument development task includes the design support, testing, and evaluations of the candidate equipment and systems needed for neutron delivery to beam experiments. The basic goal is to maximize the use of neutrons delivered by the reactor.

\subsubsection{Polarizer Development}

Studies and experiments have been made to develop better supermirror polarizers for the ANS.
Many important neutron scattering experiments cannot be done without polarized neutron beams. This is especially true for complex materials that will be the subject of many experiments done at the ANS because of the need for high neutron flux and spectrometer resolution. The studies have concentrated on the $(30 \% \mathrm{Co} 70 \% \mathrm{Fe})-\mathrm{Si}$ system deposited on silicon wafers. Good performance has been demonstrated previously for this system for reflection at angles as high as twice the critical mirror edge for the $(30 \% \mathrm{Co} 70 \% \mathrm{Fe})$ alloy. The aim of the present work is to develop supermirrors with good reflectivity out to three times the mirror edge. This would make experiments possible for 0.25 -nm neutrons, which is an often needed wavelength.

It is difficult to extend the range of a supermirror as thinner and thinner layers are needed, and the number of layers needed increases rapidly as the range is extended. As the layers get thinner, imperfections in the layers become more important, and interdiffusion must be kept to a minimum. The problem has been attacked by first constructing multilayer mirrors with thinner and thinner layers and measuring the response by neutrons and $X$ rays. These studies give information about the effective densities for the $(\mathrm{CoFe})$ and silicon layers. Information about interdiffusion is also obtained. As more information is obtained, additional multilayers are constructed using computer programs with the measured parameters as input. Electron microscopy was also used to obtain a direct picture of the layer structure.

Once the physical parameters for the layers were obtained, a supermirror was designed to cover the range between the mirror edge and three times the critical angle. Figure 2.12 shows the best result obtained to date. Essentially total reflectivity is obtained at $0.5^{\circ}$ scattering angle. Three times the mirror edge corresponds to about $1.2^{\circ}$ for the $0.25-\mathrm{nm}$ neutrons used. Note that although the mirror response looks flat, it is in fact decreasing as more mirror intercepts the beam as the scattering angle increases. This means the response must be divided by the scattering angle or that it falls a factor of two by three times the critical angle. 


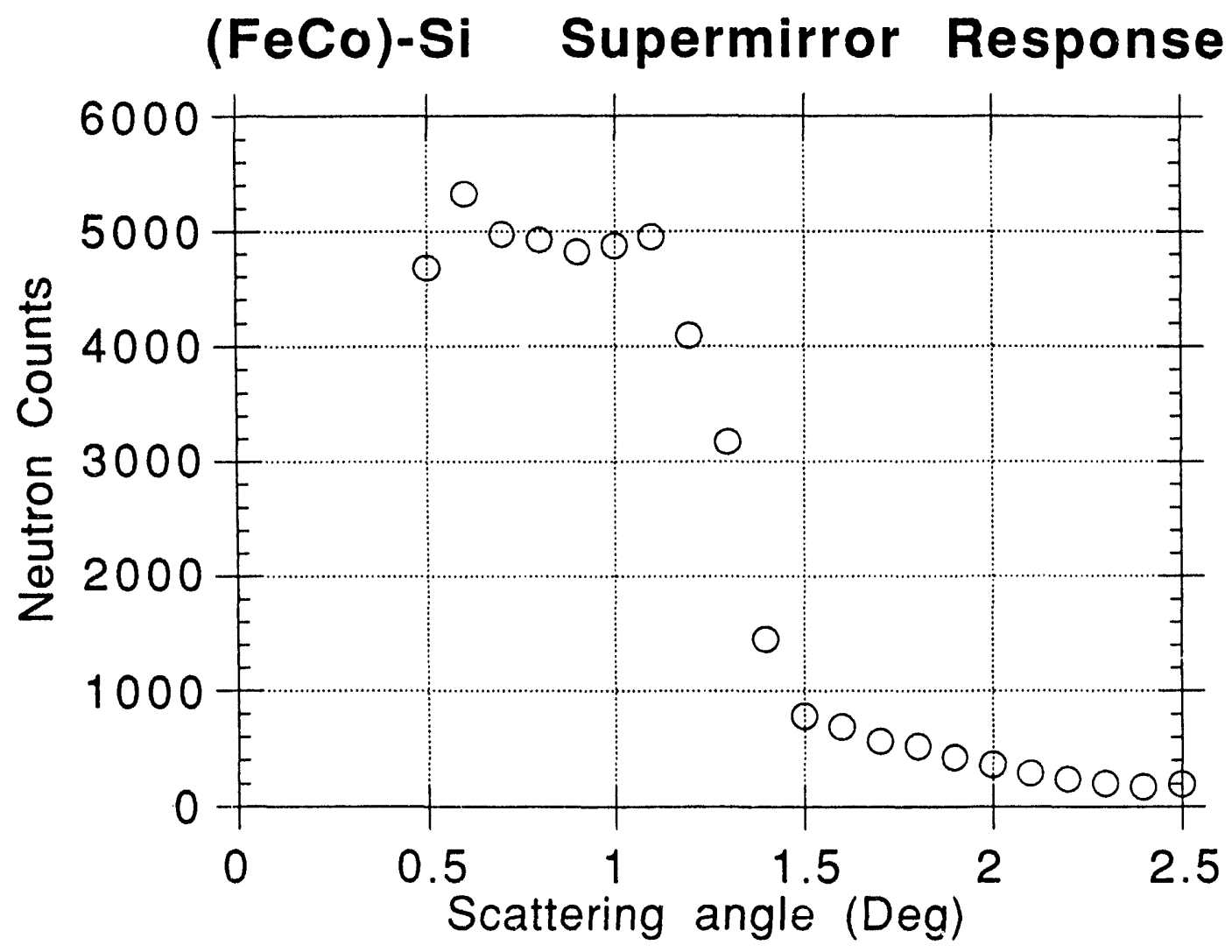

Fig. 2.12. Polarizing supermirror response as a function of scattering angle.

Thus, even though the supermirror is considerably better than any previous one, there is room for improvement. Electron microscopy shows that the $(\mathrm{FeCo})$ layers grow as large grains so that the layers are nonuniform and depend on the direction of grain growth. Further efforts will be directed at reducing the grain size to achieve smoother layers.

Studies have also been undertaken to develop better polarizing crystals for higher neutron energies. Several magnetic compounds have been identified and will be tested for polarizing efficiency and neutron intensity. Attempts will then be made to grow large crystals of the most promising materials.

\subsubsection{Neutron and Gamma Filters for Straight Neutron Guides}

The iceal neutron filter would allow transmission of thermal neutrons and would scatter the faster neutrons out of the beam. Therefore, the elements used must have very low absorption and incoherent scattering cross sections and be in the form of large, relatively perfect, single crystals. Useful elements and compounds could be $\mathrm{Si} ; \mathrm{SiO}_{2}$; $\mathrm{Bi} ; \mathrm{Al}_{2} \mathrm{O}_{3}$; $\mathrm{Be} ; \mathrm{BeO} ; \mathrm{PG} ; \mathrm{MgO} ; \mathrm{Mg}-, \mathrm{Bi}-$, and $\mathrm{Pb}-$ fluorides; $\mathrm{ZrO}_{2} ; \mathrm{Pb}$; and $\mathrm{Bi}$ silicate. Crystals used currently are perfect silicon, sapphire $\left(\mathrm{Al}_{2} \mathrm{O}_{3}\right)$, quartz, and, in some applications, pyrolytic graphite and polycrystalline beryllium. Filters 
containing the heavier elements lead and bismuth would be particularly desirable for they would also be excellent gamma filters. A combination of the heavy and light elements may be required.

To reduce the fast neutrons in the direct beam by a factor of 10 , one needs about $100 \mathrm{~mm}$ of single crystal of the best filter elements or compounds. Sapphire would require about $400 \mathrm{~mm}$, but this would undoubtedly decrease the thermal beam appreciably. Some, perhaps all, materials would require cooling to low temperatures to reduce the thermal scattering. It may prove difficult to get the most desirable materials in large enough size with a very narrow mosaic spread.

The neutron cross sections and transmission of several samples containing some of the above elements were measured at room temperature on the Oak Ridge Electron Linear Accelerator pulsed neutron source. They are $\mathrm{Pb}, \mathrm{Al}_{2} \mathrm{O}_{3}, \mathrm{SiO}_{2}, \mathrm{Bi}$, $\mathrm{ZrO}_{2}$, and $\mathrm{MgO}$ single crystals. A high-quality sapphire crystal, of the type already in use at some of the HFIR beam holes, was superior to all others. However, if $\mathrm{MgO}, \mathrm{Pb}$, or $\mathrm{Bi}$ could be obtained in larger, more perfect crystals, they could be more suitable filters. Lead and bismuth would have to be cooled to very low temperatures to reduce the appreciable neutron scattering by phonons. A pyrolytic graphite filter, a neutron filter for special purposes, was also investigated, and its transmission properties were shown to depend quite sensitively on its precise alignment along the incident neutron beam axis.

Experiments investigating the effect of cooling these filters to very low temperatures on their transmission properties at very low energies are under way.

\subsection{HOT SOURCE DEVELOPMENT}

During this report period, various hot source material compositions and locations were evaluated to arrive at a geometry that would provide the desired neutron spectrum shift for the hot source beam tubes. It was determined that to achieve the desired neutron source magnitude with $>2000^{\circ} \mathrm{C}$ neutron spectrum, the hot source would have to be moved to the core midplane and shifted closer to the reactor core. With these geometry changes, it was shown that a graphite hot source with a carbon-bonded carbon fiber insulation would meet design specifications.

\subsection{NEUTRON TRANSPORT AND SHIELDING}

\subsubsection{Cold Neutron Guide Tube Tunnel Shielding}

The analysis of the shielding requirements for the cold neutron guide tube tunnel was refined in two important areas. The source at the entrance to the guide tube was updated to be consistent with the current design of the cold source, and the GRTUNCL ${ }^{33}$ code was used to calculate a first collision source in the glass guide tube in order to eliminate the uncertainties associated with the use of biased angular quadratures in the previous DORT $^{34}$ analysis. Several DORT cases were completed to determine which components of the source were contributing to the dose rates. The results of those calculations are summarized in Table 2.3.

In order to verify the calculational techniques used in this analysis, several changes were made to the model to approximate the design configuration of the ILL cold neutron guide tube. These modifications included barytes concrete rather than ordinary concrete, boron included in the composition of the glass, source modification to approximate ILL cold source, and calculation of the dose rates at a point further from the guide tube entrance. The total effect of all these changes was to reduce the total ANS gamma ray and neutron doses shown in Table 2.3 to $7 \mathrm{mSv} / \mathrm{h}$ and $11 \mathrm{mSv} / \mathrm{h}$, respectively, for the ILL configuration. 
Table 2.3. Calculated dose rates above removable concrete roof sections

\begin{tabular}{lcccr}
\hline Source component & $\begin{array}{c}\text { Gamma dose } \\
(\mathrm{mSv} / \mathrm{h})\end{array}$ & $\%$ & $\begin{array}{c}\text { Neutron dose } \\
(\mathrm{mSv} / \mathrm{h})\end{array}$ & \multicolumn{1}{c}{$\%$} \\
\hline Gamma & 0.07 & 0.22 & 0 & 0 \\
$\mathrm{n}<0.4 \mathrm{eV}$ & 31.17 & 96.68 & 0.11 & 6.85 \\
$\mathrm{n}>1 \mathrm{MeV}$ & 0.16 & 0.50 & 1.48 & 91.72 \\
$1 \mathrm{MeV}>\mathrm{n}>0.1 \mathrm{MeV}$ & 0.02 & 0.08 & 0.01 & 0.47 \\
$0.1 \mathrm{MeV}>\mathrm{n}>0.4 \mathrm{eV}$ & 0.83 & 2.52 & 0.02 & 0.96 \\
Total & $\mathbf{3 2 . 2 5}$ & $\mathbf{1 0 0 . 0 0}$ & $\mathbf{1 . 6 2}$ & $\mathbf{1 0 0 . 0 0}$ \\
\hline
\end{tabular}

Subsequent analysis of the ANS design with modifications to include barytes concrete, boron in the glass composition, and borated polyethylene around the guide tube showed that the dose rates above the roof sections because of a single guide tube could be reduced to meet the total dose constraint of $2.5 \mathrm{mSv} / \mathrm{h}$ using approximately $300 \mathrm{~mm}$ of borated polyethylene. Preliminary analysis indicates that approximately $500 \mathrm{~mm}$ of borated polyethylene will be required to meet the design dose constraint when all seven guide tubes are included. As the design is refined, the analysis will be extended to determine the optimum shield geometry.

\subsubsection{Shielding Cross-Section Library}

The 99 neutron group/44 gamma ray group $(99 n / 44 g)$ and $39 n / 44 g$ cross-section libraries have been updated and extended so that both libraries now contain data for 138 separate nuclides. These libraries incorporate data from the original 99 group neutron-only ANSLV library and contain data for 86 more nuclides than the original $39 n$ / $44 \mathrm{~g}$ ANSLV library. These cross-section libraries are available for use in both physics and shielding analysis tasks.

\subsubsection{Flux Characterization in the Heavy Water Vessel}

The ANSLV cross-section library mentioned in the previous section was used in DORT to provide a good characterization of the flux inside the reactor and the $\mathrm{D}_{2} \mathrm{O}$ reflector tank since these fluxes are the underlying basis of the boundary sources used in the shielding analyses. A shielding model of the ANS was developed for this analysis using the current reactor physics model as a starting point. The source for this calculation was a set of fuel-cycle averaged source terms from a reactor physics calculation that included 30 zones in the reactor core region. The results of this large DORT calculation were verified by comparison with previous reactor physics analysis and with detailed fine-mesh one-dimensional calculations. The calculation was then extended to include the effects of photoneutron production, and the results of that calculation are now considered to be the reference case for preparing sources for future shielding analyses. The results of those calculations have already been utilized to calculate heating rates in the reflector vessel and in the CPBT and to prepare some preliminary estimates of dose rates during shutdown conditions at locations several metres above the ANS core.

\subsubsection{Analysis of Beam Tube Shield Plugs}

Embedded in the 2.5-m-thick concrete biological shield are shield plugs for each of the horizontal beam ports. Using sources derived from the calculations described in the previous section, neutron and gamma dose rates were calculated downstream of the shield plugs with the plugs in the closed position. The current design contains a void space upstream of the shield plug, which is approximately $300-\mathrm{mm}$ long. This space is to accommodate a gate valve used to isolate the beam tube if a leak should develop in the tube. The results of these initial analyses showed that the dose rates outside the biological shield at the shield plug locations would be reduced 
significantly if the void space could be reduced or eliminated. However, the monochromators or beam tube saddle shields downstream of the shield plugs may reduce the dose rates to acceptable levels without the need to reduce the void space.

\subsection{I\&C RESEARCH AND DEVELOPMENT}

\subsubsection{Neutron Kinetics Modeling}

A series of KENO-NR ${ }^{35}$ Monte Carlo calculations has shown that the neutron kinetics models used for the conceptual safety analyses were adequate and that the use of these models yields conservative results.

The calculations were performed with a special version of the Monte Carlo code that tracks not only where the neutrons go but how much time they take to get there. By averaging a large number of fission chains that originate at a neutron source, the code estimates the reactor impulse response. For convenience, these results are processed in the frequency domain to yield the transfer functions between the neutron source and the detectors at different locations. In this particular ANS application, the source was located in the core midplane, and the detectors were located at different radial locations in the reflector. Two additional detectors were located in the upper and lower fuel elements.

Figure 2.13 shows the time delay (estimated from the calculated transfer function phase) from both fuel elements to detectors at different radial positions in the reflector. As expected, the time delay increases as a function of distance from the core until it reaches a saturation value in the light water pool. The delay is always lower than the conservatively high value of $25 \mathrm{~ms}$ assumed in the conceptual safety analyses.

Figure 2.14 shows that the estimated transfer functions between the neutron source and both elements are indistinguishable. The solid line in Fig. 2.14 is the point-kinetics transfer function, which is in excellent agreement with the MonteCarlo-based transfer function for both cores. This excellent agreement indicates that the special ANS geometry and spectral characteristics do not impose any specific limitations to the use of the point-kinetics approximation to model ANS transients.

\subsubsection{ANSDM, PRSDYN, RELAP5/ANS Benchmark}

We have concluded a series of benchmarks among the three dynamic models used by the ANS project for transient analyses: ANSDM, ${ }^{36}$ PRSDYN,${ }^{37}$ and RELAP5/ANS. ${ }^{38}$ The benchmark cases included steady-state, natural circulation, small and medium size breaks, and reactivity insertion events. These benchmarks have resulted in satisfactory agreement between the three codes, increasing confidence in the accuracy of ANS transient calculations.

\subsubsection{Reactor Inlet Temperature Control}

The PRSDYN computer model was expanded to include detailed primary and secondary coolant system characteristics. The model then was used to evaluate control schemes to maintain desired reactor inlet temperature. Three different control schemes were examined for a variety of steadystate and transient conditions. The first scheme represents the conceptual design configuration and incorporates secondary coolant flow control to maintain constant reactor inlet temperature $\left(45^{\circ} \mathrm{C}\right)$ with variable speed pumps and constant secondary coolant off-tower temperature control $\left(30^{\circ} \mathrm{C}\right)$ with variable speed tower fans. As expected, the studies show that this technique can perform very well, and suitable algorithms were derived to deal with the long time constants associated with the coolant loops. The second scheme uses constant-speed primary pumps and variable-speed tower fans. With this arrangement, the off-tower temperature is maintained constant with fan speed control, and the reactor inlet temperature is allowed to vary 


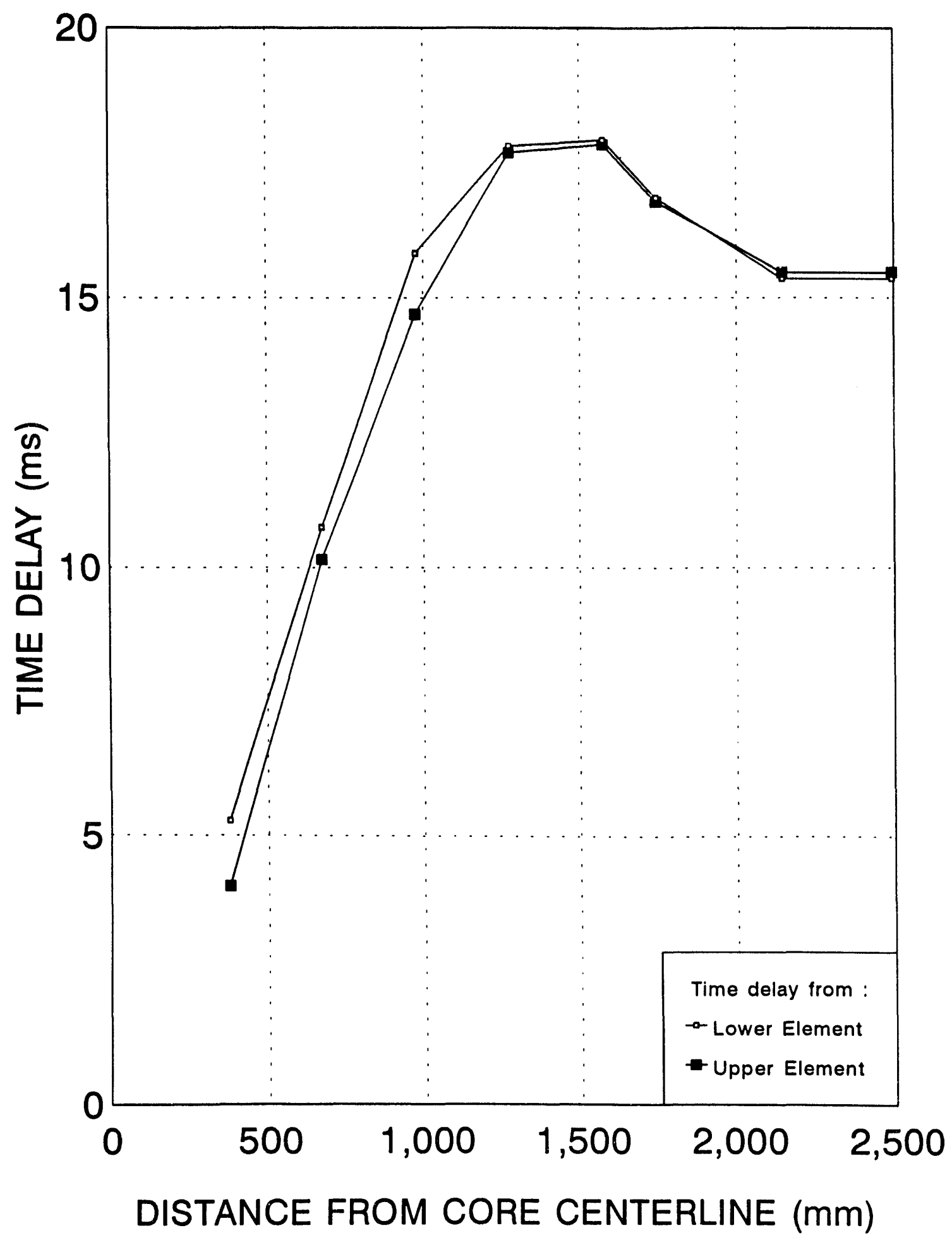

Fig. 2.13. Time delay in sensing power changes as a function of distance from core.

32 Advainced Neutron Source (ANS) Progress Report 


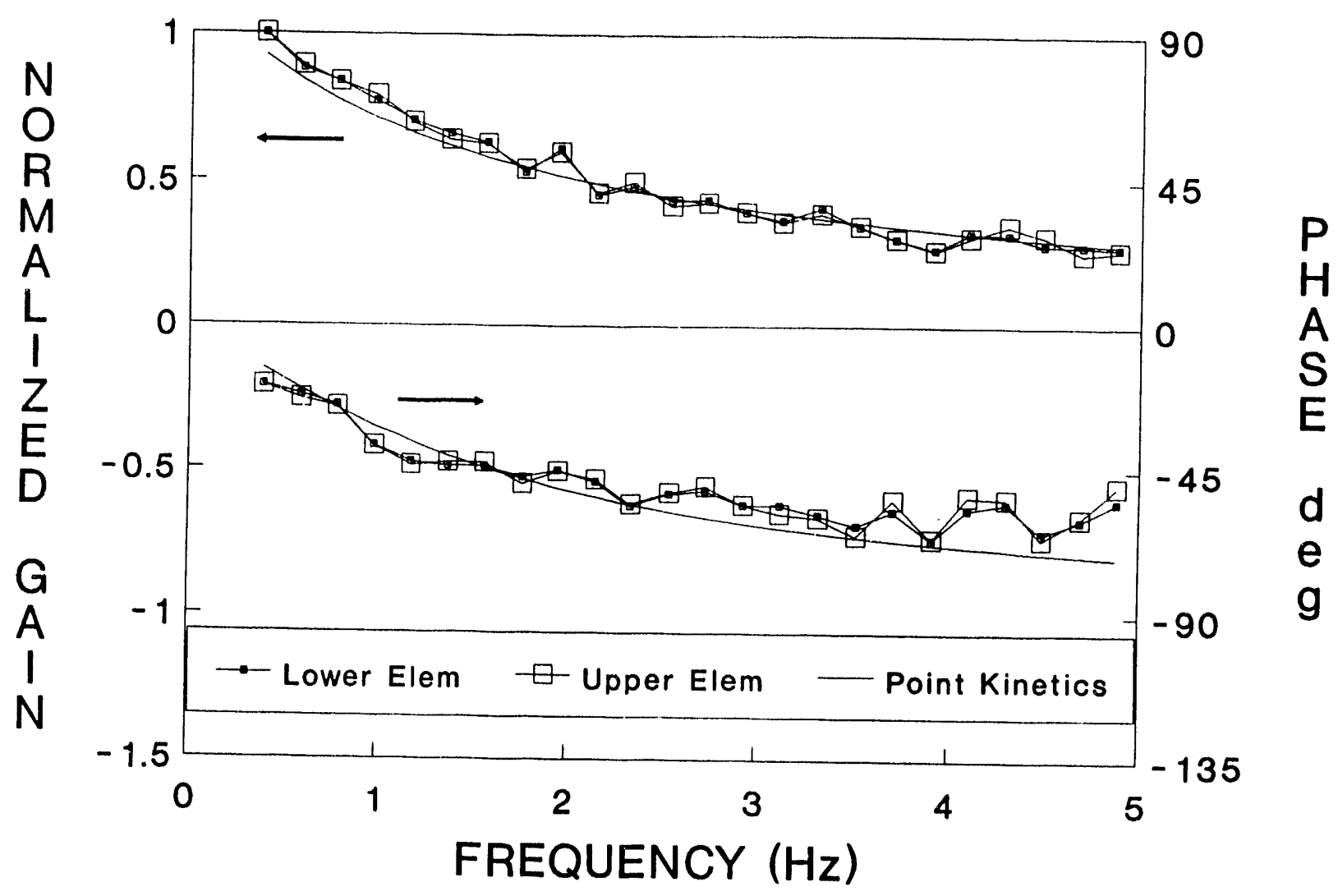

Fig. 2.14. Comparison of transfer functions and point-kinetics theory.

below $45^{\circ} \mathrm{C}$ as operating power and seasonal conditions change. This scheme also provides satisfactory performance, given the acceptability of reactor inlet temperature variations between $30^{\circ} \mathrm{C}$ and $45^{\circ} \mathrm{C}$. The third scheme evaluated used primary pump speed control to maintain the secondary hot-leg temperature at $65^{\circ} \mathrm{C}$ and fan speed control to maintain constant off-tower temperature of $30^{\circ} \mathrm{C}$. This method was proposed by the architect/engineer to enable use of the secondary coolant heat for space heating. This scheme performs satisfactorily in steady-state, but during power reduction transients, such as with a primary coolant pump trip, the reactor inlet temperature will exceed the safety trip point, resulting in reactor scram. If this scheme were to be used, additional control features would need to be added to deal with transients. The results of this study will be published in a topical report.

\subsection{FACILITY CONCEPTS}

Work on reactor concepts included further development in the definition and requirements for tests and test facilities. Additionally, two test facilities were presented to and approved by the ANS test facility review board.

\subsubsection{Test Plan Development}

An effort began to develop comprehensive test plans for all reactor components and systems. 
The goal was to define required tests to verify design requirements, to confirm design assumptions, and to mitigate design uncertainties. The adopted strategy utilized the following steps to establish and define testing requirements for each system.

1. Identify all functions to be performed for the system.

2. Identify requirements for each function.

3. Identify the conceptual hardware designed to perform the function.

4. Identify uncertainties in the hardware meeting the requirements.

5. Identify actions necessary to eliminate uncertainties and verify that it meets the functional requirements (including tests, analysis, investigations, literature searches, etc.).

6. Describe tests required, data needed, and facility requirements.

7. Define test facilities, combining tests where possible.

8. Schedule and estimate costs for required facility.

9. Present test plans to the ANS test facility review board for approval and implementation.

So far, only the inner control and shutdown rod system has been evaluated using this method.

\subsubsection{Inner Control and Shutdown Rod Tests}

The inner control and shutdown rod system was evaluated using the following functions as defined in System Design Descriptions-31 and -33 of the conceptual design report:

I. Control reactivity

A. Normal operation (regulate and shim)

B. Scram (decouple from drive system; accelerate into scram configuration; decelerate into scram configuration; and recouple to the drive system)

II. Detect absorber position

A. Normal operation (continuous position indication)

B. Scram (detect down position of absorber)

III. Limit subpile room volume (seal against leaks from reactor cooling systems)

Documents were prepared that evaluated each of the above inner control and shutdown system functions, and the following tests were identified:

1. Magnet test - to verify latch magnet performance.

2. Wet latch wear test-to characterize wear on inner control rod scram latch.

3. Corrosion product buildup test- to determine if aluminum corrosion products from fuel elements could affect latch performance.

4. Seal test-of lower control rod seal to determine leak characteristics into the subpile room.

5. Hydraulic damper test-wet test to determine designs for damper holes used to decelerate after scram.

6. Down position indicator test-wet test to verify operation of hydraulic down indicator switch.

7. Assembly test-full-scale static wet test to verify integrated unlatch, accelerate, decelerate, and relatch functions (part of WBS 1.1.7).

8. Control element test-full-scale wet test with full flow, pressure, and three control rods (part of WBS 1.1.7).

Of the above identified inner control rod tests, th: magnet test, the wet latch wear test, and the seal test were further developed.

The magnet test plan was approved by the test facility review board. Design of the magnet test apparatus was completed, utilizing an existing 
tensile test machine to apply loads to a prototype latch magnet. The test layout is shown in

Fig. 2.15. The goal of the test is to characterize the load carrying capacity and time response of the magnet and to verify analytical methods used in its design. Preliminary tests have been completed, and final test results will be published next fiscal year.

Preparation of a preliminary design and test plan have been completed for the wet latch wear test. Presentation to the test facility review board will be early in FY 1994.

\subsubsection{Other Tests}

In addition to the above work on the inner control rods, a static CPBT seal test was developed and approved by the test facility review board. This test is being designed for testing in early

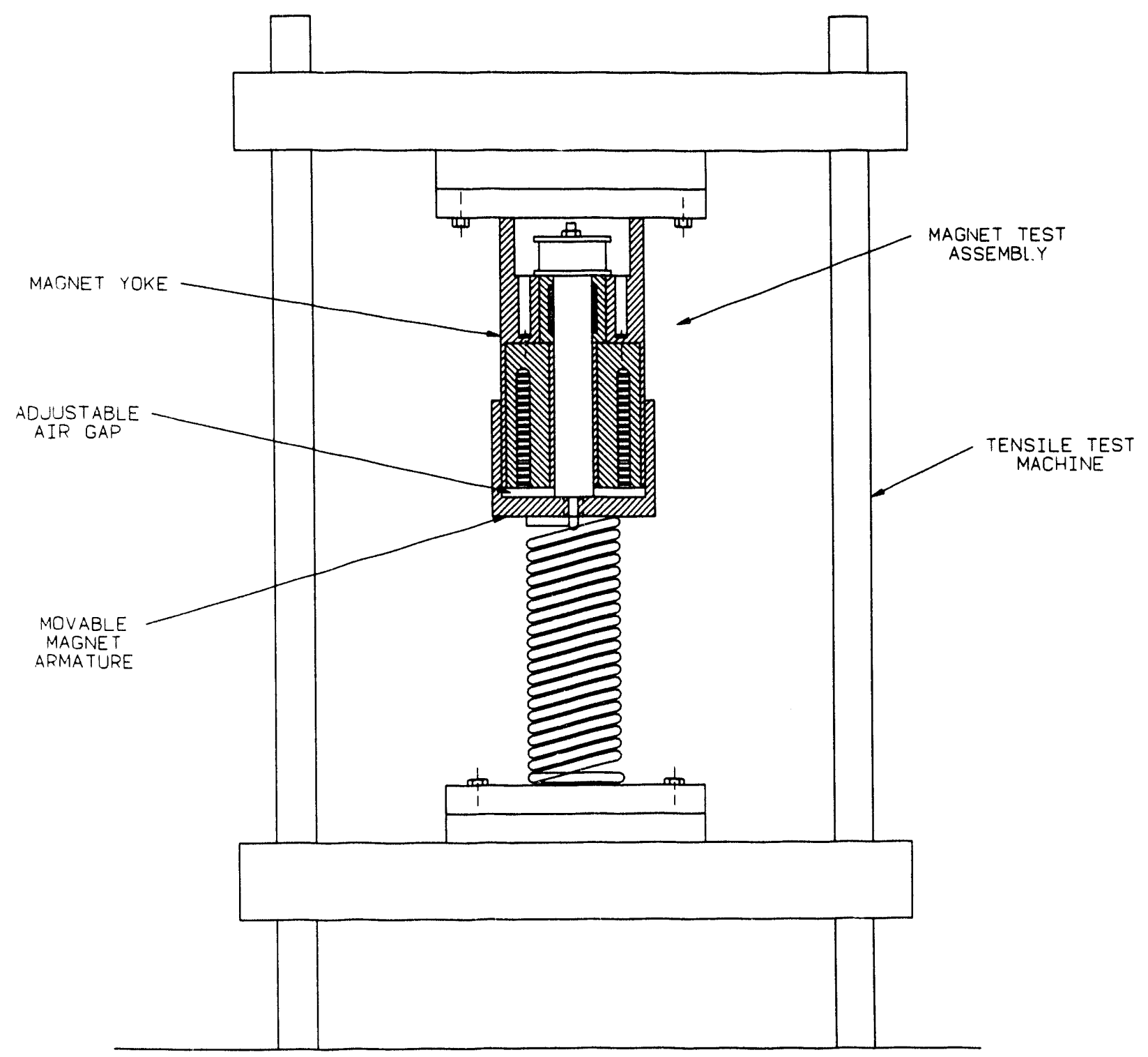

Fig. 2.15. Advanced Neutron Source latch magnet test facility. 
FY 1994 and consists of concentric cylinders joined by a prototypic lower CPBT seal. The device will be statically pressurized to characterize leak rates for this component.

Testing requirements developed this fiscal year have resulted in more definition of the tests to be completed in WBS 1.1.13.1 (reactor components tests). A block diagram describing the scope of these tests is shown in Fig. 2.16.

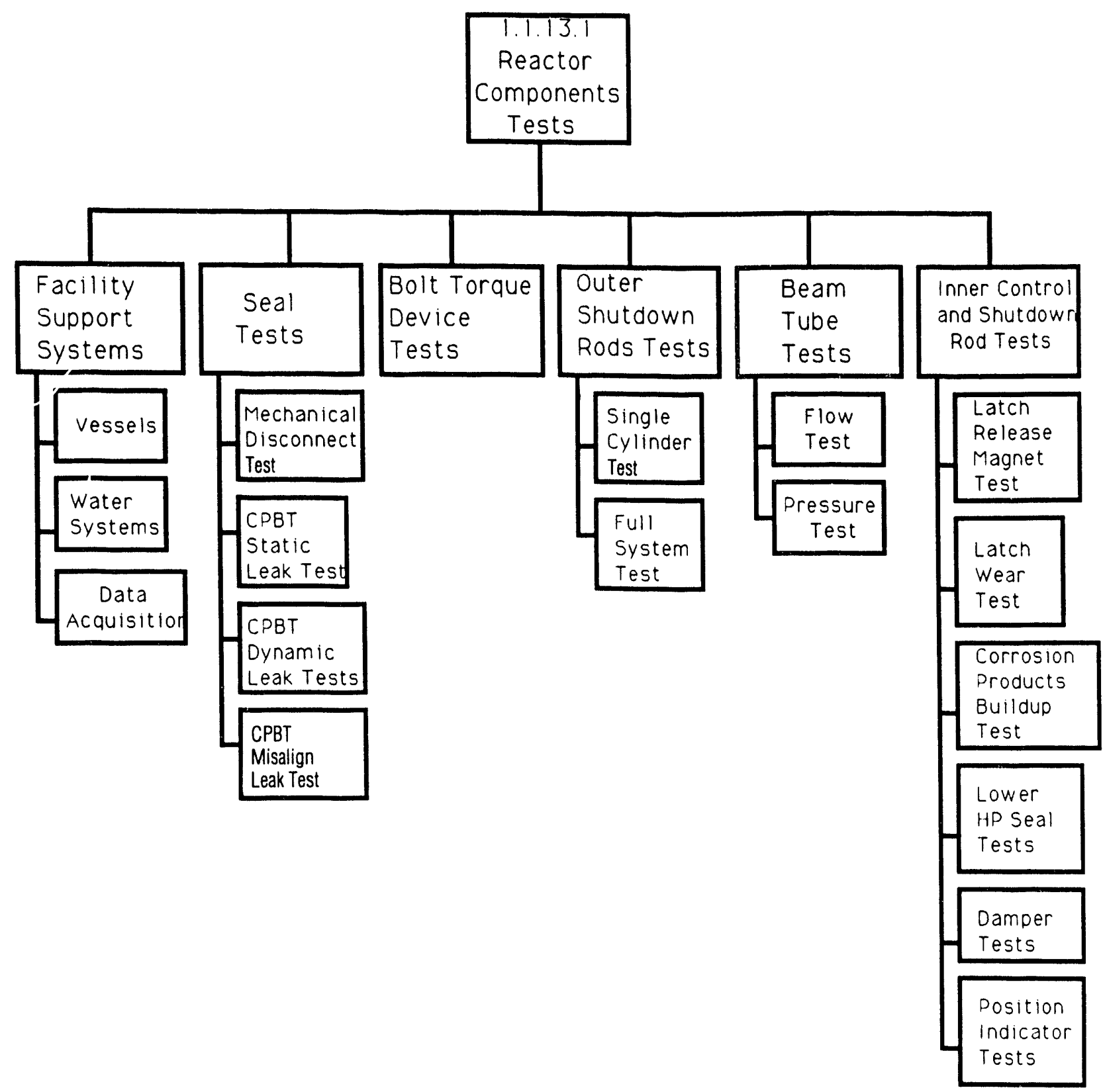

Fig. 2.16. Block diagram of reactor components tests. 


\section{DESIGN}

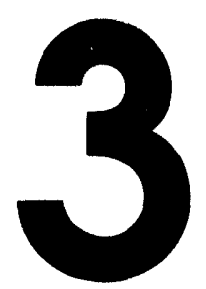

\subsection{SYSTEMS INTEGRATION}

\subsubsection{Configuration Management Philosophy}

The underlying philosophy related to the implementation of configuration control is that all baseline documents are part of the project's configuration. Management of that configuration is accomplished by follo ving specific procedures, with approval authority vested at the lowest appropriate level. The system is documented in the Configuration Management Plan ${ }^{39}$ and in an associated project procedure. ${ }^{40}$ Essential features of the concept are summarized in the table below: chaired by the project director. Type 2 documents define interfaces between project organizations, e.g., the MMES design team and the construction manager. These documents are controlled by a level 2 board that will be chaired by the prime contractor, who will have responsibility for the overall integrated design. Documents defining interfaces within an organization's scope of work (type 3 ) are controlled by a level 3 board chaired by that organization's management. Type 4 documents are typically those related to specific detailed procurement and construction tasks and are controlled by internal procedures, with approval by an MMES oversight task leader assigned for each level-3 entry in the project's work breakdown structure.

\section{Data or document category \\ Type 1, requirements}

Type 2, interfaces

Type 3, interfaces

Type 4, documents
Change control authority Configuration Control Board-1 (CCB-1); ANS project director Configuration Control Board-2 (CCB-2); prime contractor manager Configuration Control Board-3 (CCB-3); performing participant manager

Project oversight task leader

\subsubsection{Configuration Management Experience}

As indicated, a hierarchy of control responsibility and authority is established with the highest level of documentation (type 1, plant and system requirements) controlled by a level 1 board
The configuration management process was implemented at the time of the release of the conceptual design report (June 1992). Activities 
through FY 1993 have included 14 project change orders (PCOs) processed and approved by the configuration control boards. Of the 14 approved PCOs, 10 were processed and approved by CCB1, three by CCB-2, and one by CCB-3.

Two of the PCOs represented a considerable cost saving to the project: aluminum. For irradiated $20 \%$ cold-worked 316 SST with a total fluence of approximately $5 \times 10^{26} \mathrm{~m}^{-2}$ (two times that projected for a shielded PSVA in the ANS for 40 years), the calculated $\mathrm{K}_{\mathrm{IC}}$ (fracture toughness parameter) values ranged from 55 to $60 \mathrm{MPa} \mathrm{m}^{1 / 2}$ at $250^{\circ} \mathrm{C}$. This compares to a $\mathrm{K}_{\mathrm{IC}}$ of approximately

\begin{tabular}{l} 
PCO no. \\
\hline 4101 \\
5101
\end{tabular}

Three other PCOs represented a combined saving of nearly $\$ 1 \mathrm{M}$.

\subsection{REACTOR SYSTEMS}

The design effort during this year has concentrated on refining the components that make up the reactor assembly. The overall arrangement of the reactor assembly is shown in Fig. 3.1.

\subsubsection{Reactor Primary Pressure Boundary Design}

During this period, the reactor primary pressure boundary design activities included changing of the material for the primary supply vessel adapter (PSVA) from 6061 aluminum to 316 stainless steel (SST); design of the CPBT lower seals; and an analysis task to predict the behavior of the core support components under transverse loads. Several fabrication methods for the core support components were investigated to take advantage of some advanced manufacturing techniques that may add extra strength, rigidity, and fatigue resistance.

Consideration of stainless steel for the PSVA requires the study of several issues. These include material properties of irradiated 316 SST, thermal analysis at the interface with the 6061 aluminum reflector vessel (RV), and determination of the activation of 316 SST. The 316 SST for the PSVA appears to be a better material than the 6061-T6
$30 \mathrm{MPa} \mathrm{m}^{1 / 2}$ and $28 \mathrm{MPa} \mathrm{m}^{1 / 2}$ for $6061-\mathrm{T} 651$ aluminum at $99^{\circ} \mathrm{C}$ and $150^{\circ} \mathrm{C}$, respectively, irradiated to a fluence of $1 \times 10^{26} \mathrm{~m}^{-2}$. The 316 SST will have approximately twice the toughness at five times the fluence, compared to 6061 aluminum. Activation of the 316 SST is much greater than the aluminum, but this can be reduced using local shielding. The PSVA is being designed to last the 40-year life of the reactor and is located such that all maintenance will be done remotely. Heat transfer calculations done on a simplified onedimensional model resulted in temperatures at the aluminum/stainless steel interface of $125^{\circ} \mathrm{C}$. This temperature is within the acceptable range for 6061 aluminum as proposed for the $\mathrm{RV}$ in the present ASME Code case.

The fracture characteristics of aluminum have been investigated, including linear elastic fracture mechanics, elastic-plastic fracture mechanics, and probabilistic fracture analysis. Predicted allowable flaw sizes were correlated to existing nondestructive examination (NDE) techniques and to the probability of detection (POD) as a function of flaw size. Initial conclusions are that for a fracture toughness of $28 \mathrm{MPa} \mathrm{m}^{1 / 2}$ (irradiated aluminum), a crack depth less than $5 \mathrm{~mm}$ is required to prevent unstable crack growth. To meet the intent of the ASME B\&PV Code, Sect. III, Div. I for a class I nuclear pressure vessel (specifically written for ferritic materials), crack sizes have to be limited to $10 \%$ of $5 \mathrm{~mm}$. A plan 


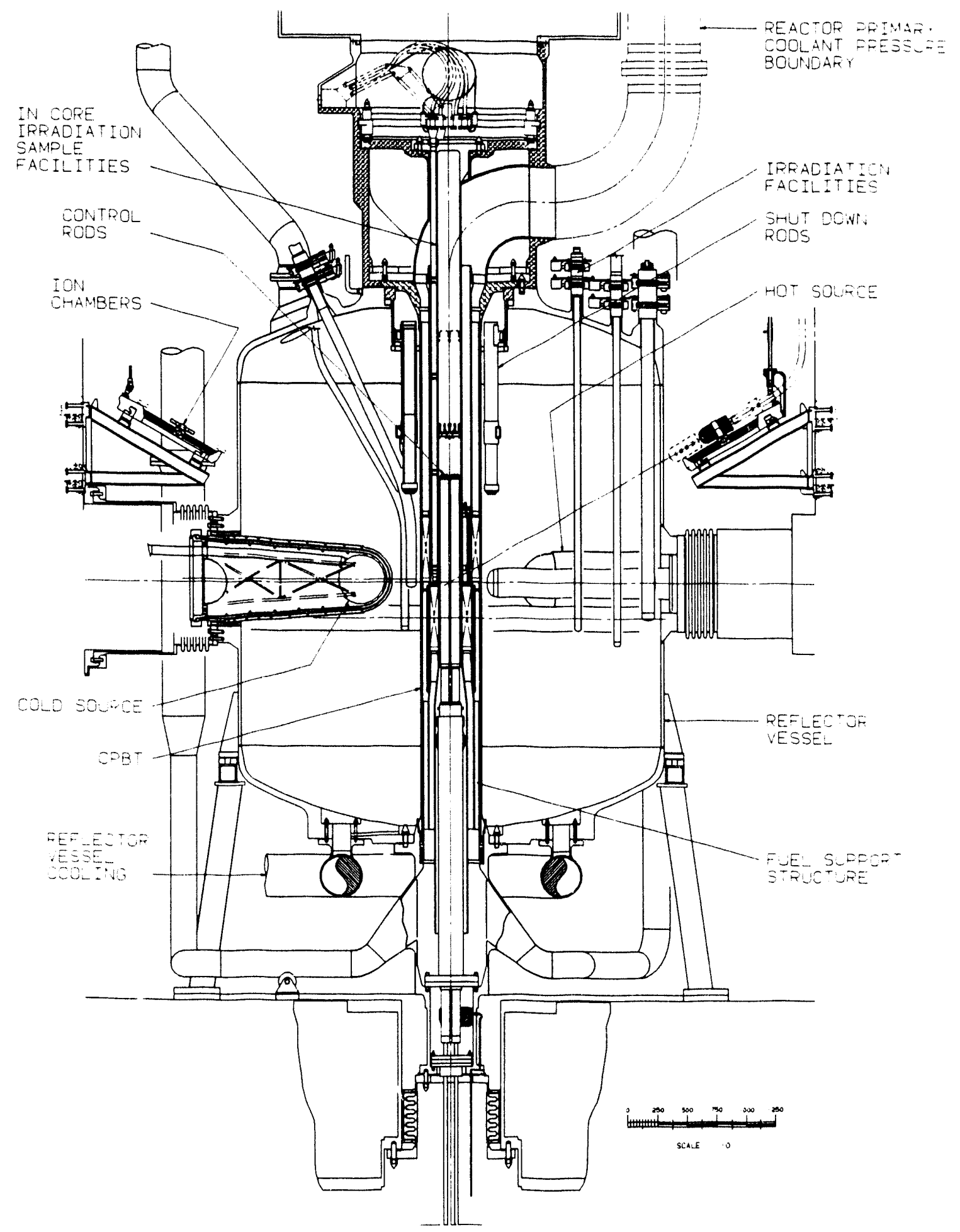

Fig. 3.1. Reactor assembly basic components. 
has been developed to utilize the POD of appropriate NDE methods in conjunction with the required flaw sizes to determine the CPBT thickness under the ANS operating conditions.

\subsubsection{Reflector Vessel}

A major change to the reflector vessel has been the replacement of the bolted joint between the upper head and the sidewall with a single-weld joint. This change was made to simplify the design by eliminating 1 weld, 2 seals, and 60 bolts or studs. This change will require that all maintenance and in-service inspection be performed through the existing penetrations.

Design effort on the reflector vessel concentrated on refining the interfaces with other structures and systems. The center penetration of the upper head was modified to accommodate the outer shutdown rod supports. The experiment tube penetrations have been designed to provide the required reinforcement per the $A S M E B \& P V$ Code. The locations of the experiment systems penetrations have been closely coordinated to ensure the proper location and alignment of experiments. Figure 3.2 illustrates the vessel configuration.

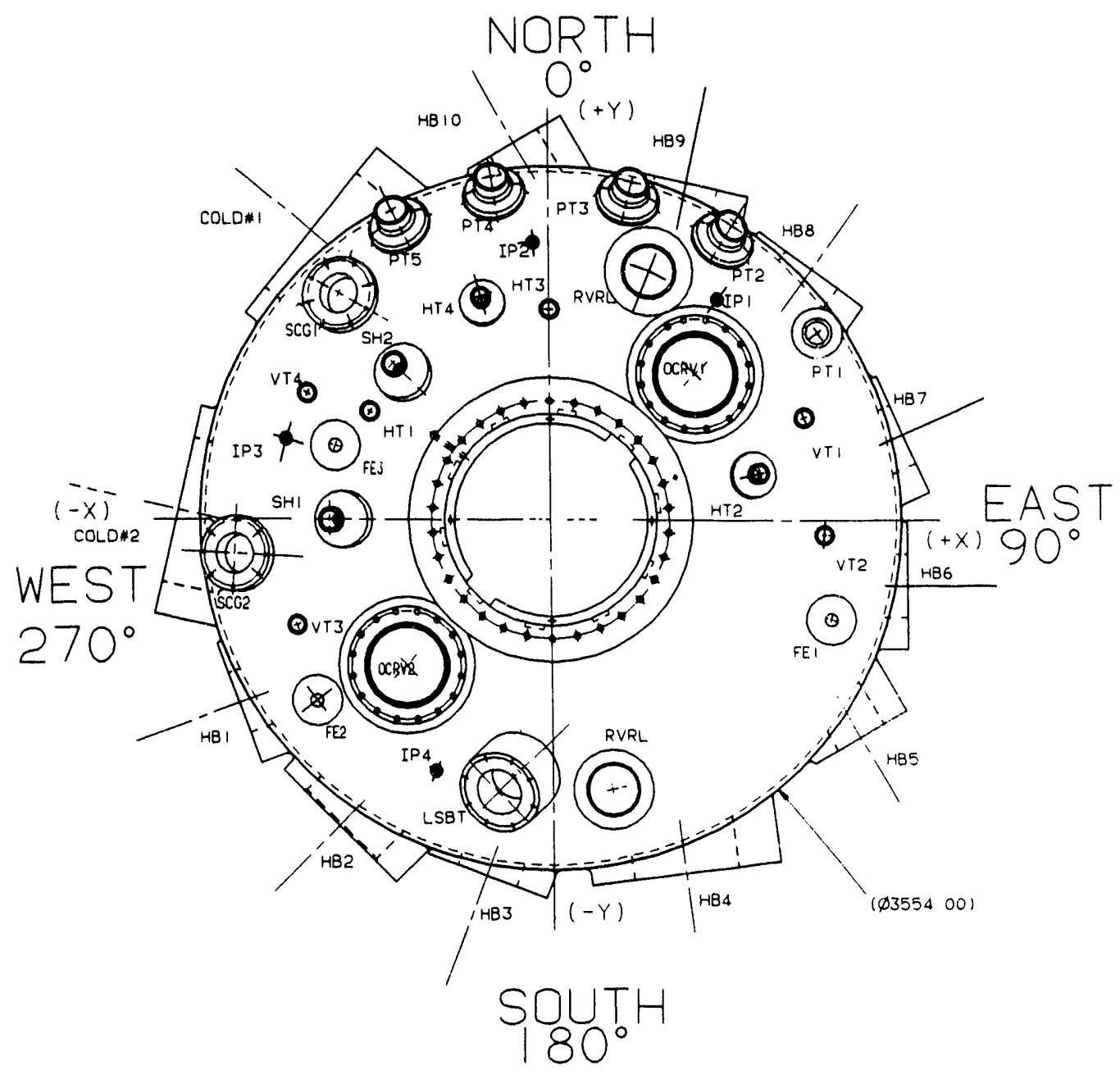

Fig. 3.2. Reflector vessel upper head. 
The thickness of the RV sidewall has been increased from $25.4 \mathrm{~mm}$ to $27.0 \mathrm{~mm}$. This thickness is based on an internal proof test pressure of $0.6 \mathrm{MPa}$. The lower head has been updated to include the required reinforcement for the center penetration, and the RV supply inlets and an integral drain passage have been added to allow drainage of the lowest elevation. A key slot has been added to ensure alignment of the holes for the PSVA mounting bolts. Figures 3.3 and 3.4 illustrate these features.

The only change to the support stand has been the deletion of the pressure skirt. Analysis showed that the volume enclosed by the skirt was too large to mitigate the effects of a break in the PSVA. A finite element analysis of the support-stand legs showed that the present design is adequate for vertical loads. Lateral stability and buckling strength remain to be verified. The reflector vessel drawings have been revised and new drawings added to reflect these changes in geometry.

\subsubsection{Control and Shutdown Rod Assembly}

The design has been modified to reduce the mass, to increase the stiffness, to make replacement less expensive, and to simplify fabrication. The basic change is the locating of the accelerating springs and the upper guide springs closer to the core, leading to a significant reduction in the overall length of the control rod assembly. This makes it possible to replace the assembly without having to raise the highly radioactive assembly above the reactor pool level, thus eliminating the need for a very expensive and extremely heavy lead cask. The assembly can now be removed along the same path as that which will be used for removal of some of the experiment facilities, always remaining submerged in either light or heavy water. Reducing the length also reduces the mass, which alleviates the problem of accelerating and decelerating the rods during a scram.

The hafnium absorber will be located inside an inconel tube as shown in Fig. 3.5. This improves the stiffness of the rods and protects the hafnium from the two sets of upper guide rollers where the action of these rollers could result in particles being worn off the hafnium tubes. The three-tube guide tube subassembly has been replaced with a single-piece guide tube that has three parallel holes thro:gh which the rods pass. A close-fitting graphite bushing for each of the three rods will be used in the upper end of the three holes to restrict lateral motion of the rod's drive tubes. The accelerating springs are below this bushing. This guide tube will be considerably stiffer than the three-tube bundle.

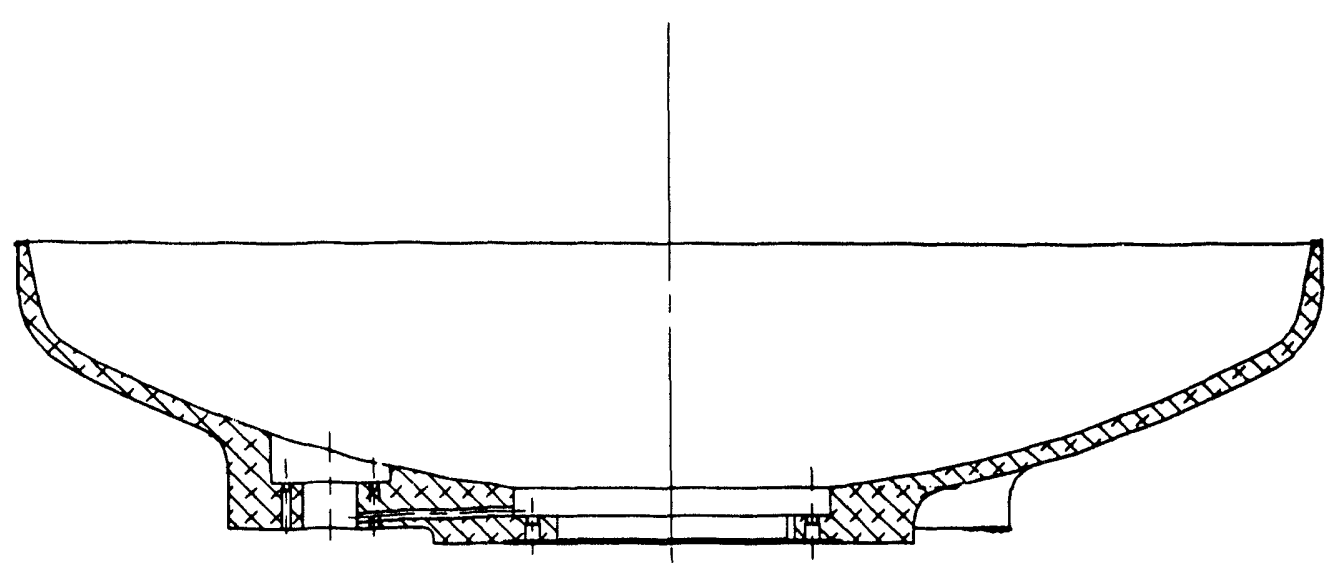

Fig. 3.3. Cross section through reflector vessel lower head. 


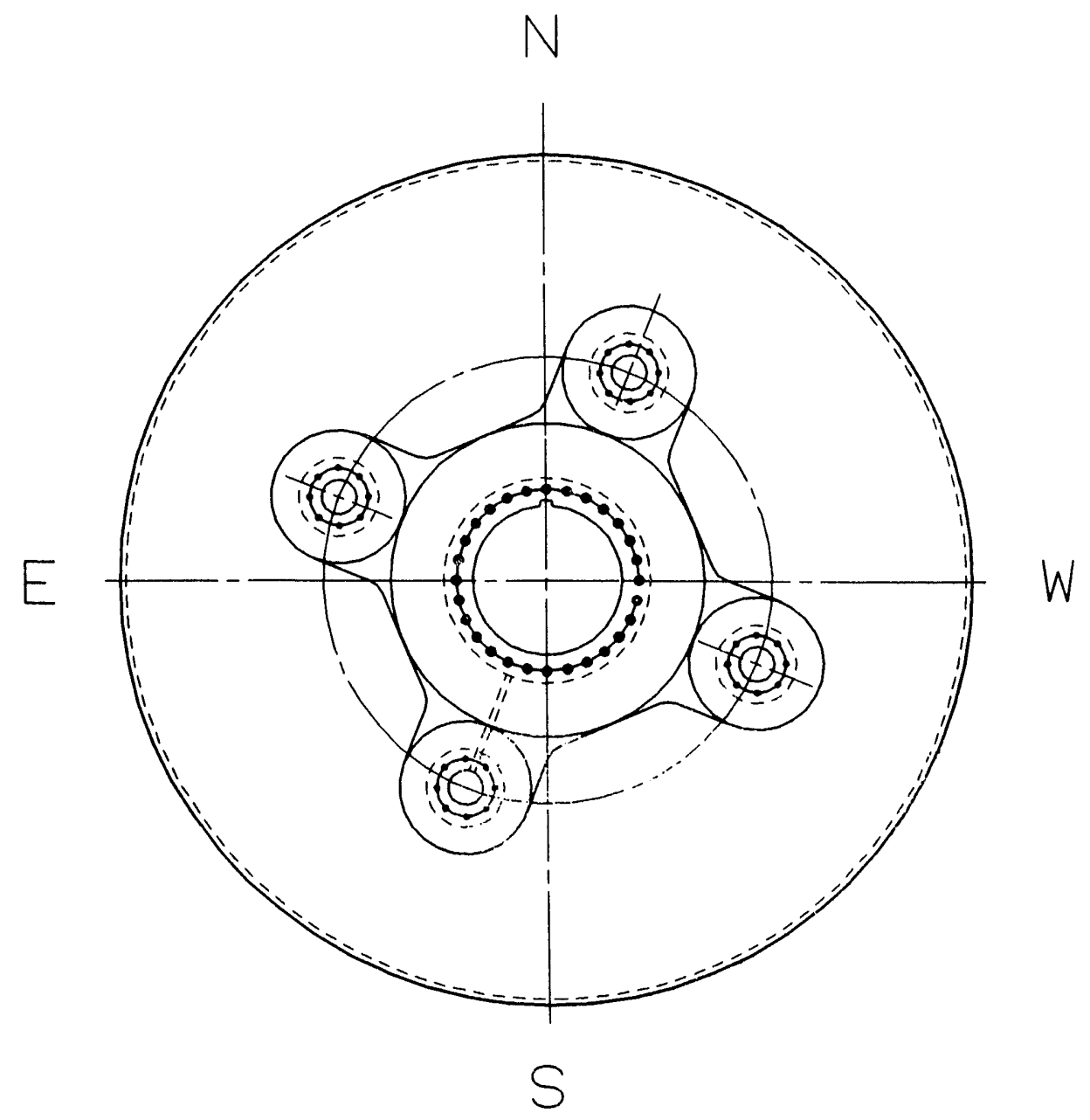

Fig. 3.4. Reflector vessel lower head.

The guide tube with the snubber (shock absorber) subassembly attached to its lower end has been raised so that the upper end is closer to the core. This permits raising of the high pressure seal through which the control rod drive shafts pass to the drive system in the subpile room.

Improvements have been made to the concept of the hydraulic-actuated rod seat switch, which should make the presence or absence of the lower end of the rod easier to detect. An improved supporting structure concept for these rods and their $\mathrm{D}_{2} \mathrm{O}$ supply line has been devised and is included in the conceptual design drawings. The support structure for the rods will be an integral part of the hydraulic cylinder casting and will be replaced when the rods are replaced. The support structure for the lower end of the $\mathrm{D}_{2} \mathrm{O}$ supply line will be separate from the hydraulic cylinder's support, and most of it can also be cast.

The conceptual design of the pressure/flow relief valve for the $\mathrm{D}_{2} \mathrm{O}$ supply line has been improved so that only one penetration in the reflector vessel head is required for each of the two lines. Conceptual design improvements have been made in the way that these rods are decelerated after a scram. As with the inner control rods, a combination of restricting $\mathrm{D}_{2} \mathrm{O}$ displacement and springs will be used for this purpose. 

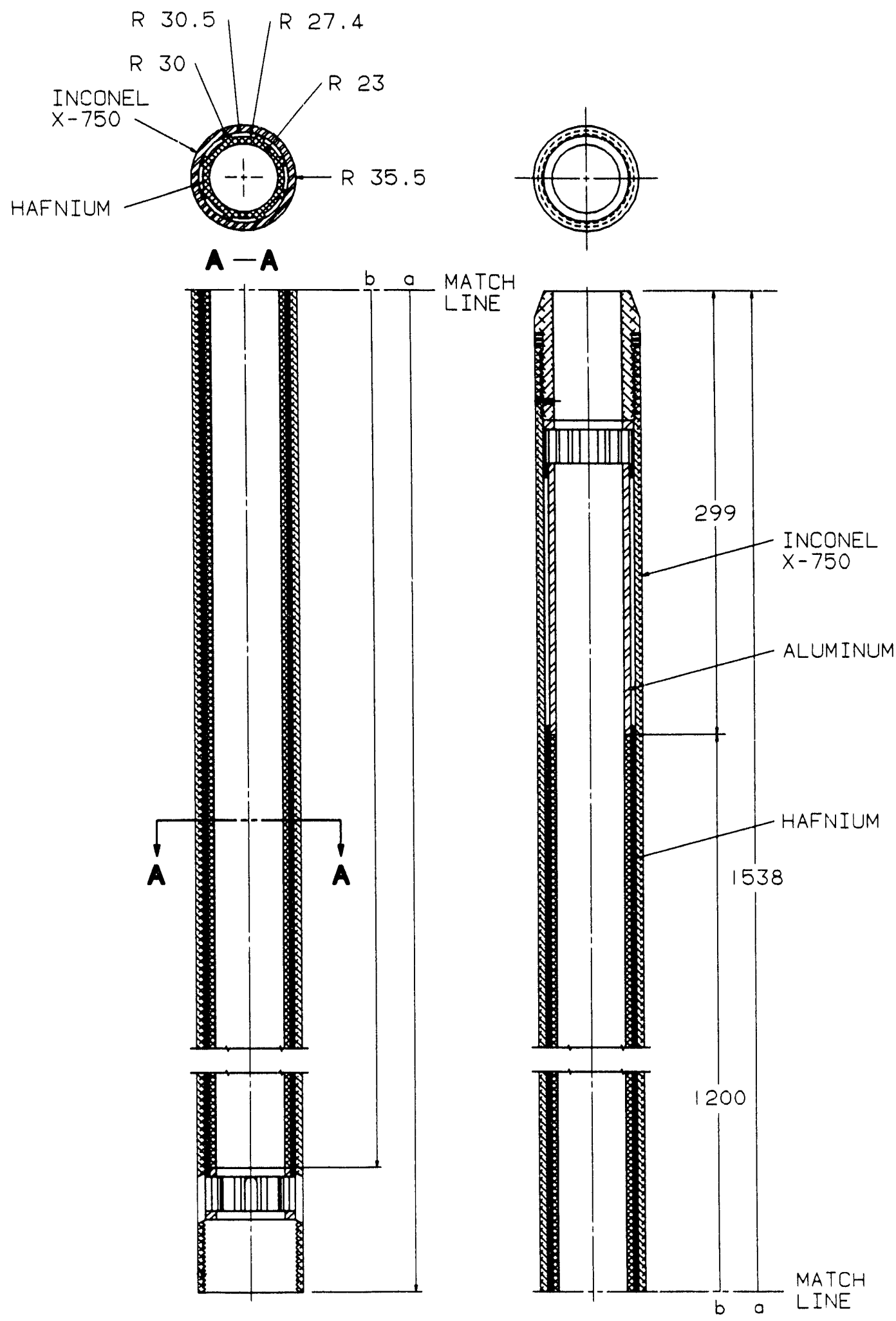

Fig. 3.5. Inner control rod with hafnium inside an inconel tube. 


\subsubsection{Refueling}

The design of the refueling system has continued to evolve during this period. An isometric view of the basic concept of the stack and tunnel structures for the refueling system is shown in Fig. 3.6. The size of the transfer cell has increased to allow for the dry storage of the tools and the laydown areas for the core components. The volume of $\mathrm{D}_{2} \mathrm{O}$ has increased slightly for the same reason.
A critical examination of the wall thickness for the cell has shown that it would not be adequate for intense neutron sources. For this reason, the transuranium production facilities will be handled with the flush/purge transfer lock system used to remove spent fuel from the $\mathrm{D}_{2} \mathrm{O}$ environment.

The number of tools needed for refueling and maintenance activities continues to change, including the elimination of an entire system to

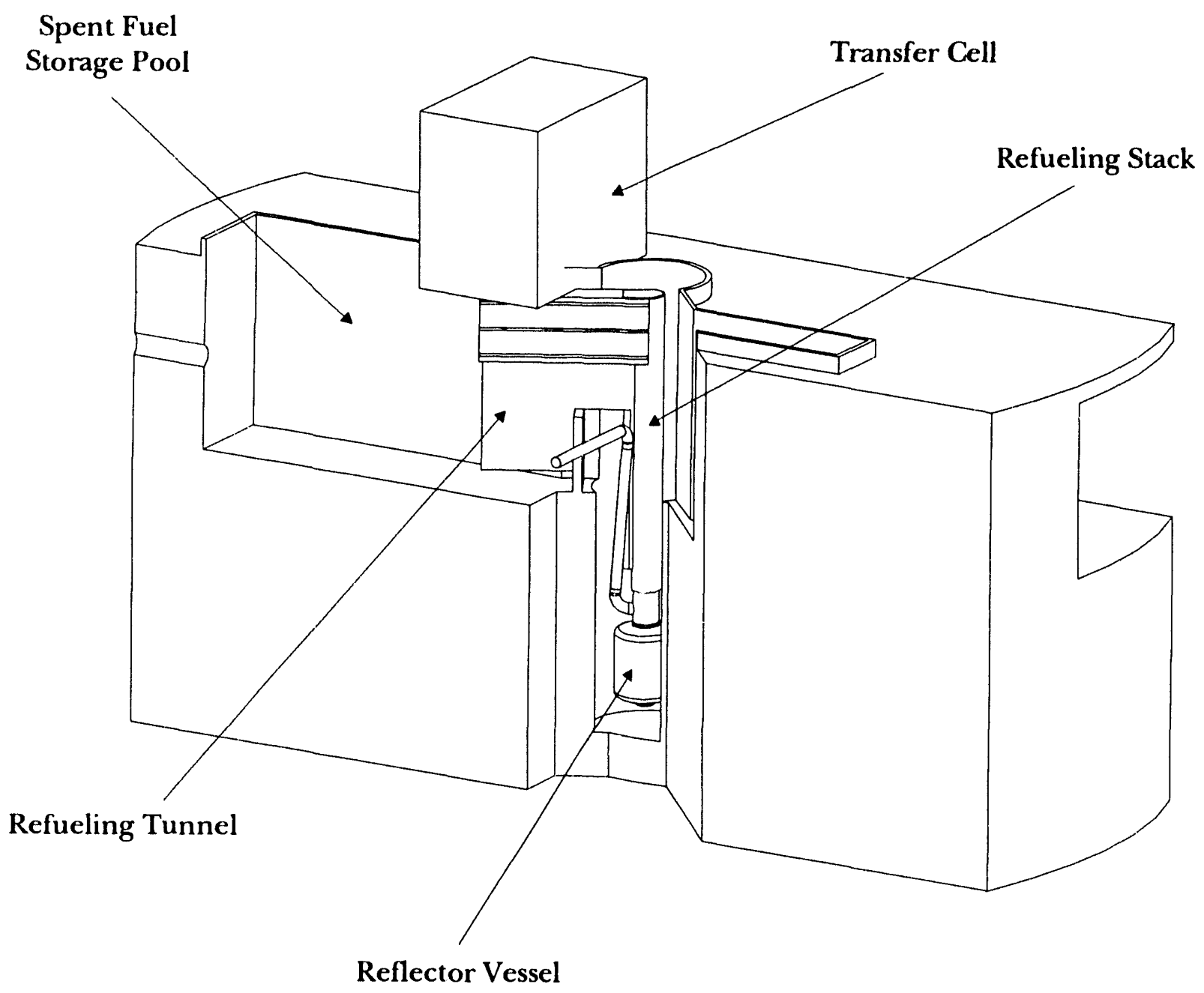

Fig. 3.6. Basic concept of stack and tunnel structures for refueling system. 
handle the inner control rods when they are withdrawn to the reactor containment building. A detailed examination of the remote tooling has also increased the number of tools and operations that will be required for a normal refueling.

\subsubsection{Reactor Maintenance}

Based on the estimated lifetime of the reactor systems components, maintenance schedules of six months, two years, four years, eight years, and sixteen years were developed. The lifetimes of the components were determined by the material property deterioration caused by increasing silicon content by the transmutation of aluminum. These schedules identify reactor assembly components requiring replacement, the order of their replacement, and their duration. The planning base assumes sequential tasks, whereas many of the replacement tasks could be done concurrently with other tasks.

\subsubsection{Modeling of the Reactor Assembly}

The majority of the reactor assembly was modeled three-dimensionally (see Fig. 3.7) in
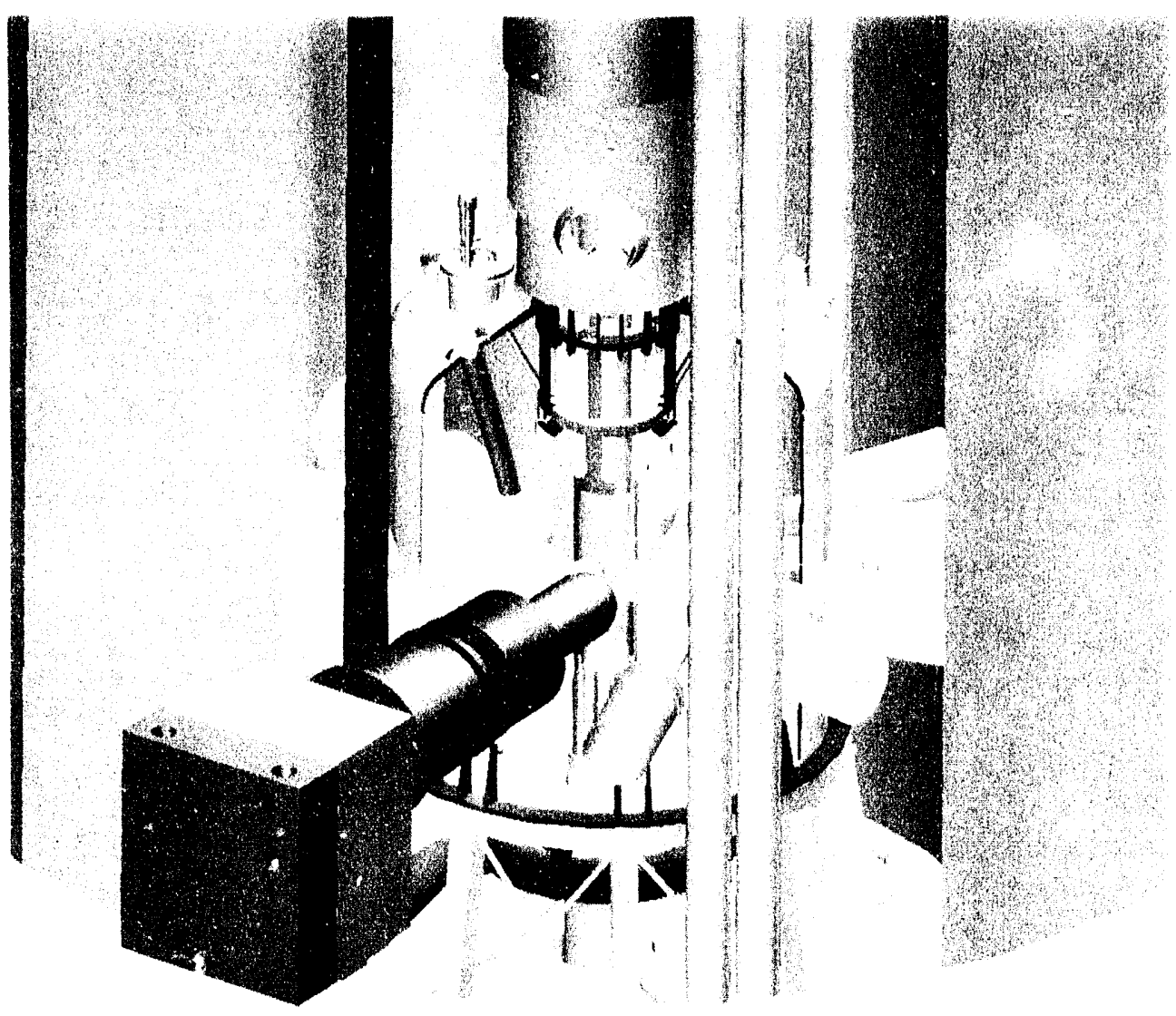

Fig. 3.7. Advanced Neutron Source reactor assembly_IGRIP model. 
Interactive Graphics Robot Instruction Program (IGRIP). IGRIP's dynamics module allows kinematic manipulation of components and subsystems. Animated videos were created from this model that demonstrate the installation and start-up of the reactor and the replacement of the hot source tacility.

\subsubsection{Thimbles and Light Water Transition Assemblies}

Investigations have been conducted to select and optimize a cooling scheme for the thimbles. Following preliminary comparisons of many options, four design concepts were selected for more detailed analyses. The thermal-hydraulic analyses conducted showed these concepts to be feasible from a thermal-hydraulic standpoint. Further studies are being conducted to select the final cooling scheme for the thimbles.

The current design wall thickness $(14.78 \mathrm{~mm})$ for the beam tube thimbles is based partially on the ASME B\&PV Code, Sect. III. The Code is intended to apply to internally loaded pressure vessels, and the beam tube thimbles are externally loaded. Analysis has been performed to optimize the wall thickness for the beam tube thimbles, based on actual operating conditions and material properties. This analysis is complicated by the lack of fracture toughness data for irradiated aluminum. Fracture toughness data on samples currently being irradiated in HFIR will be used in the analysis. It is critical to optimize the beam tube thimble wall thickness in order to minimize neutron attenuation.

A value engineering study was conducted for the light water transition assemblies (LWTA). The study recommended that a welded joint be used at the reflector vessel interface and that the pool wall seal be relocated at the beam room interface for access. Other recommendations included modifications so that the LWTA can be replaced dry by a horizontal removal/insertion technique through the biological shield and that lowa: tivation materials be used in locations where conditions merit such a selection.

\subsection{EXPERIMENT SYSTEMS}

\subsubsection{Overview}

The performance of the hot source was analyzed with the conclusion that the center of the hot source needed to be closer to the core in order to reach the desired temperatures. The design was revised, and a new layout for the beam tubes and the hot source was developed that also required changing the location of the instruments within the beam room. A design for the monochromator shielding drum used by scattering instruments in the beam room was developed based on modifications of the concept used in HFIR. The isotope separation on-line (ISOL) facility design has been developed, and an improved layout proposed, including a future expansion location for bringing a beam out of containment. A positron source conceptual design has been developed featuring copper as the target material instead of radioactive krypton gas.

\subsubsection{Neutron Beam Transport}

The baseline configuration for the neutron beam tubes and the hot source within the reflector vessel has been revised. The heating rate of the hot source was found to be inadequate at the $1.45-\mathrm{m}$ radius used for the original concept. The desired operating temperatures could be obtained by moving to a radius of $1 \mathrm{~m}$ and using improved thermal insulation. In addition to moving closer to the core, the hot source was moved to a region away from the cold source to avoid having large penetrations close together (which would lower the local neutron flux). Also, the hot source could then be moved from $400 \mathrm{~mm}$ above the reactor core midplane to the midplane, which would increase the heating and thermal flux. The new configuration is shown in Fig. 3.8. The layout of the thermal beam lines was changed to make the spacing of the penetrations more uniform and to provide more space between the thimbles. The through-tube was raised and moved outward

\section{Advanced Neutron Source (ANS) Progress Report}




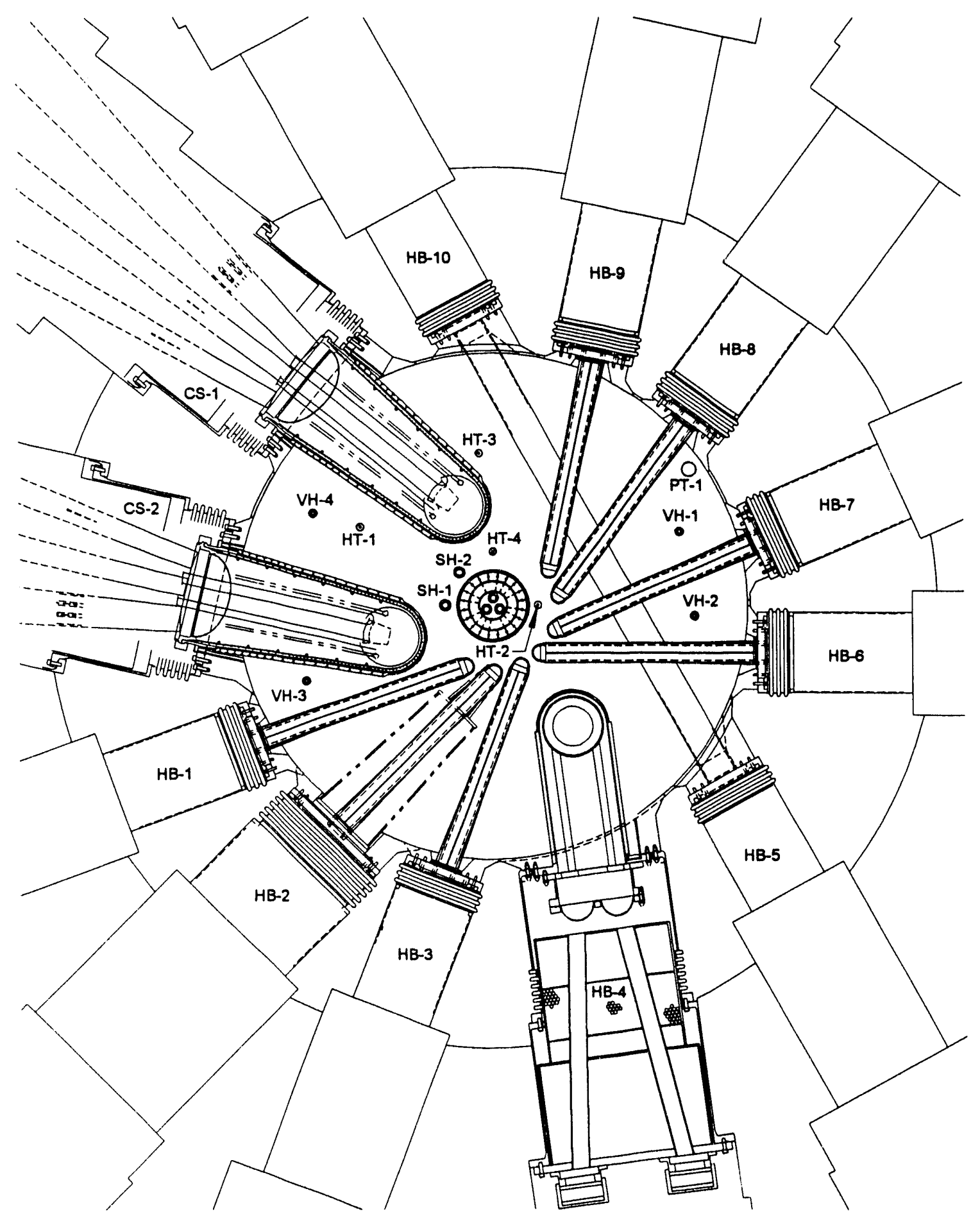

Fig. 3.8. Beam line and hot source configuration. 
slightly. This allowed the standard biological shield penetration size to be used on both sides of the through-tube. The two hot source beams have been combined in one penetration assembly. This simplifies what was a complex light water transition assembly for the two hot beams and allows for horizontal access and also eliminates one biological shield penetration.

Preliminary radiation shielding calculations were performed for the horizontal cold guides within containment. These calculations show a significant shielding advantage if borated glass guide material can be used in place of nonborated glass in the first sections outside the biological shield. Acceptable dose rates were calculated outside the 600 -mm-thick heavy concrete enclosure using borated glass guides, with the addition of approximately $500 \mathrm{~mm}$ of borated polyethylene around the guides.

A study of the very cold neutron (VCN) guide system and the ultracold neutron (UCN) turbine that included neutron transport models was conducted at the University of Rhode Island. The horizontal arrangement was found to be acceptable, and several recommendations for improvement were made. The proposed layout has a straight section of very cold guide within the cold source thimble and the biological shield. The UCN turbine and VCN guide were arranged to feed the turbine at the bottom from a diverging 5-m straight section. Double-curved sections of VCN guide connect the straight sections.

\subsubsection{Neutron Scattering and Physics Instruments}

The hot source and beam layout changes resulted in a new instrument layout as shown in Fig. 3.9. The $\mathrm{H}-1$ single-crystal instrument position on the hot source was eliminated, and the $\mathrm{H}-2$ general purpose diffractometer was moved closer to the biological shield. Several other instruments were also located closer to the biological shield in this arrangement. The through-tube loading station configuration has been changed, and the positions of the loading station and the high resolution spectrometer reversed.

A design effort was started to develop a specific design for ANS monochromators. It was desired to base the design on the proven concepts used at HFIR, but because of the larger beam size in ANS, modifications were required. A layout of the shielding system is shown in Fig. 3.10. The HFIR system is equipped with one set of wedges that raise to allow beam access to the center of the monochromator. The ANS design uses two sets of wedges, with an upper set that raises and a lower set that drops. Each wedge is pie-shaped and is supported by two cam followers that are captured in cam tracks much like the HFIR-design approach. These wedges are placed adjacent to each other, forming two bundles that surround the crystals. These wedge bundles are forced along cam tracks as the exit collimator rotates about the center of the monochromator. The cam tracks guide the wedges, causing the upper set to rise and the lower set to fall as they pass the beam opening in the biological shield. This arrangement does not require mechanical interlocks to prevent accidental opening of the shielding.

Additional definition of the layout requirements for the ISOL on the second floor have been developed as shown in Fig. 3.11. The large slant beam tube is oriented at 32 degrees from vertical and is attached to the reflector vessel with a flange connection. On the second floor, a separator magnet, an ion source(s), and a collection chamber are shielded with 1-m-thick concrete, forming the ISOL room. This room must be accessible to personnel and to any shielded handling casks. Access to the rotary shutter within the biological shield and to the top end of the large slant beam tube also is possible from this room. Penetration through the ISOL room shielding is required to connect the ion beam exiting the collection chamber with the beam switchyard. Four measurement stations are connected radially with beam tubes to the switchyard. Each station is shielded and has space allocated for a standard workbench. The ion implantation station will be removable to provide the option of extending the ion beam through the reactor containment walls 


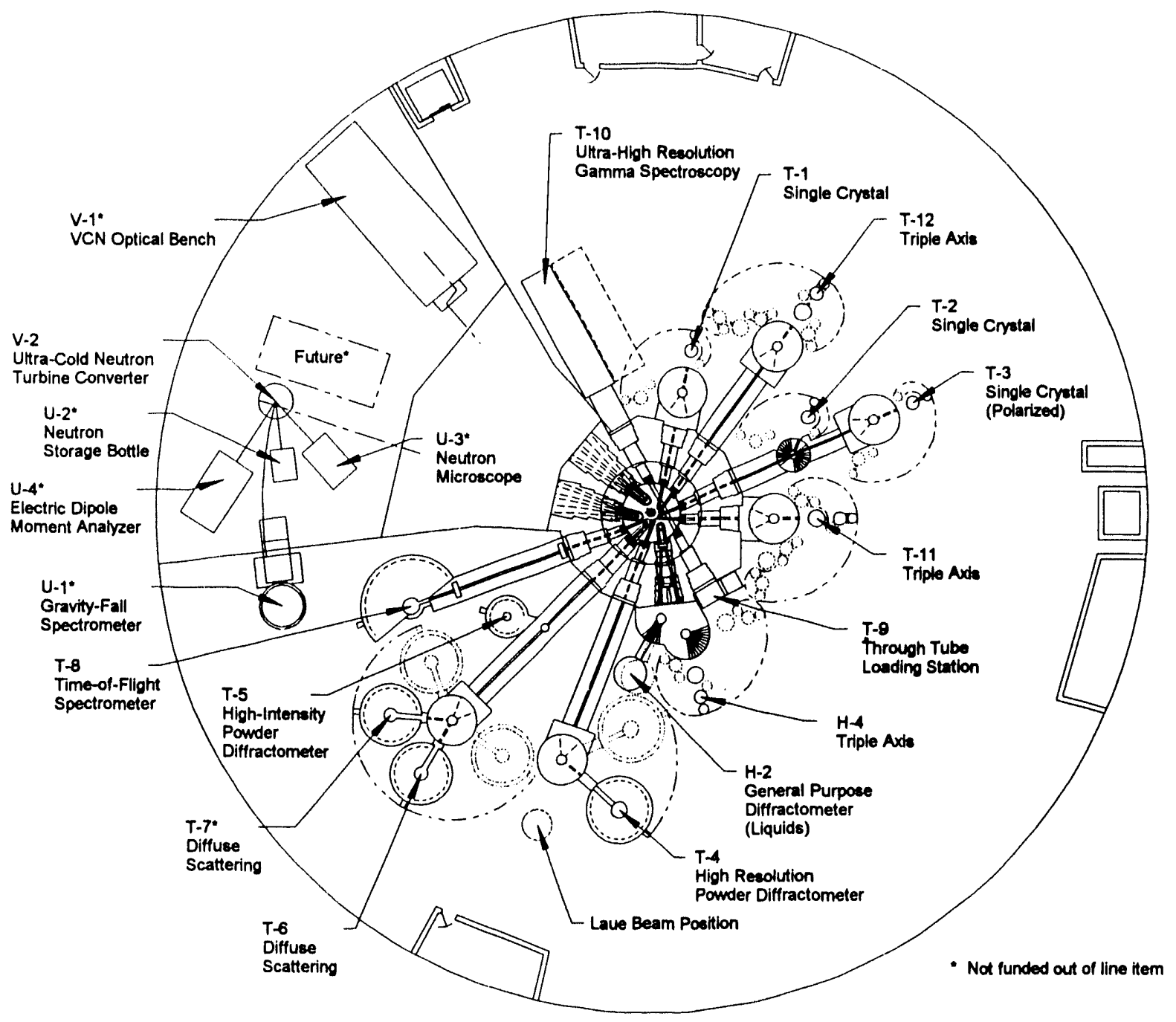

Fig. 3.9. Beam room instrument layout.

and into a radioactive ion beam facility. $A$

$15 \times 91-\mathrm{m}^{2}$ layout for this possible future upgrade has been made adjacent to the guide hall in the future expansion area.

\subsubsection{Irradiation and Isotope Production Facilities}

Mechanical support concepts for the material irradiation capsules within the CPBT have been developed to allow for several different radial locations to be selected for the noninstrumented capsules.
A study of the transuranic targets has indicated that the length can be shortened by using smaller void regions on each end. This increases the lateral stiffness of the rods and makes handling easier. Fins will be needed on the targets to increase stiffness against lateral vibration and will also improve heat transfer.

\subsubsection{Hot Source}

The basic design of the hot source has remained the same, an insulated graphite block heated by radiation to a temperature above $2000 \mathrm{~K}$ 


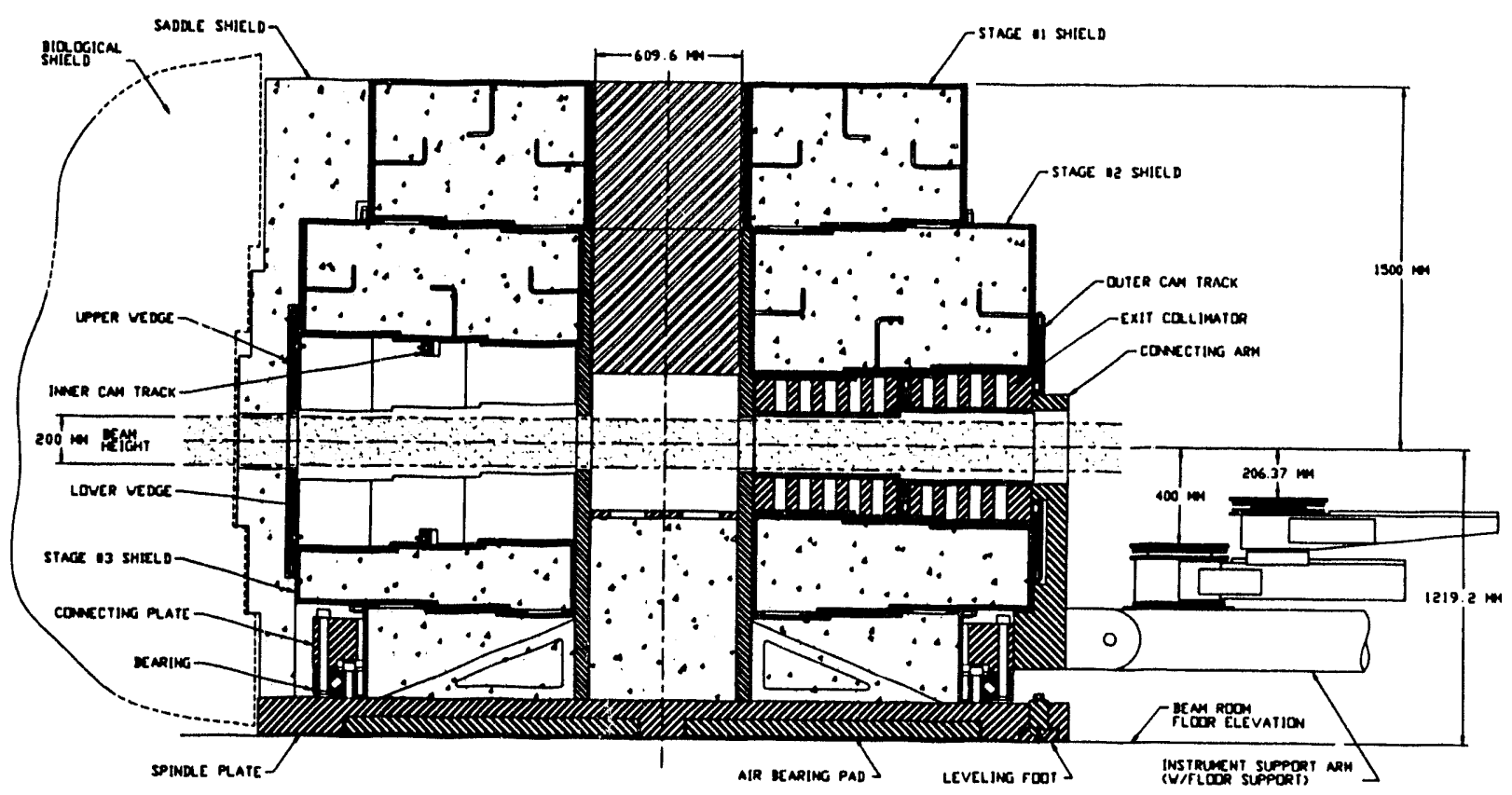

Fig. 3.10. Advanced Neutron Source monochromator shielding.

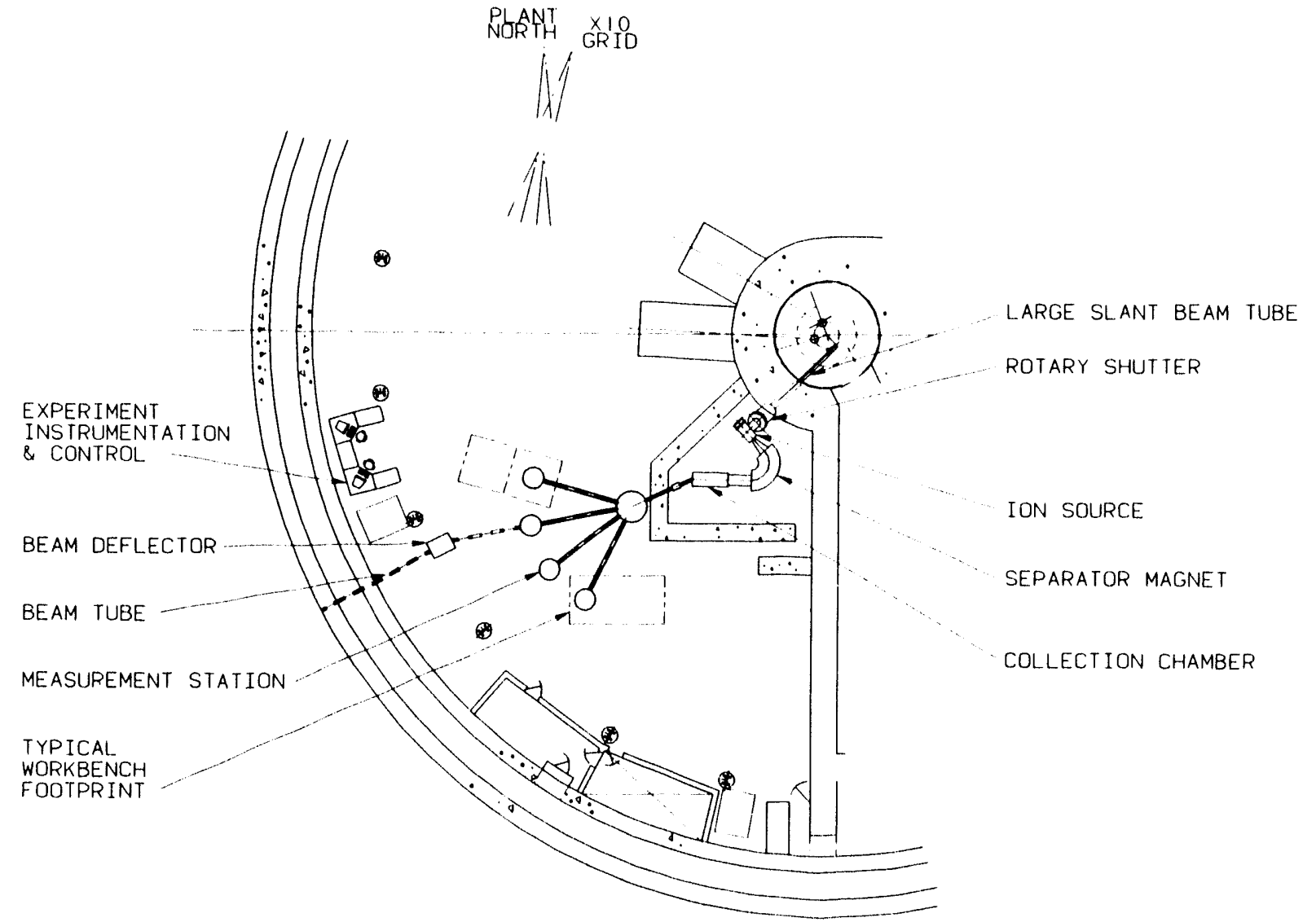

Fig. 3.11. Second floor isotope separation on-line facility.

50 Advanced Neutron Source (ANS) Progress Report 
and contained within a double-walled, watercooled Zircaloy vessel. This vessel is contained within a thimble assembly in the heavy water in the same manner as a cold source.

In order to meet the desired temperature goal, a carbon-bonded carbon fiber (CBCF) insulation has been tentatively selected. Literature information indicates that CBCF has a lower thermal conductivity than the graphite felt previously proposed. Testing of samples will be performed under the R\&D program to establish the high temperature properties and to predict the extent of material degradation because of sublimation and diffusion mass transfer. The exact behavior of the carbon materials above $2300 \mathrm{~K}$ is not fully known and may impose temperature limitations.

The thickness of the insulation has also been increased and the geometry of the graphite block changed from cylindrical to spherical. The current design, as shown in Fig. 3.12, consists of a $275-\mathrm{mm}$ graphite sphere insulated by $68 \mathrm{~mm}$ of CBCF with a spherical double-walled Zircaloy vessel. The new proposed location is on the midplane at a radius of $1 \mathrm{~m}$. Personnel at INEL have calculated overall heating rates for this

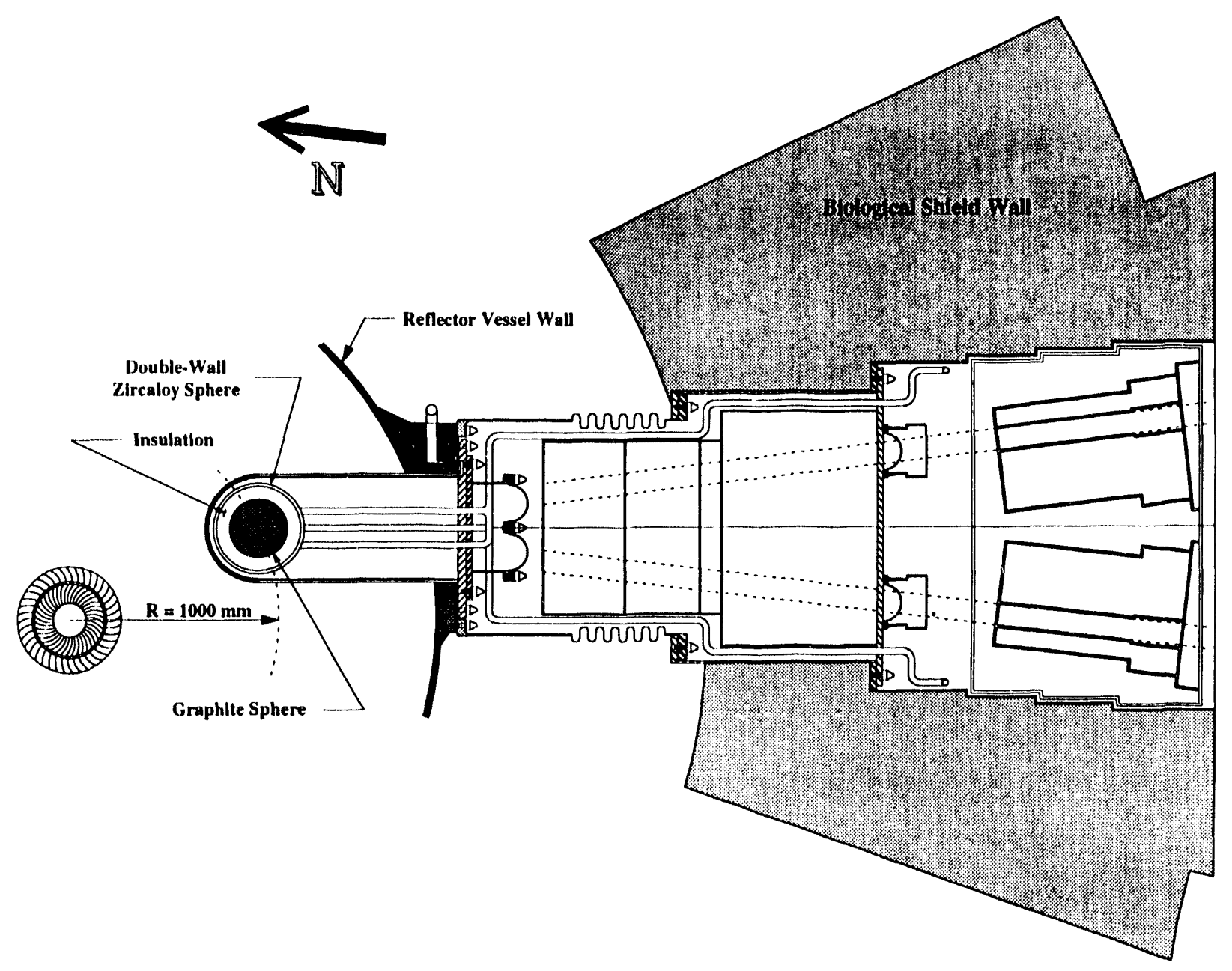

Fig. 3.12. Hot source and biological shield penetration assembly (HB-4). 
geometry. Thermal models using the best available thermal conductivity information for CBCF indicate that moderator temperatures above $2300 \mathrm{~K}$ should be achievable.

\subsubsection{Positron Source}

A new conceptual design study for the positron source was conducted. The design presented in the ANS conceptual design report was based on using krypton gas as the source material. Because of concerns over the consequences of accidental release of this radioactive gas within containment, an alternative was desired.

The modified ANS positron source concept is based on irradiating ${ }^{6.3} \mathrm{Cu}$ with a high neutron flux to produce ${ }^{64} \mathrm{Cu}$, which emits positrons in one of its decay modes. The ${ }^{64} \mathrm{Cu}$ half-life is $12.7 \mathrm{~h}$, and approximately $19 \%$ of the decays emit a positron with energy less than $550 \mathrm{keV}$. Naturally occurring copper can be used since it is approximately $69 \%$ ${ }^{63} \mathrm{Cu}$ with the remainder being ${ }^{65} \mathrm{Cu}$. These isotopes, when subjected to neutron irradiation, transmute to ${ }^{64} \mathrm{Cu}$ and ${ }^{66} \mathrm{Cu}$, neither of which produces an appreciable quantity of long-lived radioactive waste in its decay chain.

The ${ }^{64} \mathrm{Cu}$ positron source concept is shown schematically in Fig. 3.13. The copper material is in the form of microspheres (or BBs). These are loaded into a capsule (or rabbit) in a hot cell. From there, the rabbit is transported by a flight tube to an irradiation position in the reflector vessel approximately $500 \mathrm{~mm}$ radially from the core axis and $500 \mathrm{~mm}$ below midplane, where the perturbed neutron flux is approximately $3.6 \times 10^{19} \mathrm{~m}^{-2} \cdot \mathrm{s}^{-1}$. After irradiation for two to four half-lives $(24-48 \mathrm{~h})$, the rabbit is returned to the hot cell. The $\mathrm{BBs}$ are then removed and inserted into a source

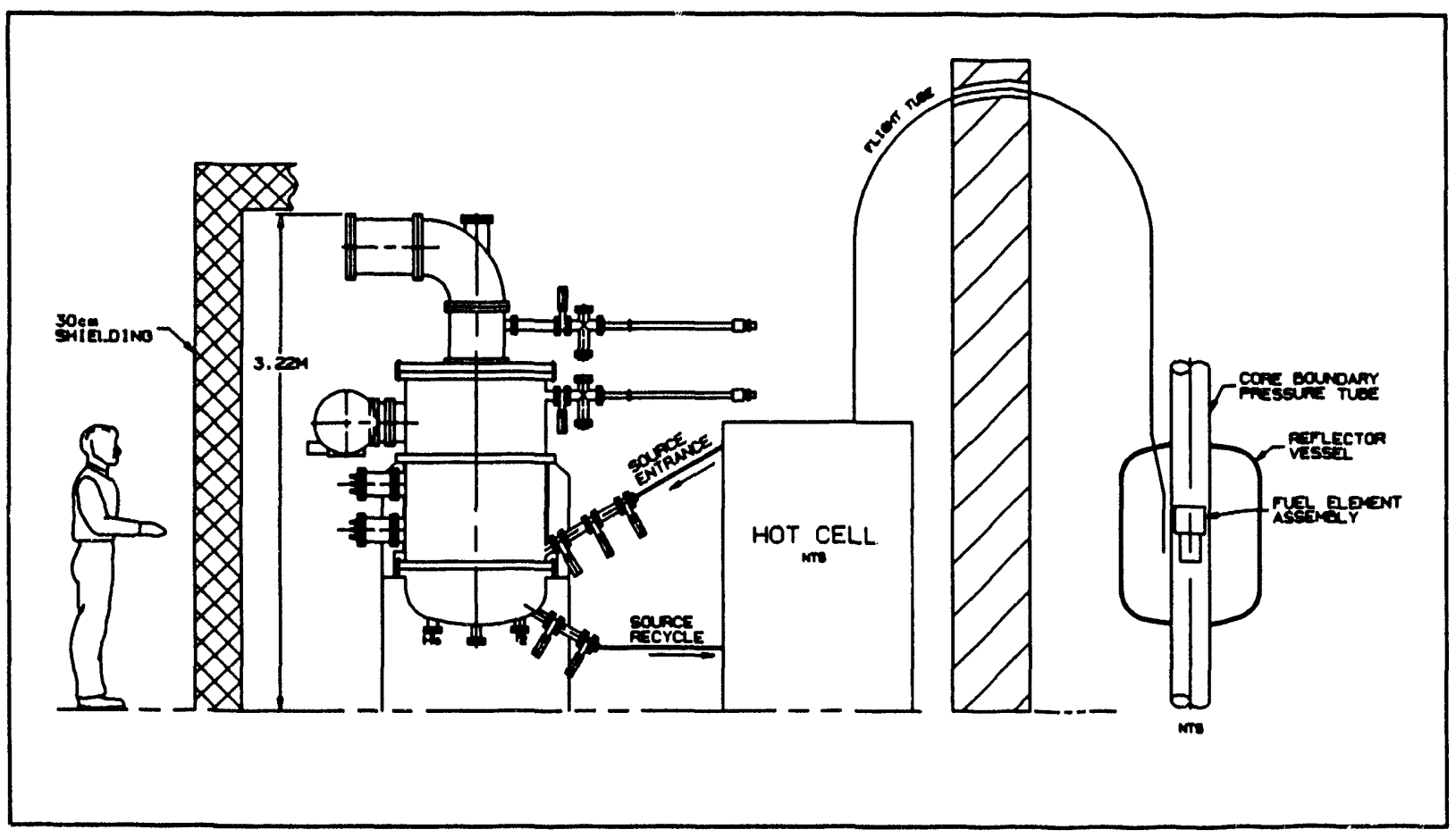

Fig. 3.13. Schematic of ${ }^{64} \mathrm{Cu}$ positron source. 
chamber where they are deposited onto a round plate that is mechanically vibrated to obtain a monolayer of BBs. A vertical cylinder is positioned above the plate. Solid neon is condensed on the inner surface of this cylinder to serve as a moderator. Positrons emitted by the source material that strike the surface of this cylinder will be moderated, and, after exiting the cylinder, will be electrostatically focused onto a 40- $\mathrm{mm}$ diam tungsten remoderator, or brighiness enhancer. After exiting the first remoderator, the positrons will be further focused and remoderated a second time. They then pass through an Einzeln transfer lens (used to adjust the focal point's axial position) followed by a spherical beam deflector and an Einzeln trim lens. Positrons exiting the trim lens enter the beam transport pipe, which contains beam monitoring devices and ultimately connects to the detectors.

\subsection{BALANCE OF PLANT}

\subsubsection{Value Engineering}

The value engineering study undertaken this year resulted in selective redesign and in a reduction in the cost estimate. The study focused on the balance-of-plant portions of the facility, with a goal to identify areas that could be changed to a less costly design yet still retain the critical ANS functions. The major recommendations arising from the study are described in Sect. 3.4.1.1. The adopted value engineering proposals were incorporated into a revised design issued in April 1993. Also indicated in the following sections are those proposals that required additional work to confirm a potential saving from the proposed changes.

\subsubsection{Value Engineering Proposals Adopted}

A general discussion of the recommendations that were incorporated into the design are listed here. Specific changes to the overall design and any associated impacts are identified and described in these sections.

Eliminate grade crossing. An elevated grade crossing at Melton Valley Access Road and Melton Valley Drive was eliminated. Although the original design was intended to avoid safety concerns because of traffic flow, it is believed that an at-grade crossing can be provided safely.

PIDAS fence realignment. A protective high-security plant intrusion, detection, and security (PIDAS) fence surrounds the site. The proposed rerouting of the fence will incorporate only essential facilities in the current design. Fencing of future facilities will be accommodated as necessary. Approximately 110 metres of fence were deleted.

Delete storm water retention basin. The conceptual design identified two retention basins on the site, one to the northeast and another to the southwest. The northeast basin also served as a pond and visual focus for the site. An analysis of the drainage patterns and the fill necessary to construct the pond indicated that a considerable saving could be achieved if the northeast pond were deleted. Additional space would also be available for the office building and related parking.

Eliminate temporary construction support building. The proposal to eliminate the temporary construction office building was coupled with a proposal to construct a portion of the permanent office building wing for use as a temporary construction office. At the end of construction, the office building would be completed and upgraded for use as the ANS office building.

Reduce fill. Revising the grade in the future expansion area and moving the stormwater retention basin to the east side of the perimeter road resulted in a considerable saving in earth-fill placement and a reduction in wetlands impact.

Use fabric construction structures. In lieu of traditional metal structures for the temporary construction buildings, ANS is proposing selfsupporting fabric structures. The expected lifetime is in excess of seven years, which is adequate for such use. 
Miscellaneous architectural changes. A number of changes were suggested that affected the architectural features of the buildings. Elimination of the clerestory windows in the guide hall, relocation of the visitors' gallery in the guide hall, and modification of interior architectural treatments in the office building were all included in this recommendation.

Optimize building spaces. Several buildings included more space than necessary when requirements were reviewed in greater detail. Most of the inefficiency was a result of the irregular building envelope. Providing more rectangular building envelopes and arranging the interior space more efficiently reduced the total building area.

Eliminate lead shielding on the neutron beams. A significant saving was realized as a result of the elimination of unneeded lead shielding on the neutron guides.

Change structural requirements. Physically separating the nonsafety-related facilities from the safety-related facilities allowed for structural design of the office building, the operations support building, and the reactor mock-up building to a lower wind and seismic loading.

\subsubsection{Value Engineering Proposals Not Adopted}

Although most of the civil, architectural, and structural proposals were adopted as part of the revised design, the following cost reduction options identified during the value engineering studies have not been implemented yet because they relate to safety systems or because the idea is not fully mature. Studies continue to determine if these options should be incorporated into future design revisions.

Eliminate emergency heat exchangers. Eliminating the emergency heat exchangers and reconfiguring the cooling loops, yet still maintaining the same level of redundancy, could potentıally reduce the cost of this system.

Reduce primary/secondary cooling loop capacity. A study to determine the optimum cooling loop capacities is ongoing. A reduction in the cooling loop capacity or a reduction in the number of loops could result in a significant saving. The first results of this study are discussed in a later section.

Utilize ANS waste heat. The waste heat rejected by the reactor during operation is significant. Waste-heat utilization could offer a saving in the operating cost of the facility, and a study is ongoing to address both the advantages and disadvantages of the proposal.

\subsubsection{Site and Buildings}

A major revision to the balance-of-plant facilities incorporated most of the value engineering proposals identified above. Several of the more significant changes are discussed in the following sections.

\subsubsection{Site Characterization}

Site characterization efforts included preparation of a quality assurance plan, quality assurance procedures, and technical procedures for drilling, logging, sampling, and testing of soil and rock, as well as preparation of a draft site characterization plan for the project. Field work at the preferred site was limited by funding restrictions to wetlands delineation activities and some of the site preparation work required for support of the drilling, sampling, and testing effort.

\subsubsection{Buildings and Site Arrangement}

Figure 3.14 depicts the revised general arrangement of the buildings, structures, and other major features of the preferred site such as roads, fences, parking areas, and the stormwater retention basin, as well as the delineated wetlands. As was true with the earlier arrangement, the buildings and site are divided into distinct security and activity zones.

The portion of the site to the north and west of the reactor building, which is dedicated to research 


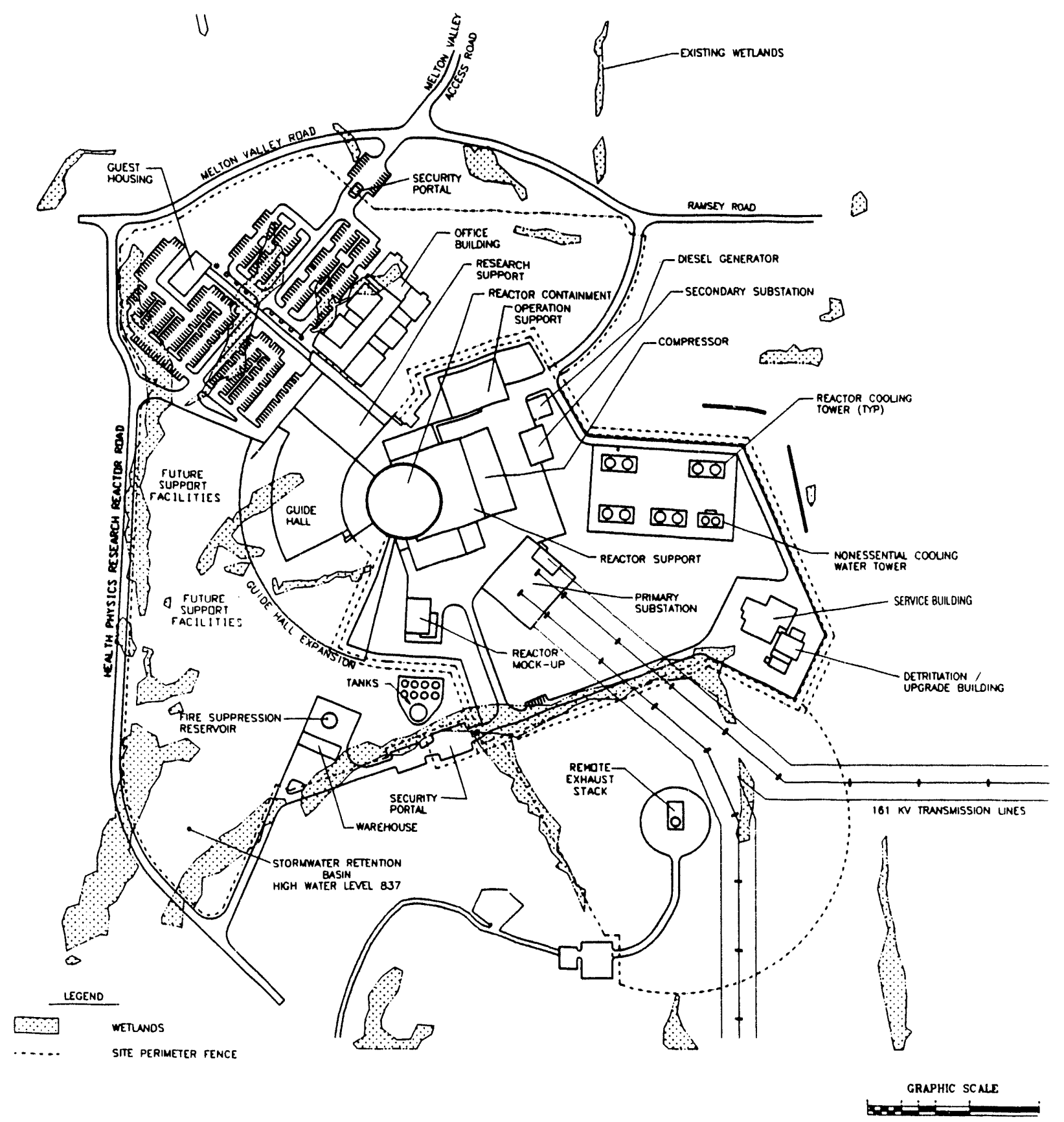

Fig. 3.14. Revised building arrangement on the site overlaid on the identified wetlands.

facilities, has the minimum level of security services and controls on the site.

The major revisions to the design in the west portion of the site included lowering the finished grade elevation of the future expansion area and locating the stormwater retention basin on the east side of the Health Physics Research Reactor Road. These revisions resulted in a major reduction in the quantity of controlled earth-fill required and reduced by $25 \%$ the area of wetlands impacted 
by the project. Although it is not likely that we can eliminate all wetland impacts, the design will attempt to reduce them where possible and compensate them where necessary.

The major site-related impacts caused by revisions of the main facilities resulted from a decision to separate the safety-related from the nonsafety-related facilities. The earlier arrangement required the buildings to be designed to the same seismic and wind loads as the safetyrelated structures, at a considerable cost penalty, because they were contiguous structures. The current design allows for the office building, the operations support building, and the reactor mockup building to be designed to conventional seismic and wind loadings. This was achieved by separating the safety-related facilities and the nonsafety-related facilities, yet still maintaining the proximity of the office building with the interface area and the operations support building with the reactor support building. This was done without sacrificing the concept of physically separate security zones.

The reactor support building has been reduced in size because of a more efficient arrangement of equipment inside the structure. In addition to this more efficient layout, some of the functions that were previously housed in the reactor support building have been relocated to the operations support building. The separate operations support building includes two distinctly separate wings, one for office/training activities and the other for shops and laboratories. Because this building will be designed to a less stringent criteria, there is an overall saving in cost.

The reactor mock-up building has been relocated to the south of the reactor support building, opposite the refueling entry. Further work on the reactor mock-up building has allowed the relocation of the structure from its previous location in the operations support building to an area south of the reactor building. Moving the building away from a congested area allowed an improvement in the layout because it facilitated access to the building from the reactor support building and from the reactor building.

The office building has been redesigned extensively. The seven-story structure is now a more modest three stories with a somewhat larger footprint. The reduction in height, the current modular concept, and the physical separation from the research support building all have been combined into the current design. The design requirements were significantly reduced by these actions. See Figs. 3.15 and 3.16.

A modified concept for the research support building allows for flexibility, for future upward expansion, and for relocating the visitors' viewing gallery.

In the east and south portions of the site, the major revisions to the design include realigning the double fence that defines the higher security operations area, relocating the detritiation facility to the eastern edge of the site, and locating the warehouse and tanks outside the high security area. Although the cooling towers are not required to be inside the high security area, the current design allows for easier access by operations personnel and eliminates one of the penetrations of the double fence. The current location of the warehouse and tanks, immediately outside the security portal, allows for easy access by both operations personnel and outside vendors. Relocating the detritiation facility reduced the quantity of both excavation and earth-fill required.

\subsubsection{Maintenance, Operation, Radiation Zone-Space-Related Data Base}

It was recognized early in FY 1993 that an optimized design of the ANS facilities should include an effort to create a data base of all requirements that have an effect on space planning. Those requirements include, but are not limited to, maintenance issues such as schedule, storage, laydown areas, right-of-way, flow to and from shops, shop requirements (size, number, and distribution), radiation sources, zones, shielding requirements, personnel planning, waste minimization requirements, and materials flow. Subsequently, a user-friendly, interactive data base model has been developed that provides the space planners the tools to integrate all these requirements. It provides the responsible system 


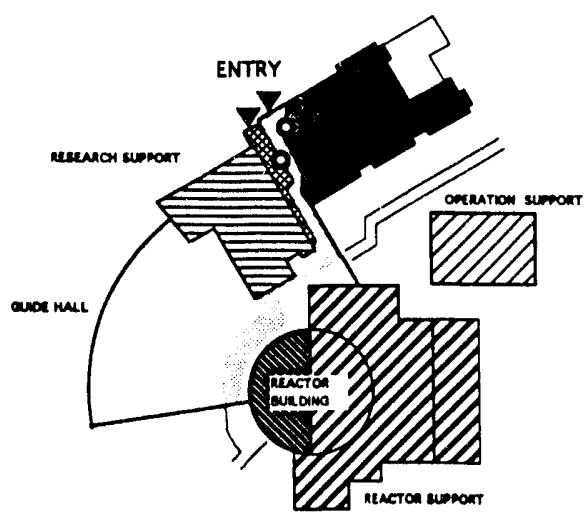

MAINENTRY LEVELL (2nOEL)

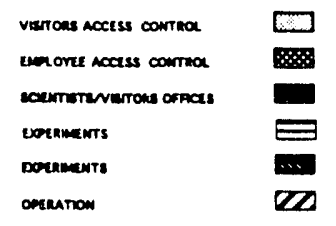

controusto nocesen rowt 0

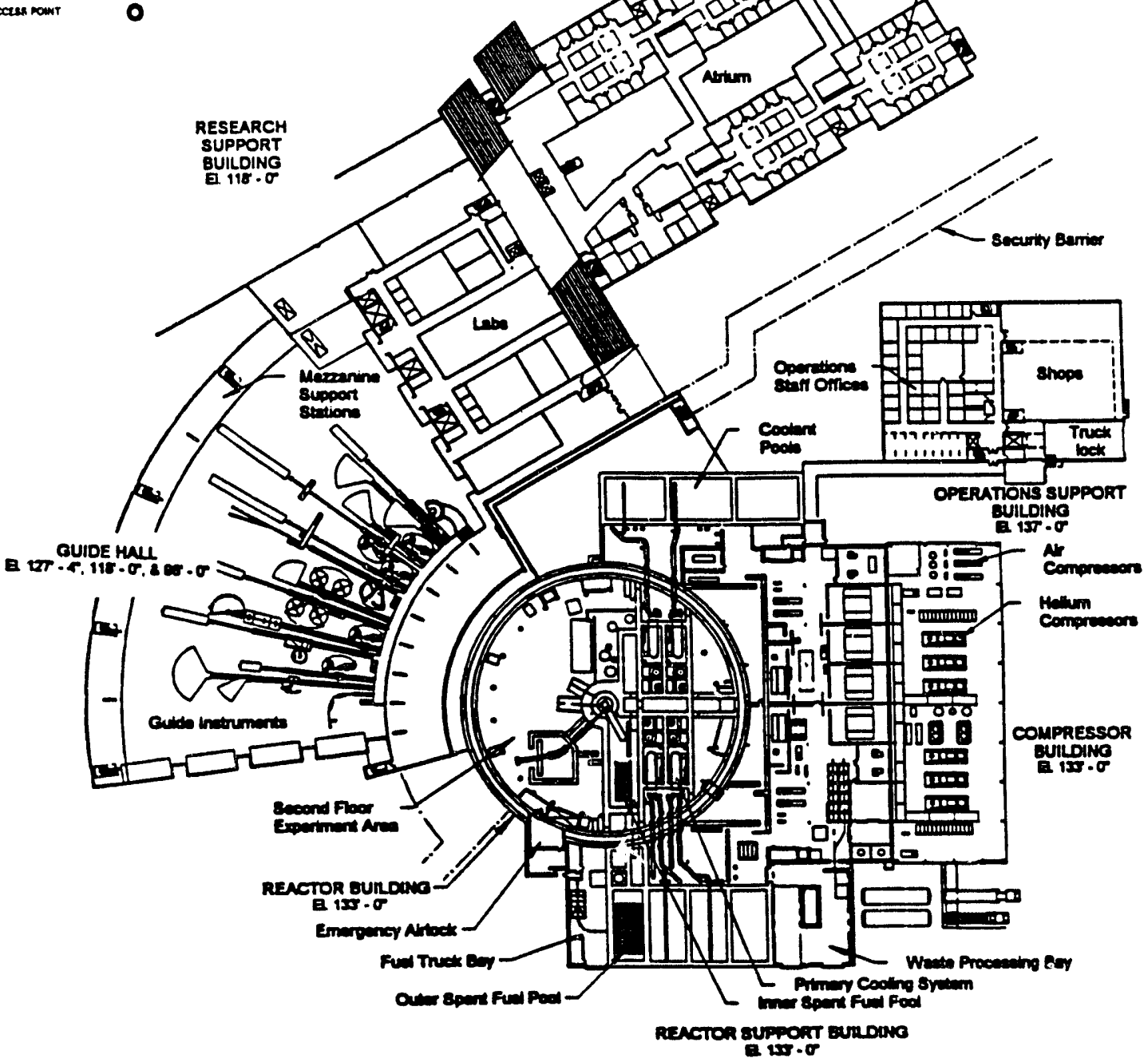

Fig. 3.15. Revised core building configuration with experiment and equipment locations-main levels. 


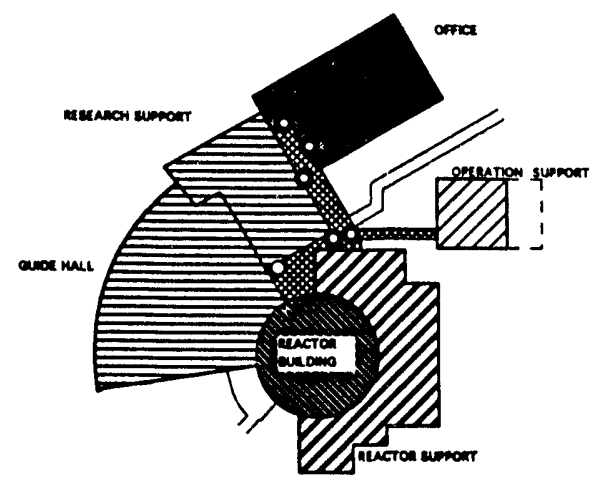

LOWERLEVEL (ITIEL)

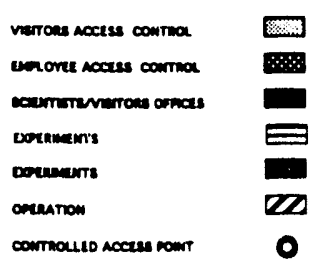

$$
\begin{aligned}
& 20 \\
& \square \\
& \square
\end{aligned}
$$$$
\text { 。 }
$$

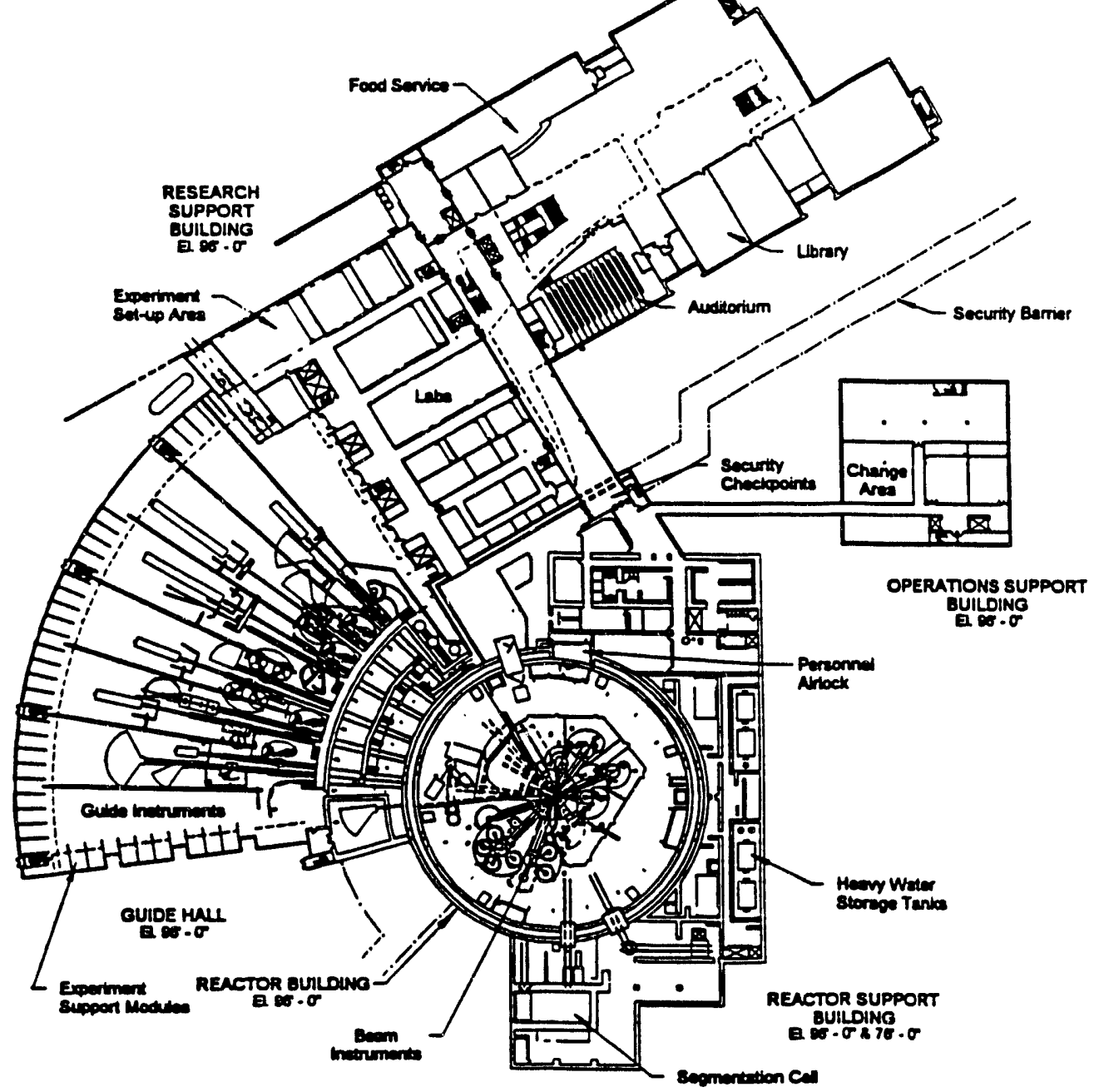

Fig. 3.16. Revised core building configuration with experiment and equipment locations--lower levels. 
designers with an understanding of the space/ environment conditions and the constraints on their system. The data base also provides an opportunity to resolve conflicts with other systems.

\subsubsection{Building Systems}

\subsubsection{Reactor Primary Cooling System Study}

The reactor primary cooling system specified in the conceptual design consists of four independent loops, three of which are normally in operation, with the fourth an isolated spare. Primary coolant flows up through the core through a single hot leg, and flow branches out to the four primary heat exchangers. Heavy water primary coolant flows through the shell side of the heat exchanger; light water secondary coolant flows through the tubes. After flowing through the primary heat exchangers, coolant flows into the shell side of the emergency heat exchangers. Both heat exchangers are immersed in a light water pool. The emergency heat exchangers function in the event of a loss of the normal secondary heat sink and transfer heat directly to the pool by natural circulation of pool water through the heat exchanger. In normal operation, the coolant entering the emergency exchanger is already cool, and only a small amount of heat is transferred to the pool. From the emergency heat exchanger, coolant flows into the primary circulating pumps and is returned through a strainer to the reactor assembly where the three flows are recombined. The primary pumps have dc pony motors capable of providing $10 \%$ of the reactor flow. The entire primary coolant system is arranged in a simple, elevated configuration so that natural circulation will occur upon the loss of both normal and dc pony motors. Manually activated loop isolation valves, primary circulating pumps, strainers, and key instrumentation are located in limited-volume dry cells; the rest of the system is located either in the flooded heat exchanger cells or in a flooded pipe tunnel connected to the reactor pool.
This design was the result of several personyears of effort that included safety analysis, regulatory evaluations, preliminary availability studies, input from the HFIR design, and a reactor cooling system workshop held in February 1990.

In December 1992, a DOE review committee recommended that, "The feasible options for the number of coolant loops should be studied in detail to support the choice of the minimum number of loops that will ensure safety and minimize cost without significant impact on reactor availability."

To address this recommendation, a study group consisting of key project personnel was formed. Initially, all options were again considered. However, only three $33-1 / 3 \%$, four $33-1 / 3 \%$, and four $25 \%$ capacity loop options were considered as viable options. Six evaluation categories were identified. These include reactor power; reactor safety; plant value; licensing risk; reliability, availability, and maintainability; and miscellaneous. Several evaluation parameters were identified and ranked for each category. To support the rankings, two availability studies were performed; a single failure analysis was made; various transient analyses were performed; and several cost benefit analyses were performed. As a result of this effort, the study group concluded that the conceptual design baseline of four 33-1/3\% capacity loops is the optimum design. This option can safely meet the needs of both the users and the operators with a minimum of risk, and the additional cost would be recovered by increased availability within a reasonable period of time.

\subsubsection{Building Heating System}

The findings from the value engineering study done in 1992 led to a study to determine the feasibility of using the waste heat from the reactor secondary cooling system as the primary heating source for the building heating system, with the present steam system retained as a back-up secondary source. Both side-stream and parallelflow configurations were studied. The parallelflow configuration was chosen as the most cost effective method. 


\subsubsection{Cryogenic Helium System}

The system specified in the conceptual design consisted of two separate and identical helium refrigeration systems supplying $5 \mathrm{~K}$ helium at $2 \mathrm{~kg} / \mathrm{s}$ and at a pressure of $12 \mathrm{MPa}$, with a total refrigeration capacity of $32 \mathrm{~kW}$. This original concept was chosen to minimize the area of the helium-to-deuterium heat exchanger surfaces and also to minimize the liquid deuterium inventory. However, the amount of equipment and associated electrical power requirements to provide helium at the $5 \mathrm{~K}$ temperature was extensive.

A subsequent, more detailed study showed that by using a compact aluminum heat exchanger and a forced deuterium pumping system, a significant reduction in hardware costs could be realized. The helium supply temperature could be raised to $19.2 \mathrm{~K}$ (above the freezing point of deuterium) at $1.04 \mathrm{~kg} / \mathrm{s}$ and at a pressure of $0.74 \mathrm{MPa}$ and still produce the $32 \mathrm{~kW}$ of refrigeration required at the deuterium heat exchanger. The need for the second stage compressors was eliminated; the cold box size was reduced; the number of expansion turbines was reduced from six to two per cold box; and the deuterium inventory was further reduced.

\subsubsection{Plant Fire Protection System}

Work on the plant fire protection system consisted of addressing a recommendation from the December 1992 DOE review "that a safe shutdown analysis be performed after the fire hazard analysis to demonstrate that the design contains adequate separation to achieve safe shutdown conditions with various fires as the initiating event." In response to this recommen iation, the system design description document was revis do be more specific on the requirements for performing a safe shutdown analysis.

Work was also started on a preliminary fire hazard analysis, and a conceptual fluid system diagram was developed showing the plant fire protection yard distribution system, the fire pumps, the fire water tank, the interfaces with the potable water system, and the Seismic Class 1 supply to the standpipes located in safety-related areas.

\subsubsection{Heavy Water Upgrade and Detritiation Facility}

As a result of changes in the location of the detritiation facility and changes in the design of the facility itself, the quantity of heavy water to be contained in the reactor system has been reestimated. The latest estimates are shown in Table 3.1.

It was determined by DOE headquarters personnel that DOE would commit to supplying isotopically clean heavy water of $\mathrm{pH} 7.0$, with a tritium content of up to $10 \mathrm{Ci} / \mathrm{L}$ from Savannah River Laboratory supplies. Westinghouse Corporation would process the heavy water by demineralization and distillation. Several other important issues remain to be worked out, including the transportation of the water from Savannah River, the required tritium content of the initial fill, the chemistry requirements of the ANS coolant, the processing requirements for the water at the detritiation facility, and the temporary storage requirements. It has also been determined that the detritiation facility will have to be constructed early in the project to detritiate the heavy water prior to initial fill. Schedules for the detritiation facility construction have been revised to account for this. A schedule was developed for detritiating the water that shows a completion date of December 2000 as the best case, September

Table 3.1. ANS heavy water inventory

\begin{tabular}{|c|c|}
\hline Primary coolant & $126 \mathrm{~m}^{3}(139.3 \mathrm{Mg})$ \\
\hline Reflector & $46 \mathrm{~m}^{3}(50.8 \mathrm{Mg})$ \\
\hline Refueling pool & $126 \mathrm{~m}^{3}(139.3 \mathrm{Mg})$ \\
\hline Cleanup system & $20 \mathrm{~m}^{3}(22.1 \mathrm{Mg})$ \\
\hline Detritiation & $26 \mathrm{~m}^{3} \quad(29.2 \mathrm{Mg})$ \\
\hline Reserve & $126 \mathrm{~m}^{3}(139.3 \mathrm{Mg})$ \\
\hline Total & $470 \mathrm{~m}^{3}(520.0 \mathrm{Mg})$ \\
\hline
\end{tabular}


2001 as the worst case, and bracketing the desired date of May 2001.

Since the quantity of heavy water to be contained in the reactor system has been reestimated, additional calculations of a new tritium equilibrium level were also completed. These calculations were done by the ORNL Computing Applications Division's Reactor Physics Group. The design detritiation rate will not be changed because the combined electrolysis and catalytic exchange (CECE) column is to be used for deprotiation as well, and this sets the desired capacity. The new tritium production rate was calculated as a function of time over the life of a single core and is listed in Table 3.2.

The integrated value of tritium production is $6.40 \mathrm{~g}$ tritium per cycle, equivalent to 1.05 million curies per year assuming 17 fuel cycles per year. This is only a few percent less than the previously calculated rate.

As a result of the processing schedule for the Savannah River heavy water, the heavy water upgrade and detritiation facility (HWUDF) heavy water storage area will be enlarged to accommodate storage of the heavy water reserve. The balance of the heavy water will be stored in an existing ORNL facility after processing, prior to loading into the reactor facility.

The changes to the system design description document during the advanced conceptual design phase include the downsizing of the air cleanup system, the updating of the flowsheets to include tritiated deuterium processing (from the ANS cold sources), and the revising of the utilities for the plant to conform to present facility plans. Also,

Table 3.2. ANS tritium production

\begin{tabular}{lc}
\hline Cycle time $(\mathrm{d})$ & Total tritium production rate $(\mathrm{g} / \mathrm{d})$ \\
\hline $0.00(\mathrm{BOC})$ & 0.3409 \\
1.00 & 0.3586 \\
8.50 (MOC) & 0.3769 \\
12.75 & 0.3855 \\
17.00 (EOC) & 0.3923 \\
\hline
\end{tabular}

the use of fuel cells in place of the trickle-bed recombiners, the upgrading of the air cleanup system model to include tritium sorption, and the use of different molecular sieve dryer types were calculated.

ANS began a CECE development program with Atomic Energy of Canada, Ltd. (AECL) research, which is intended to reduce uncertainties relative to the mathematical models of the CECE column design. AECL did not believe that their mathematical models of the CECE column were defired well enough to enable precise placement of the heat exchangers that are required to remove the heat of reaction from one of the hydrogen exchange reactions. In addition, since the nature of the column operation requires a variable column throughput, AECL did not believe there were sufficient data to define the minimum liquid-to-gas flow ratio with the ANS-size columns. Other studies were conducted relative to determining the operating envelope for the system and to studying the Darlington tritium removal facility (TRF) and the ILL-TRF to make recommendations for improved maintenance.

CECE flow rate testing equipment has been assembled and the random bed catalyst placed in the column. The column is operating, and preliminary testing has been initiated. A computer program for modeling the column operation with varying feeds and simultaneous heat and mass transfer modeling work has also been completed. Rotary and compound dryers have been investigated for use in the HWUDF air cleanup system and in the process off-gas dryers. A report was issued indicating that there is no advantage to either for the ANS systems. There are concerns about the air cleanup system being too large for the use intended and about the allowable release limit for tritium. These concerns were addressed in that the system size will be reduced in a future design revision. A future task for the HWUDF design team is to determine the suitability of various types of tritium monitors. A promising technique that lends itself to process monitoring is laser Raman spectroscopy, but further investigation will be required before a decision is made to use it. Also, a proposal for future work 
concerning the test of a prototype of Electrolyser Corporation's (Toronto, Ontario) low inventory electrolysis cell was discussed. This will be developed into a formal proposal at a later date, but the purpose is to test a full-scale $25 \mathrm{kA}$ electrolysis ceil coupled with an appropriately sized CECE column. There is little operational data with such a large low inventory cell, and this program will provide this data along with testing the catalyst with local water, developing control concepts, and developing an experience base at ORNL with this type of equipment.

\subsubsection{Instrumentation, Computing, and Electrical Systems}

\subsection{Computer design models}

Three design models were generated using advanced software application products from
Intergraph Corporation (Huntsville, Alabama). A three-dimensional architectural model of the ANS main control complex (main control room, technical support facility, irradiation control room, supporting offices, cable spreading area, and conference room) provides designers and operations personnel with visual walk-through capabilities useful for design optimization and training. An overview generated from this model is shown in Fig. 3.17. A computer model of the ANS electrical power distribution system combines a conventional graphic representation of the system with electrical equipment design and operating characteristics into a single, integrated, data-base driven package, thereby allowing power distribution system design, analysis, and documentation to be performed concurrently. Similarly, process and instrument diagram design models of several experiment systems utilize database driven graphics to speed and enhance the design process by facilitating report generation, by

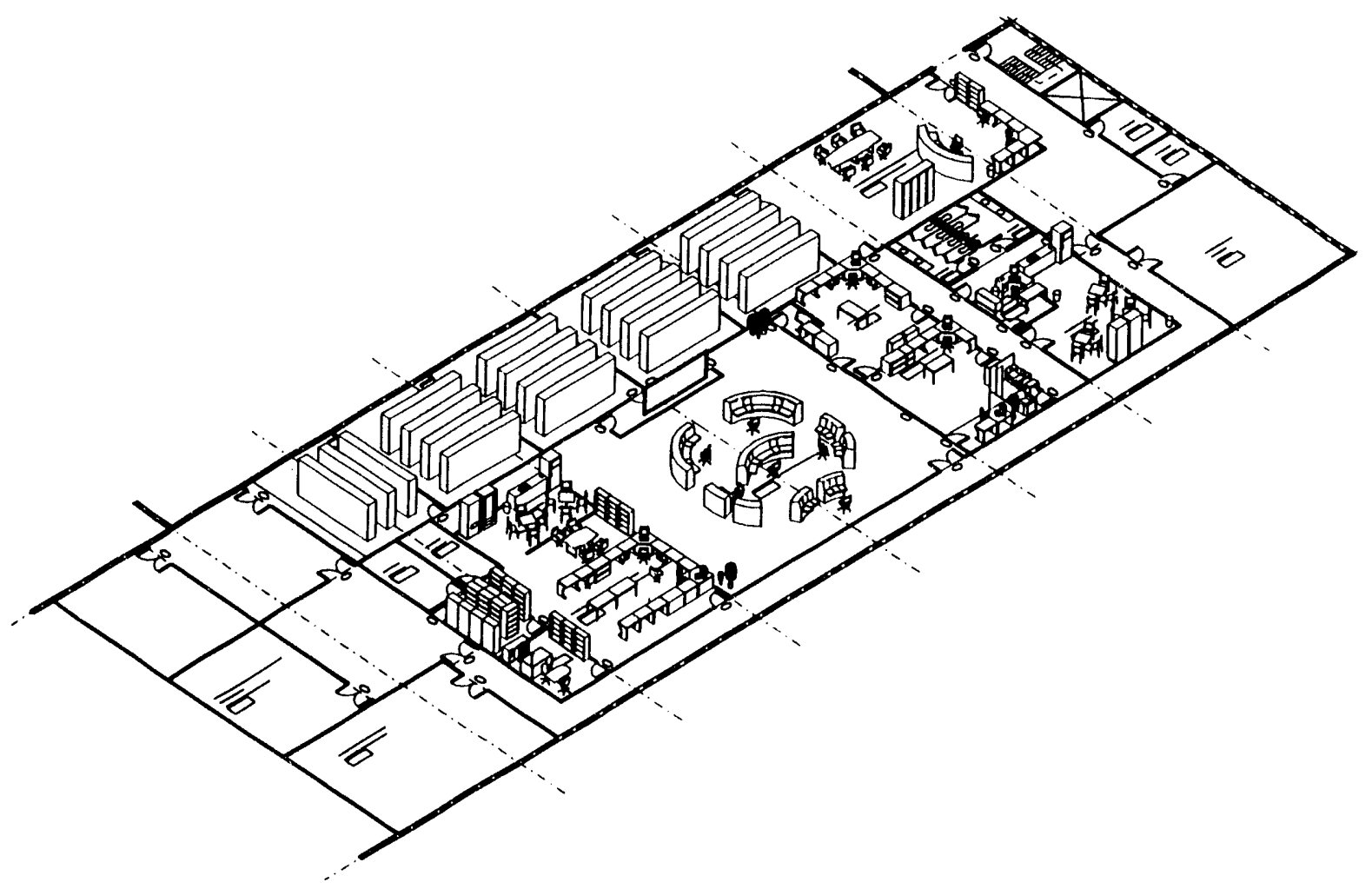

Fig. 3.17. A three-dimensional sketch of the reactor control complex. 
enabling design rules checking, and by sharing project data among engineering disciplines.

\subsubsection{Application-specific integrated circuits for the reactor protection system}

Application-specific integrated circuits (ASICs) is a technology relatively new to the nuclear industry and has the potential to reduce greatly the software verification and validation work needed to qualify digital-based equipment in reactor protection systems. A Ccoperative Research and Development Agreement effort with the Electric Power Research Institute was initiated, and a conceptual design for an ASIC to be used in ANS was completed. This effort includes design, fabrication, verification/validation, structured software development, electromagnetic interference/radio frequency interference testing, and other proof-of-principle activities needed to demonstrate ASIC as a viable technology for the ANS and for power plant and other reactor protection systems. A depiction of the ASIC proposed for use in ANS is shown in Fig. 3.18. Other major changes to the power distribution system design are to accommodate the reduced cold source load requirements, to redesign the 13.8-kV line to ORNL to provide a more effective configuration, and to complete a study to delete the $13.8-\mathrm{kV}$ bus from the power distribution system. Changes in the instrument systems include completion of a conceptual design for multiplexing irradiation module signals that will greatly aid refueling operations; completion of requirements definition and conceptual design for a project-wide computer network to be used by approximately 500 project personnel to generate, store, and manage all electronic data; completion of three functional specifications defining the

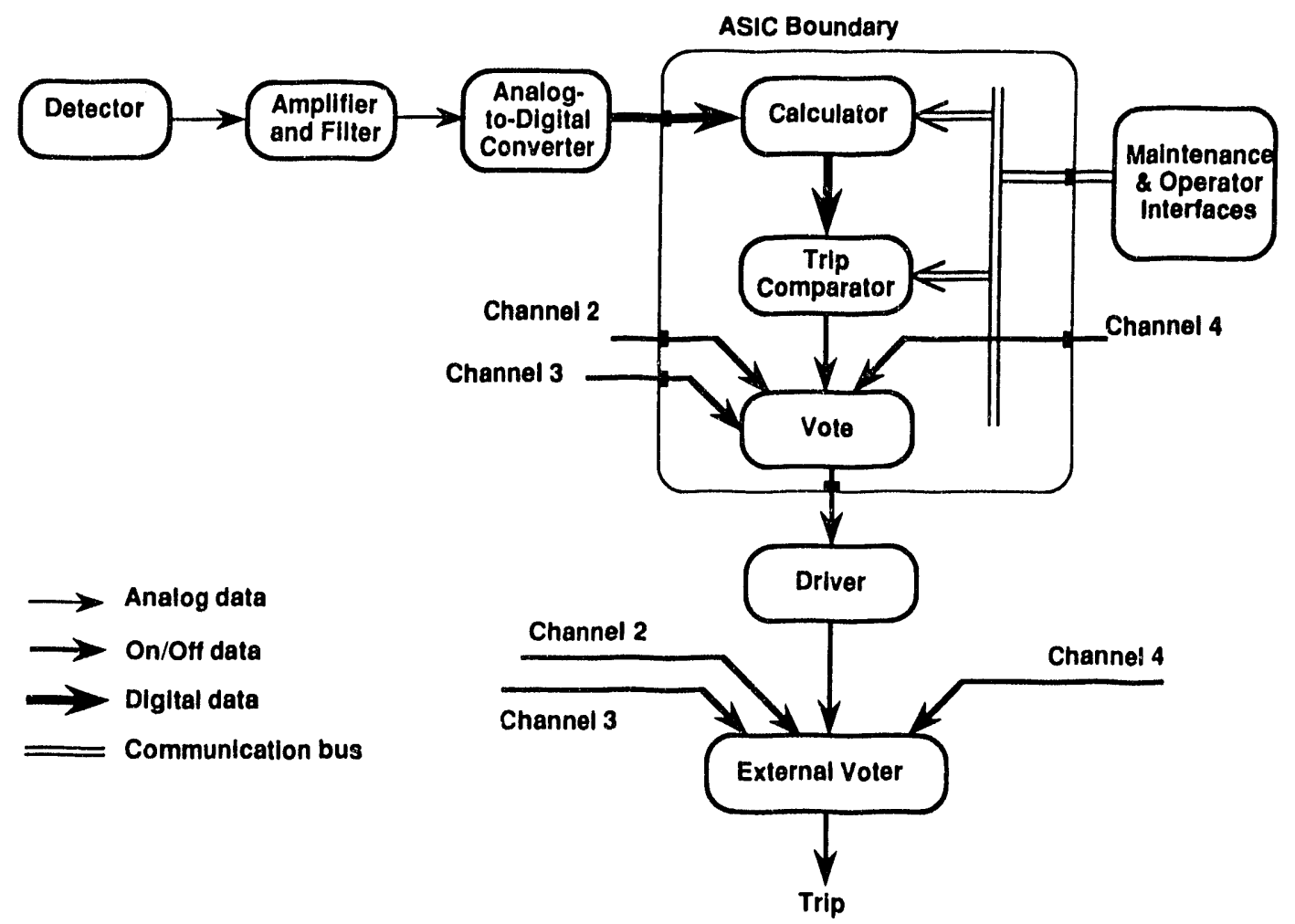

Fig. 3.18. Single parameter signal flow for an ASIC-based reactor protection system. 
requirements for other aspects of the reactor protection system and control and data acquisition system computers; and initiation of requirements definition and conceptual design of a safety parameter monitoring system that will be used by the HFIR and that will provide valuable experience and training for ANS personnel. 


\section{SAFETY}

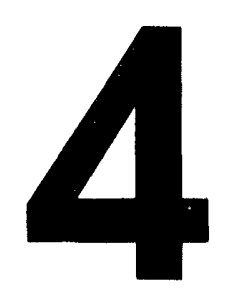

Activities during FY 1993 involved safety studies in support of advanced conceptual design and development efforts to improve analytical capabilities. Significant milestones met during FY 1993 include the completion of combustible gas safety evaluations, the issuance of a draft Level 1 probabilistic risk assessment (PRA), RELAP5 validation and verification studies, and studies of alternative containment concepts.

\subsection{CONCEPTUAL SAFETY ANALYSIS REPORT}

A conceptual safety analysis report (CSAR) was completed during FY 1992. During the current reporting period, the cold source cryogenic system conceptual design was completed, allowing a more accurate estimate of cold source cryogenic system $D_{2}$ inventory to be made. Subsequently, $\mathrm{D}_{2}$ combustion safety studies were completed, and supplementary revised sections on combustible gas control and on cold source accidents were issued. Highlights for the $D_{2}$ safety studies are summarized in this section.

The potential sources of $D_{2}$ inside primary containment include the deuterium inventory of the two cold sources (about $15 \mathrm{~kg}$ of liquid $\mathrm{D}_{2}$ and $5 \mathrm{~kg}$ of gaseous $D_{2}$ in each); deuterium that could be produced in a severe accident involving melting of the fuel and oxidation of the aluminum in the core (a total of about $20 \mathrm{~kg}$ of $\mathrm{D}_{2}$ could be produced this way); and a miscellaneous category that includes oxidation and radiolytic decomposition (an insignificant amount, estimated at $\sim 30 \mathrm{~g} \mathrm{D}$, produced in $30 \mathrm{~d}$ ). The additional Three-Mile-lsland-related requirements of
10 CFR 50.34(f) require that analyses must show that the uniformly distributed hydrogen (deuterium) concentration in containment does not exceed $10 \%$, that combustible concentrations of deuterium will not collect in areas where unintended combustion or detonation could cause loss of containment integrity or loss of appropriate mitigating features, and that safe shutdown equipment remain functional following the release of deuterium.

The uniform concentrations of deuterium as a result of the worst-case scenarios would result in a concentration of less than $0.4 \mathrm{vol} \%$ in the $64,000-\mathrm{m}^{3}$ volume under the dome, much less than the $5.6 \%$ lower limit for flammability of deuterium. This is such a low concentration, and the dome is such a large open area, that there is little risk of a detonation. Nevertheless, detonation pressure pulse peaks were estimated for the dome (see Sect. 4.4) and do not appear to threaten structural integrity.

There are a few confined areas, e.g., the letdown tank and the cold source cryogenic system enclosure rooms, that could possibly receive significant $D_{2}$ source terms under worstcase conditions. Mitigation systems for these will receive close attention during Title I design. The letdown tank would receive kilogram quantities of deuterium during the severe accident scenario postulated for the 10 CFR 50.34(f) evaluations, and it is currently baselined to have an oxygen cover gas. Title I design will investigate adding an inert cover gas and other mitigation measures for the letdown tank. The cold source cryogenic systems are housed in relatively small enclosure rooms on the first floor beam room and the second floor experiment room. The release of $D_{2}$ from a 
cryogenic system into one of these small enclosures would be a safety concern but would require simultaneous failure of two or three boundaries. During Title I design, both probabilistic and deterministic analyses will be used to define source terms for the realistic assessment of risk and the evaluation of mitigation concepts.

\subsection{PROBABILISTIC RISK ASSESSMENT}

\subsubsection{Level I Probabilistic Risk Assessment}

The Phase I Level I draft PRA of the ANS conceptual design examines the contribution to plant risk and unavailability from internal event initiators. Its purpose is twofold. The primary intent of the draft conceptual PRA was to give a rough approximation of the core damage frequency to show if the core-melt risk limitation goal of $10^{-5}$ events resulting in core damage per year can possibly be met with the existing plant configuration. A secondary goal resulting from accomplishing the first was to identify areas in the design that contribute significantly to plant risk and/or unavailability.

Initiating event and component failure data were largely based on that contained in the HFIR risk assessment because of its like mission as a research reactor and the similarities in fuel element design. Initiating event categories included reactor scrams, loss of off-site power, loss of pressure control, flow blockages, losses of primary coolant, experiment facility failures, and general transient events. Where there were obvious differences in plant equipment and design, other sources of data were consulted.

The plant model represents the possible sequences of events that follow an initiator by questioning the likelihood of the availability of specific supports and functions required to protect the core. The ANS model consists of three event trees-electrical support, mechanical support, and front line. The top events, called out in the event trees and modeled using fault trees, represent part or all of the following systems: electric power, plant control and data acquisition, nuclear power control, reactor protection, instrument air, nonessential cooling water, reactor pressure and inventory control, reactor primary cooling, and reactor secondary cooling.

The basis for whether or not a system was included in the analysis was determined by its role in protecting the fuel following a transient initiating event. Future updates to the draft PRA will incorporate more systems as the scope expands to include specific plant damage states, external events, and the risk from other sources of potential fission product releases.

The top five contributors to fuel damage in percent of the total estimated core damage frequency of $\sim 9(10)^{-5}$ per year were:

Flow blockage $83.0 \%$ Undetected defective fuel $\quad 26.0 \%$ Large pipe break near core $\quad 0.5 \%$ Anticipated transients without scram $\quad<<0.5 \%$ Station blackout $\quad<<0.5 \%$

The only significant contributors to plant risk were flow blockage, defective fuel, and a large pipe break very near the core. The lack of risk contributors at this level is attributable to the many redundancies and safety features in the plant design. For most transients, the only requirements for successful mitigation are (1) a reactor scram by one of two redundant and diverse scram systems and (2) at least one primary flow path available for natural circulation cooling. The presently estimated $\sim 9(10)^{-5}$ per year total risk of core damage is in excess of the ANS Project's risk limitation goal of $10^{-5}$ per year. Therefore, efforts are focusing on ways to decrease the likelihood of flow blockage and undetected fuel defect scenarios and to evaluate the cost-risk benefit of some of the redundant systems. This is currently being done with an ANS-specific flow blockage evaluation and various availability studies, some of which are discussed below. 


\subsubsection{The Three Versus Four Loop Study}

The purpose of this study was to evaluate the unavailability of power operation expected for two specific alternative plant designs-- (1) the four $33-1 / 3 \%$ capacity loop conceptual design where one loop is maintained in standby during plant operation and (2) a four $25 \%$ capacity loop design where all loops are operating at the same time. Fault tree methodology similar to that used in the ANS draft PRA was used to model each configuration. Time dependent availabilities were calculated using BRAVO $2.0^{(\bullet)}$ from JBF Associates, Inc., ${ }^{41}$ and failure data from the ANS draft PRA. Repair times were taken from PLG-0500 Volume 3, Database For Probabilistic Risk Assessment of Light Water Nuclear Power Plants-Maintenance Data, ${ }^{42}$ but adjusted upward to allow for xenon poisoning as specified below.

In the in-house study, fault tree models for each design option questioned the response to loss of a single loop and considered the likelihood of multiple loop failures. It is noteworthy that the four $33-1 / 3 \%$ loop fault tree models the availability of only $100 \%$ power operation, because of the standby loop, whereas the four $25 \%$ loop tree models availability of power operation at either $100 \%$ or at reduced power (approximately $80 \%$ ). Because of the short time before xenon poisoning precludes start-up and the length of time required to repair a scram-producing failure, the repair time used in the equations for unavailability was set to a minimum of three days to allow for xenon burn off prior to restart. The results indicated that, from the standpoint of unavailability (not available $1.5 \%$ of the time vs $2.5 \%$ for the four $25 \%$ loop design) and expected number of failures per year ( 1.5 vs 2.5 ), the four $33-1 / 3 \%$ loop design is preferable to the four $25 \%$ loop design.

As a check on the in-house study, a consulting firm (Reliability and Performance Associates, Knoxville, Tennessee) was employed to perform a simplified evaluation. The consultant examined the possible plant operating scenarios for each cooling configuration based on best loop availability using a success state matrix and 6000 hours per operating year. HFIR operating data was tabulated for the main cooling pumps from May 1990 until June 1993, to obtain loop availabilities for the HFIR primary system. The outcome showed that, as loop availability decreases, the time spent at power levels below full power increases greatly for the four $25 \%$ loop design over the four $33-1 / 3 \%$ loop design, primarily because of the opportunity to maintain full power using the spare loop with the later design.

Both studies indicate that high availability can be obtained with either system. However, as unavailability increases, the time spent at less than full power or shutdown is much greater with the four $25 \%$ design, while there is only a modest increase with the four 33-1/3\% loop design. Since operation at full power is very desirable for the ANS research mission, this trend provides a basis for maintaining the current four at 33-1/3\% baseline. Additional justification is discussed on p. 59.

\subsubsection{The Cold Source Availability Study}

This preliminary study is examining the contribution to plant unavailability because of forced outages that occur as a result of failures in one of the two cold source liquid deuterium circulators and supporting systems. There are four types of rotating equipment associated with these systems (compressors, turbo-expanders, vacuum pumps, and circulating pumps), and in the baseline design a direct scram signal is produced by a failure in either cold source, so there is a concern that unanticipated scrams on cold source parameters could preclude the plant from attaining its overall availability goal of $80 \%$. This study is scheduled to be completed in the first quarter of FY 1994.

\subsubsection{Flow Blockage Risk Mitigation Plans}

The in-house flow blockage hazard evaluation is a combined effort that will eventually involve several members of the ANS design team working 
to identify potential flow blockage scenarios and ways to prevent them from occurring. Figure 4.1 represents the tasks planned to assess the flow blockage hazards inherent to the ANS design and the proposed solutions to them. The outcome of this entire effort will be a report identifying flow blockage hazards and the actions taken or proposed to be taken to minimize the occurrence and/or effects of each hazard. Additions to systems and changes in applicable procedures will have to be continually monitored to ensure that they do not obviate existing flow blockage prevention measures.

\subsection{TRANSIENT THERMAL- HYDRAULIC ANALYSIS}

Major efforts this year have focused on flow blockage issues as well as on transient accident response. The flow blockage test facility (FBTF) was constructed during this period, and experimental measurement techniques were developed to measure local heat transfer conditions downstream of a core inlet flow blockage. In parallel with this effort, analytical studies aimed at selecting a fluid dynamics code for flow blockage analysis were initiated. This involved the evaluation of several different codes as well as the performance of initial code benchmarks against existing flow blockage data.

Transient accident analysis also continued using the RELAP5/MOD3 code. This effort included accumulator gas volume optimization and a reevaluation of pipe breaks at different locations in the primary coolant system. The RELAP5 model and coding were also improved by initiating a task to develop a lumped node accumulator model and by code modifications to improve the thermal-hydraulic correlations. RELAP5 verification and validation activities were also performed during this period.

\subsubsection{Flow Blockage Experiment Lóop}

As explained above, the effect of inlet flow obstruction is of concern. A combined experimental and computational approach is currently being pursued to define the range of inlet flow velocity and temperature allowable. The FBTF was constructed to measure the spatial variation of the heat transfer characteristics downstream of a partial blockage of

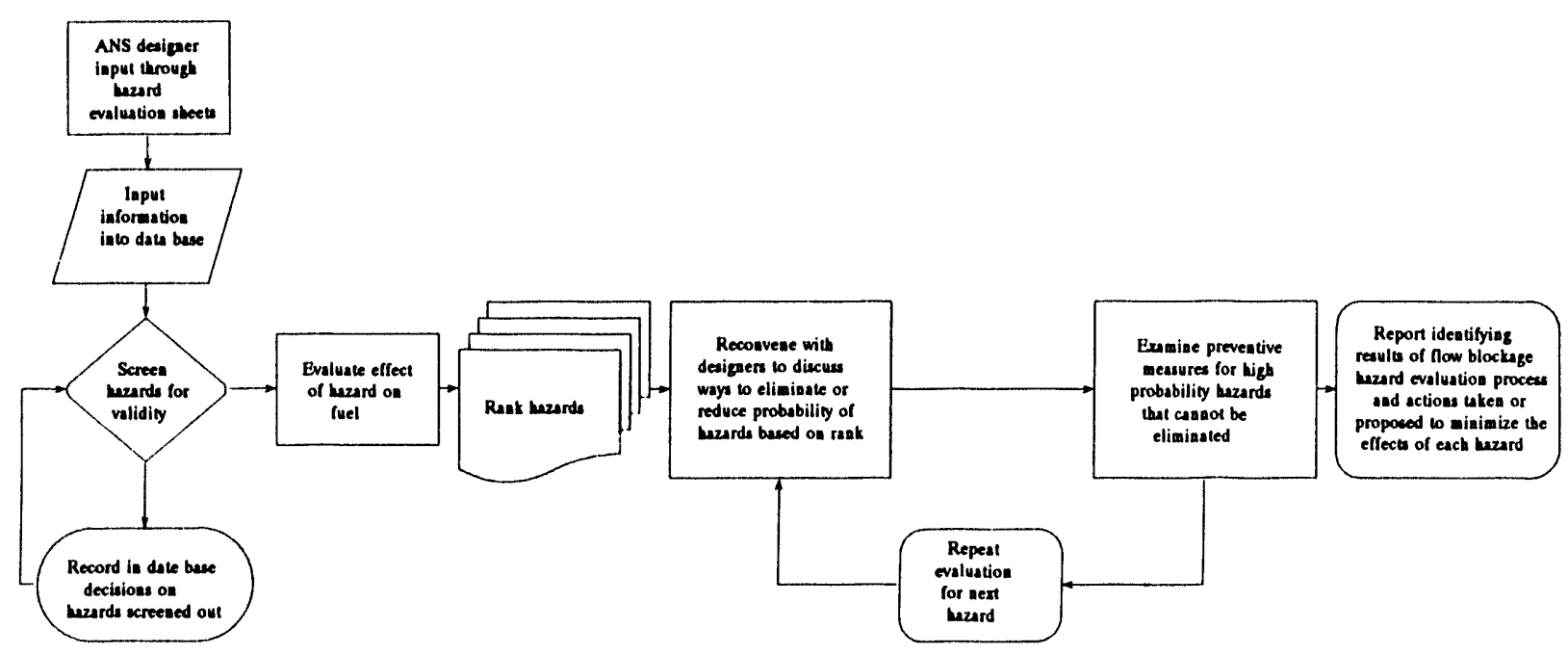

Fig. 4.1. Flow chart for planned tasks for assessing flow blockage hazards. 
a prototypic core coolant channel. This is necessary for validation of the computer code that will be used to establish the maximum blockage size consistent with adequate cooling of the fuel element. A computational fluid dynamics (CFD) code will be used to model the experimental test apparatus for validation purposes and will later be extended to model flow blockage of the ANSR.

Construction of the FBTF was completed during this year and included installation of the test section assembly, electrical utilities, instrumentation, and piping. Initial shakedown tests indicated that the pump installed in the loop could not reach its rated differential head capacity and, as a result, the ANS nominal velocity of $25 \mathrm{~m} / \mathrm{s}$ could not be obtained. A new pump was purchased and will be installed to provide prototypic ANS velocities in the flow channel.

The test section is prototypic in channel width, span, and length. A full or partial span obstruction can be inserted at the inlet of the channel to allow measurement of the effects on velocity and heat transfer characteristics downstream. A diagnostic heater coated on the back side with a thermochromic substance is installed as part of the flow channel wall in the channel entrance region. This will provide a map of coolant velocities downstream from the blockage. Initial tests show that the basic design of the test section works well.

A strong analytical effort is under way to support the ANS flow blockage experimental efforts. CFD computer codes will provide a means of expanding our understanding of the fluid behavior beyond the scope of the experimental data. An evaluation of several CFD codes was made, including a formal vendor questionnaire and input solicited from many users. A preliminary benchmark exploration of a few of these codes was made using comparisons to experimental results from the scientific literature. During this evaluation, the accuracy of the model results was often unsatisfactory. An investigation of possible error contributions was made, focusing on grid size, turbulence models, and simplifying assumptions. The effect of turbulence model variations was found to be the most significant. These results led to the selection of the FLUENT ${ }^{43}$ and Flow-3D 44 codes for further study. Leases for these codes have been placed, and expanded benchmark efforts will be made as soon as data becomes available from the FBTF. Also, an extensive literature search has been completed to identify additional existing data resources that may be useful as CFD benchmarks.

\subsubsection{RELAP5 Transient Calculations}

\subsubsection{RELAP5 Code and Model Modifications}

Several improvements have been made to adapt RELAP5 to ANSR geometry and conditions and to improve the general analysis capability of the code. These changes, documented in a recent INEL report ${ }^{45}$ include:

1. Improving the transition from turbulent forced convection to nucleate boiling by replacing the Dittus-Boelter ${ }^{46}$ forced convection Nusselt number correlation in the Chen nucleate boiling correlation ${ }^{47}$ with the Petukov correlation. ${ }^{48}$

2. Improving the low velocity heat transfer prediction by incorporating a laminar flow correlation at low flow rates when the ANS options are invoked.

3. Improving natural convection predictive capability by enhancing the forced to natural circulation transition criteria, adding the capability of utilizing more realistic characteristic lengths and improving the natural circulation capability under two-phase conditions.

Development of a new accumulator model was initiated during this period. The existing way of modeling the accumulator is not totally satisfactory because the discrete nodes normally utilized in RELAP5 modeling do not allow precise tracking of accumulator level changes and associated phenomena. A lumped parameter approach, utilizing 18 simultaneous ordinary differential equations to treat the various mass and energy 
balances, was devised. Prior to incorporation into the ANS RELAP5 model, this model was assembled off-line and its calculated results compared against actual test data from a Savannah River Laboratory accumulator test (New Production Reactor Test \#3A). This test featured the blowdown, from $2.17 \mathrm{MPa}$, of a $0.2-\mathrm{m}^{3}$ tank of light water pressurized by a $0.031-\mathrm{m}^{3}$ nitrogen bubble. Modeling assumptions regarding tank geometry were changed to be consistent with the test rig. Fluid properties based on light water were used. There is excellent agreement between the measured and calculated pressure responses; agreement between calculated and measured gas temperatures is considered to be satisfactory, recognizing the limitations of the test rig and its instrumentation. These comparisons between calculations and measurements give confidence in the new model, and it will be incorporated into the next generation of ANS RELAP5 calculations.

\subsubsection{RELAP5 Transient Analvicis}

Transient analyses were co extend the project's knowledge of phen, associated with a variety of double-ended pipe breaks. Current plans are to eliminate double-ended breaks from the design basis of the ANS by taking advantage of the fracture resistance of stainless steel; however, the analyses presented below are of more than academic interest because they have led to design improvements that will enhance the ability of the ANS reactor to undergo rapid depressurization events without fuel damage. For example, the pressure switch that initiates the low pressure scram is to be moved from its present location, in the limited volume air cell adjacent to the accumulator injection point, to an upstream location where it can more quickly initiate scram. In addition, accumulator design options are currently being studied that would restrict the rate of outflow during the later part of the depressurization such that accumulator injection does not compete with the primary coolant pumps' pony motor flow. The design options to tailor dynamic accumulator injection characteristics will be selected within that constraint.

It is important that accident analysis calculations cover a complete time range from event initiation until the point at which recovery is assured. For a worst-case pipe break event, the entire range of interest includes the initial break and depressurization, the primary coolant pump coastdown and transition to pony motor flow, and (assuming an extended station blackout) the transition to natural circulation flow after $0.5 \mathrm{~h}$ when the pony motor batteries are assumed to be depleted. To address this entire range of events, the CSAR analysis of transient response to a double-ended-guillotine (DEG) break at the primary system vessel adaptor weldment (PSVAW) located $\sim 1.5 \mathrm{~m}$ below the inlet of the lower fuel element was expanded to look at details of the core thermal-hydraulic performance over longer time scales.

Figure 4.2 shows the FE thermal limit ratio (formed by dividing the lımiting safe heat flux per the Costa correlation by the actual heat flux) calculated at the hot spot over more than $1800 \mathrm{~s}$. The break was initiated at $10 \mathrm{~s}$. The results reveal that (1) the first FE ratio minimum is pressuredriven because of the initial depressurization during the phase from break initiation to reactor scram at about $0.4 \mathrm{~s}$, (2) the second FE minimum is flow-driven because of the diminishing core flow caused by the break flows and accumulator injection that occurs at abr ut $4 \mathrm{~s}$, and (3) the third FE minimum is flow-conirolled by the transition from forced convection to natural circulation when the pony motor batteries are assumed to become depleted after $1800 \mathrm{~s}$. To ensure margin for the forced to natural circulation transition. the design battery life is significantly longer than $1800 \mathrm{~s}$.

The depth and timing of the three minima on Fig. 4.2 are controlled by system characteristics and design. The first minimum is controlled by both the break opening time and area characteristics; longer break opening times delay the minimum and cause it to become more shallow. The second minimum is caused by the interplay between the break flow, the pump flow, and the accumulator injection characteristics. 
Three FE Minima (long time scale)

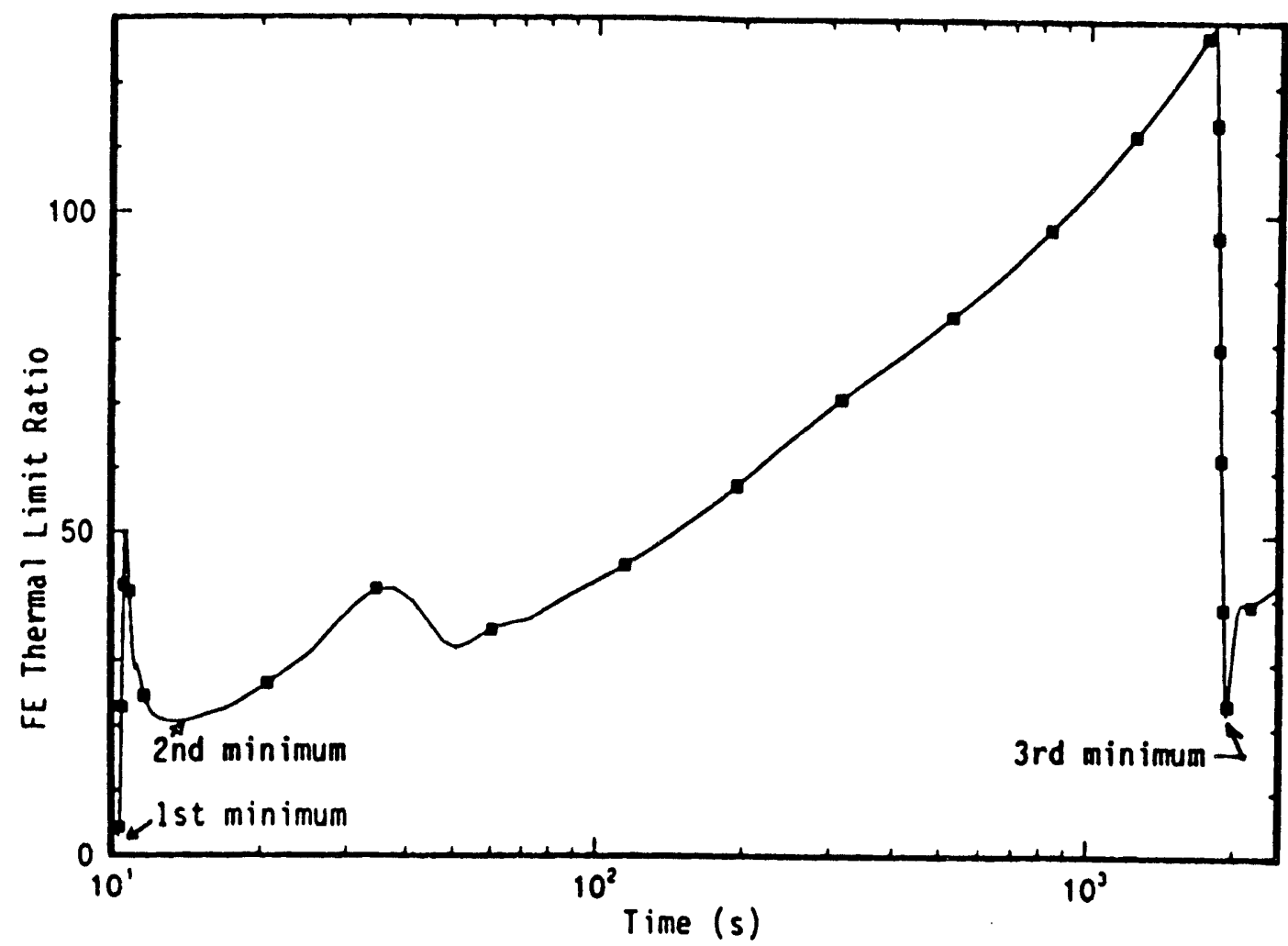

Fig. 4.2. FE thermal limit ratio during 1.1-s primary system vessel adaptor weldment double-ended guillotine break with $0.065-\mathrm{m}^{3}$ accumulator bubble.

During this phase of the double-ended break, the depressurization is largely complete, but outflow continues from the accumulator. This continued outflow competes with the primary coolant pumps (coasting down to pony motor speed at this point) and reduces the upward flow through the reactor core. Therefore, an accumulator capable of injecting more flow into the primary coolant system during this phase of the accident would make the second minimum approach the limit more closely. The depth of the third minimum is determined in part by the coastdown time of the pony motors and the time it takes for the hot leg temperatures to heat up and provide the buoyancy difference to drive natural circulation. As shown in Fig. 4.2, the thermal limit ratio at both the second and the third minimum is much higher (more margin) than the previously investigated minimum that occurs during the initial depressurization.

A reexamination of the ANSR system performance with respect to DEG breaks at a variety of locations throughout the coolant system was also performed. A summary of the results of this evaluation is presented in Table 4.1. The times and break sizes indicated in the table represent the worst-case conditions that can be survived without violating the $\mathrm{FE}$ or $\mathrm{CHF}$ limits. The breaks were sized in increments of $25 \mathrm{~mm}$. These results indicate that the largest instantaneous break near the core inlet not leading to core damage can be from 51 to $76 \mathrm{~mm}$, depending on the precise geometry and limiting condition. As the break location moves farther from the core inlet, the size of the instantaneous break that does not cause the 
Table 4.1. Maximum survivable breaks in the ANSR determined by RELAP5 (9/1/93)

\begin{tabular}{|c|c|c|c|}
\hline Break location & $\begin{array}{c}\text { Time for break } \\
\text { formation }\end{array}$ & $\begin{array}{c}\text { Thermal limit: } \\
\text { maximum diameter } \\
(\mathrm{mm})\end{array}$ & Comments \\
\hline \multirow{4}{*}{ PSVAW $^{a}$} & Instantaneous & $\begin{array}{l}\mathrm{FE}:^{b} 51 \\
\mathrm{CHF}:^{b} 76\end{array}$ & $\begin{array}{l}\text { Used fine-mesh cold leg } \\
\text { noding scheme. Reflection off } \\
\text { IFD drops FE limit below } \\
\text { heat flux for the } 76-\mathrm{mm} \text { break }\end{array}$ \\
\hline & $\begin{array}{l}\text { Instantaneous } \\
\text { (no IFD) }\end{array}$ & FE: 76 & $\begin{array}{l}\text { Used fine-mesh cold leg } \\
\text { noding scheme }\end{array}$ \\
\hline & $\begin{array}{c}0.5 \mathrm{~s} \text { to survive } \\
\text { depressurization; } \\
0.7 \mathrm{~s} \text { to avoid flow } \\
\text { reversal }\end{array}$ & FE: 326 & $\begin{array}{l}\mathrm{DEG}^{\mathrm{d}} \text { break; } 0.065 \mathrm{~m}^{3} \\
\text { accumulator bubble size }\end{array}$ \\
\hline & $\begin{array}{c}0.5 \mathrm{~s} \text { to survive } \\
\text { depressurization; } \\
\text { flow reversal occurs } \\
\text { up to } \sim 5 \mathrm{~s}\end{array}$ & FE: 326 & $\begin{array}{c}\text { DEG break; SDD-61 bubble } \\
\text { size }\left(0.52 \mathrm{~m}^{3}\right)\end{array}$ \\
\hline \multirow{2}{*}{$\begin{array}{l}\text { Main } \\
\text { hot leg } \\
\text { header }\end{array}$} & Instantarieous & $\begin{array}{l}\text { FE: } 102 \\
\text { CHF: } 152\end{array}$ & $\begin{array}{l}\text { Used fine-mesh hot leg } \\
\text { noding scheme }\end{array}$ \\
\hline & $0.5 \mathrm{~s}$ & FE: 560 & $\begin{array}{c}\text { Times later than } \\
10 \mathrm{~s} \text { after break not calculated }\end{array}$ \\
\hline $\begin{array}{c}\text { Pump } \\
\text { discharge } \\
\text { (upstream of } \\
\text { check valve) }\end{array}$ & Instantaneous & $\begin{array}{l}\text { FE: } 152 \\
\text { CHF: } 203\end{array}$ & $\begin{array}{l}\text { Used fine-mesh cold leg } \\
\text { noding scheme }\end{array}$ \\
\hline $\begin{array}{l}\text { 7-m upstream } \\
\text { of PSVAW }\end{array}$ & Instantaneous & $\begin{array}{l}\text { FE: } 102 \\
\text { CHF: } 127\end{array}$ & $\begin{array}{l}\text { Used fine-mesh cold leg } \\
\text { noding scheme }\end{array}$ \\
\hline $\begin{array}{c}\text { Upstream of } \\
\text { heat exchanger }\end{array}$ & Instantaneous & FE: 152 & $\begin{array}{l}\text { Used fine-mesh hot leg } \\
\text { noding scheme }\end{array}$ \\
\hline
\end{tabular}

aPSVAW means pressure supply vessel adaptor weldment (vessel in which cold legs come together just upstream of the core inlet).

${ }^{b} \mathrm{FE}$ refers to the flow excursion thermal limit and CHF refers to the critical heat flux limit.

'There is a section of reduced-diameter piping in each cold leg called the inertial flow diode (IFD).

${ }^{d} \mathrm{~A}$ DEG break is a double-ended guillotine break.

FE or CHF thermal limits to be exceeded increases. Seven metres upstream of the PSVAW, the maximum break size increases to 102 to $127 \mathrm{~mm}$, while at the pump discharge ( 33-m upstream of the PSVAW) the maximum break is 152 to $203 \mathrm{~mm}$. Similar behavior is observed in the hot leg as the limiting break, which does not cause the FE limit to be exceeded, increases from
$102 \mathrm{~mm}$ in the hot leg header to $152 \mathrm{~mm}$ immediately upstream of the heat exchanger.

The installation of a model that more accurately calculates the FE ratio in the ANS RELAP5 model hot channels has improved the calculated thermal margins during rapidly opening large breaks. For example, the previous RELAP5 results 
for a 326-mm DEG break in the PSVAW predicted that break opening time would have to be $1100 \mathrm{~ms}$ or greater to avoid violating FE ratio limits during the initial depressurization phase, whereas the improved model now indicates a comparable safety margin for a break opening tirne of only $500 \mathrm{~ms}$.

\subsubsection{RELAP5 Verification and Validation}

\subsection{Pressure wave behavior}

Verification and validation activities were pursued in three important areas: pressure wave behavior, the flow excursion process, and a comparison of RELAP5 results to those of other codes.

RELAP5 has indicated that the limiting phenomenon for an instantaneous break in the ANSR piping is the expansion wave traveling at acoustic speed into the core region. This expansion wave causes a very brief local pressure decrease that leads to violation of the FE thermal limit. Whether this momentary violation of the FE thermal limit would actually induce flow excursions severe enough to cause burnout in the very short period of time involved is arguable; however, the current efforts to understand and to better quantify the phenomenon are certainly necessary to prove the argument.

Because RELAP5 is not validated for ability to calculate pressure waves moving at sonic velocity, a study was undertaken to evaluate its ability to accurately track such pressure waves. Initial hand calculations of expansion wave propagation indicated that RELAP5 could come adequately close to the correct magnitude and speed for a simple case amenable to analytical treatment, a step change in cross-sectional area. To expand this effort to more complex geometries, test cases were run involving comparison of RELAP5 results with PTA2 results. PTA2 is a validated ${ }^{49}$ water hammer analysis code that was developed at Argonne using the method of characteristics.

One of the test cases tracked ihe onedimensional propagation of an acoustic wave down a pipe with the objective of determining the details of the pressure wave prediction. A pressure discontinuity exists at the center of the pipe at time zero; as time progresses, an expansion wave travels through the half of the pipe with a higher initial pressure, and a compression wave of equal magnitude travels in the other direction. This test allows a direct assessment of RELAP5 regarding two types of numerical error, dispersion and dissipation, since the method of characteristics is subject to neither of these errors. Numerical dispersion results from the inadequacy of a nodal solution to resolve high frequency signals and is evidenced as spatial "wiggles" with a wavelength of twice the nodal spacing. The dispersion was shown to be much worse for models with coarse node structure. Numerical dissipation stems from various sources, including the upwind differencing scheme. It is evidenced by the smoothing out of the pressure discontinuity as it travels along the pipe. Comparison of the PTA2 and RELAP5 results indicates that RELAP5 can adequately predict the pressure wave propagation if care is taken to ensure that the piping structure is modeled with sufficiently small nodes.

An additional, more demanding test case closer to the real geometry highlights the capability of RELAP5 to predict the magnitude of acoustic reflections and transmissions at abrupt area changes. The test was run using the actual flow path geometry for a single flow channel in the lower core, the annular upper fuel bypass region, and the 610-mm main hot leg header. An expansion wave was initiated in the hot leg, and the subsequent pressure distribution was compared with particular attention to reflections and transmissions at the interfaces between the hot leg and the upper fuel bypass and between the upper fuel bypass and the single fuel channel. Both of these changes in cross section represent area reductions in the direction that the signal initially travels. The acoustic impedance discontinuity is greatly exaggerated in this test problem, compared with the actual reactor geometry, because other parallel flow paths (e.g., the other fuel channels) have not been represented.

Figure 4.3 shows the results from PTA2 and RELAP5 at zero, 1, 3, and $5 \mathrm{~ms}$. At $1 \mathrm{~ms}$, the expansion wave is traveling up the main hot leg 


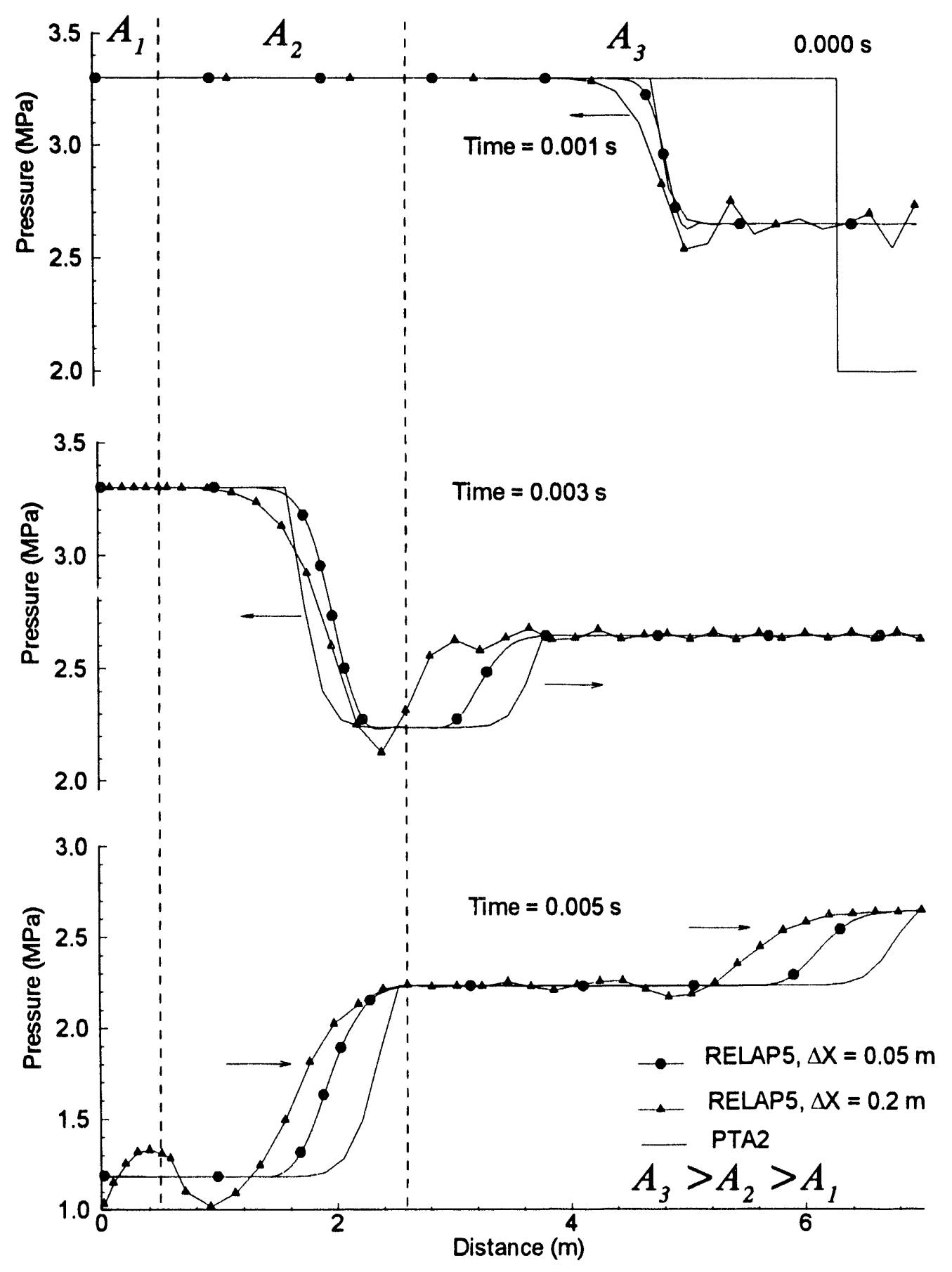

Fig. 4.3. Second pressure wave propagation test case: reflections and transmissions.

header toward the core. Between 1 and $3 \mathrm{~ms}$, a reflection and transmission occurs at the area change between the hot leg and the upper fuel bypass $\left(A_{3}\right.$ to $\left.A_{2}\right)$. At an area reduction, waves reflect and transmit without reversing polarity, so the expansion wave is reflected back and the amplitude of the wave traveling toward the core is increased. Between 3 and $5 \mathrm{~ms}$, the wave reaches 
the second area reduction $\left(A_{2}\right.$ to $\left.A_{1}\right)$, and a second reflection is produced. Once again the magnitude of the transmitted wave is increased. The comparison shows that RELAP5 tracks the magnitudes of the reflections and transmissions accurately with a numerical node length $(\Delta X)$ of $.05 \mathrm{~m}$. Because both codes are one-dimensional, the multidimensional nature of some of the problems is not addressed by either code (e.g., pressure wave propagation within the PSVAW).

\subsection{Flow excursion process}

Using the present correlations, the flow excursion phenomenon is the limiting criterion for many of the accident scenarios that are being studied for ANS. A task was initiated to evaluate the capability of RELAP5 to predict flow excursion phenomena. The first two parts of this task have been completed: (1) an evaluation against steadystate data of Costa of the RELAP5/MOD3 models and correlations pertinent to flow excursion behavior and (2) exercise RELAP5/MOD3 using a simple model of the ANS core region to demonstrate current code capabilities for predicting flow excursion behavior. Later RELAP5/MOD3 flow excursion correlations will be tested against existing experimental data of transient flow excursion behavior.

A comparison of RELAP5 calculated, subcooled, two-phase pressure drop to that measured by $\operatorname{Costa}^{27}$ in a rectangular channel was performed during the current fiscal year. The basic comparison is depicted in Fig. 4.4. The codecalculated pressure profile is represented with the solid circle symbols, while the measured pressure profile is represented with the solid square symbols. This figure shows that when the nominal test boundary conditions are used, the RELAP5calculated decline in pressure with distance from the inlet to the channel compares well with the test data in the single-phase region, but significantly underpredicts the pressure decline near the end of the channel where the fluid is two-phase. A parametric evaluation was performed to examine the sensitivities of this profile. The best matches between calculated and measured data were obtained when the inlet temperature was increased from nominal (from the $347 \mathrm{~K}$ reported in Costa's report to $358 \mathrm{~K}$ ) or the test section power was increased to $130 \%$ of nominal. RELAP5-predicted void profiles versus those inferred from the experiment also show some discrepancies. However, when the proper void fraction is present, the calculated pressure decline matches the experiment well. Therefore, both the RELAP5 single-phase and two-phase wall friction models appear to be reasonable for this application. The required parameter variation necessary to match experimental and calculated void fractions implies that the RELAP5 correlation used to determine the occurrence of the first void is not adequate for this application.

The evaluation of RELAP5's ability to undergo a flow excursion transient was examined in three different scenarios using a simplified model of the ANSR geometry. The model featured the standard RELAP5 three-channel representation of the low $r$ core region of ANS (an average channel, a 95\% nonexceedance-probability hot channel, and a $99.9 \%$ nonexceedance-probability hot channel) driven by inlet flow and temperature and an outlet pressure boundary condition. Three situations were evaluated with the model:

(1) declining core flow at full power (loss-of-flow transient), (2) declining exit pressure at full power (loss-of-coolant transier.t), and (3) declining core flow at reduced core power and natural-circulation flow rates (transition to natural circulation). Conclusions from these studies indicate that RELAP5 is capable of simulating flow excursion behavior (i.e., flow reduction in the channel as the vapor generation in the channel increases). It was also shown that flow excursion predicted by the Costa correlation (currently used to indicate fuel damage) was consistently more conservative than that predicted by RELAP5 (not surprising in view of the result discussed in the preceding paragraph). In addition, the RELAP5 simulations indicate relatively well-behaved and slowly developing flow excursion events. The durations of the calculated flow excursions appear long (sometimes on the order of seconds), indicating 
$P$ vs Length Sensitivity to Inlet Temperature and Power

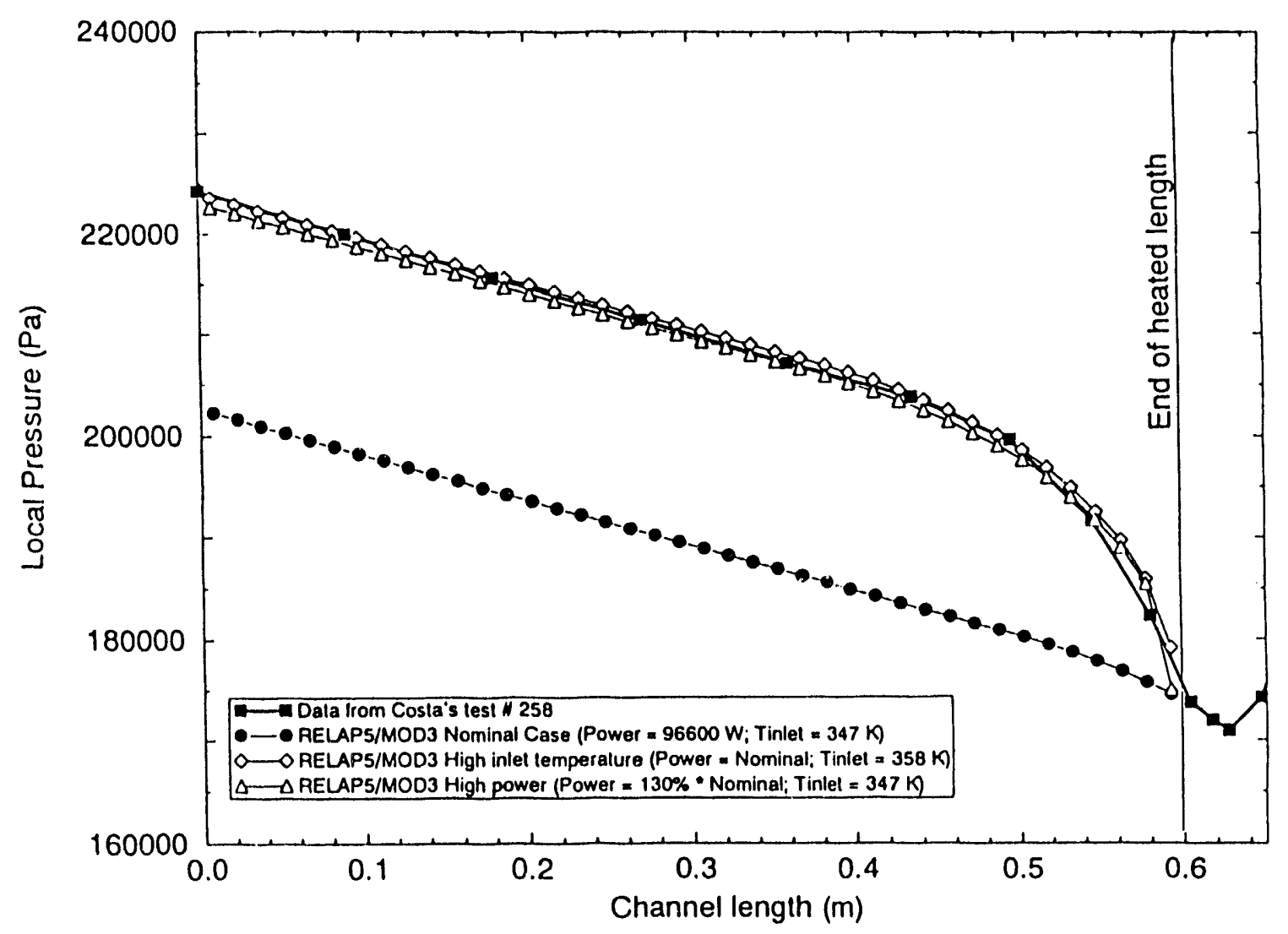

Fig. 4.4. Calculated and measured axial pressure profiles for Costa test 258.

that the assumption that the event occurs immediately once the Costa criteria is exceeded may also be conservative.

RELAP5 appears to have the capability of predicting the phenomenon of flow excursion; however, it will be necessary to evaluate and alter some of the correlations currently being used before relying on the code to predict this phenomenon accurately. For the time being, it will be adequately conservative to continue to utilize the Costa correlation to mark the onset of flow excursion because the correlation uses only the single-phase coolant properties and is not dependent upon mechanistic knowledge of the initiation of voiding and other two-phase phenomena. Additional validation of RELAP5 flow excursion modeling against measured testloop data is a part of the ANS Project's planned R\&D.

\subsection{Code-to-code comparisons}

During the current period, code-to-code comparisons were completed ${ }^{50}$ between RELAP5 and the ANS dynamic model and between RELAP5 and the pressure dynamics code. Both of these are single-phase transient codes designed to evaluate the effectiveness of the ANS reactor control and protection systems. The comparison 
included four transients: small and large pipe breaks with finite-time break openings, a station blackout event, and an $\$ 0.80$ reactivity insertion accident. The comparison was made for both steady-state (pretransient) and transient conditions.

The small break comparison considered a $51-\mathrm{mm}$ diam core outlet break with a $250-\mathrm{ms}$ break opening time (this event would simulate a crack in the outlet piping as there is actually no piping this size to rupture near the core outlet), while the large break comparison considered a DEG break in the PSVAW (356-mm break with a 1.1-s opening time). The station blackout event (loss of off-site power with failure of emergency diesel generators in start) was assumed to initiate main circulation and pressurizing pump trips, while letdown isolation was initiated by a low core inlet pressure signal. Secondary coolant flow is also assumed to be lost. The reactivity insertion event analyzed was an $\$ 0.80$ reactivity insertion, considered to be the bounding reactivity event. It represents a collapse of multiple beam tubes with both aluminum and vacuum volumes instantaneously replaced by $\mathrm{D}_{2} \mathrm{O}$.

A comparison of the predicted pressure responses for the 356-mm PSVAW break is presented in Fig. 4.5. The comparison between the codes for this transient and these parameters is extremely good. Other parameters such as local heat flux show some discrepancies because of slightly differing modeling assumptions. In general, the three codes produced very similar results for the transients compared when modeling assumptions and input parameters were the same in all three.

\subsection{SEVERE ACCIDENT STUDIES}

During the current reporting period, major scoping studies were completed on the performance characteristics of alternate containment concepts, the calculation of transient pressure pulse magnitude and duratior associated with hypothetical $D_{2}$-air detonation events at several points in the reactor building, and the preliminary estimates of the impact of fission product chemistry on releases of halogens and noble gasses from pools during severe accidents. In the experimental program, two in-pile powerburst experiments were successfully conducted using $\mathrm{U}_{3} \mathrm{Si}_{2}$-fueled miniplates in the NSRR.

Supporting model development and analyses were also initiated. Additionally, experimental data characterizing the interaction between subcooled water and molten $\mathrm{U}_{3} \mathrm{Si}_{2}-\mathrm{Al}$ droplets were analyzed, and a focused effort was put in place to develop a comprehensive severe accident experiment plan.

The results of these FY 1993 activities are summarized in the following sections.

\subsubsection{Performance Calculations for Alternate Containment Configuration Concepts}

In December 1992, a DOE review of the project resulted in a requirement for additional calculations of the relative merits of alternate containment concepts. The base case sequence utilized for the comparison calculations was selected from a series of scenarios that were previously analyzed (utilizing MELCOR and MACCS computer codes) and reported in the 1992 progress report." These studies had shown that steaming pool cases-those during which most of the decay heat of the fission products is deposited in coolant that becomes heated and liberates water vapor-would lead to larger overall pressure buildup. Specifically the CFR 100 scenario, based upon energy and radionuclide partitioning as suggested in 10 CFR 100, would lead to maximum steaming and pressurization loads, so this particular sequence was chosen as the base case for the calculations described below. In essence, this scenario postulates that at the start of the severe accident, $100 \%$ of the reactor core noble gasses, $25 \%$ of the halogen inventory, and $1 \%$ of the remaining radionuclides are sourced into the primary containment air volume, whereas the remainder stay within the reactor pool water, causing steaming. For conservatism, it was further assumed that the reactor pool water inventory would become depleted to $100 \mathrm{~m}^{3}$ because of a 


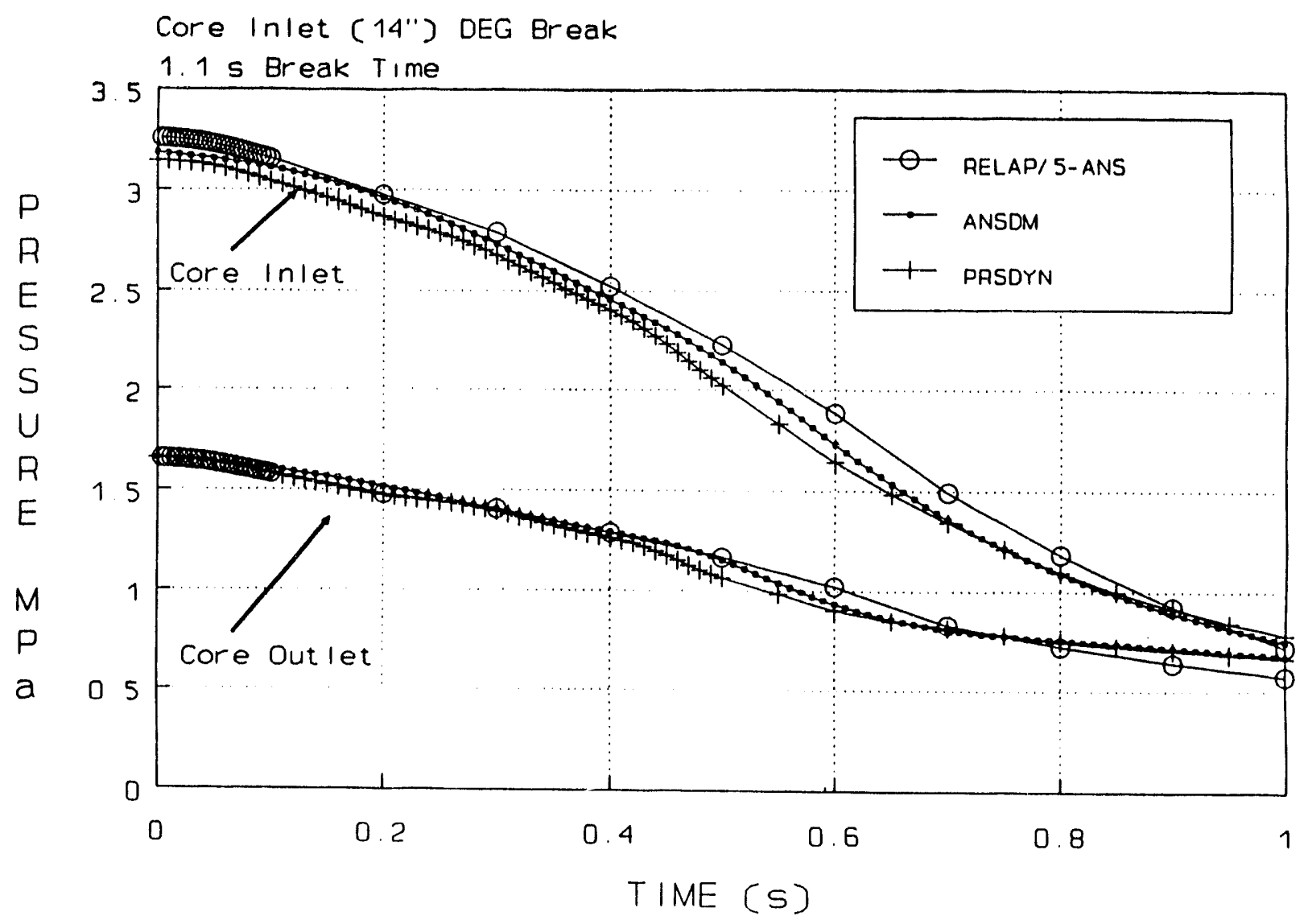

Fig. 4.5. Comparison in pressures at the lower core inlet and outlet during the double-ended guillotine break with $1100-m s$ opening time.

hypothetical seismic event. The MELCOR severe accident code ${ }^{51}$ was used to develop an overall model representation of the ANS containment and to capture transport and response phenomena. This model is a suitably modified version of that described in the FY 1992 progress report.

The CFR 100 scenario was evaluated using the above-mentioned MELCOR model for various combinations of containment configurations anu modeling parameters. A total of four different cases were analyzed as summarized in Table 4.2. Modeling was done to investigate single versus dual containment configurations and the presence or absence of air gaps between the steel shell and concrete backing. Table 4.2 also summarizes results of key thermal-hydraulic parameters of interest. Note that, as compared to the baseline design, the single steel containment case (CFR $100 \mathrm{~S}$ ) shows 25\% lower pressure buildup (because of enhanced convection cooling) but approximately an order of magnitude increase in radionuclide releases to the environment (because of elimination of the secondary containment).

The addition of a soncrete layer outside the steel primary (case CFR $100 \mathrm{SC}$ ) provides a massive heat sink that enhances heat removal over that seen in case CFR $100 \mathrm{~S}$ and reduces the pressure buildup somewhat. On the other hand, even a small air gap (case CFR 100 SCA) insulates the steel from the concrete and results in pressure buildup similar to that for the base case.

For the purpose of conducting a relative merit comparison from an off-site consequence standpoint of the dual versus single containment 
Table 4.2. Containment performance for the reference conceptual design and three alternatives

\begin{tabular}{|c|c|c|c|c|c|}
\hline Case identifier/description & $\begin{array}{c}\text { Pmax } \\
\text { kPa/psig }\end{array}$ & $\begin{array}{c}\text { Pfïnal } \\
\text { kPa/psig }\end{array}$ & $\begin{array}{l}\mathrm{Mrp} / \mathrm{Mfp}^{c} \\
\mathrm{~kg} \times 1000\end{array}$ & $\begin{array}{c}\text { Thb/Tan }{ }^{d} \\
(\mathrm{~K})\end{array}$ & $\begin{array}{c}\mathrm{t}, \mathrm{rp} / \mathrm{t}, \mathrm{fp} \mathrm{p}^{e} \\
(\mathrm{~h})\end{array}$ \\
\hline CFR 100 -base case & $121.5 / 2.8$ & $121.0 / 2.7$ & $60 / 0$ & $335 / 317$ & $3 / 150$ \\
\hline $\begin{array}{l}\text { CFR!O0 S-no secondary } \\
\text { containment (filtered leakage } \\
\text { to environment) }\end{array}$ & $115.0 / 2.0$ & $113.5 / 1.75$ & $60 / 0$ & $326 /-$ & $3 / 150$ \\
\hline $\begin{array}{l}\text { CFR } 100 \mathrm{SC} \text {-annulus gap } \\
\text { removed (concrete directly } \\
\text { on steel) }\end{array}$ & $113.5 / 1.75$ & $113.5 / 1.75$ & $60 / 0$ & $322 /-$ & $3 / 150$ \\
\hline $\begin{array}{l}\text { CFR } 100 \text { SCA-annulus gap } \\
\text { reduced to } 2.54 \mathrm{~mm}\end{array}$ & $117.0 / 2.5$ & $117.0 / 2.5$ & $60 / 0$ & $328 /-$ & $3 / 150$ \\
\hline
\end{tabular}

"Pmax-maximum pressure noted during transient up to $72 \mathrm{~h}$.

bPfinal--pressure at end of transient.

'Mrp/Mfp-boil-off mass of water for reactor pool and/or refueling pool.

"Thb/Tan-temperature of high bay volume and/or annulus.

et,rp/t,fp-time from start of transient to start of boiling for reactor pool and/or refueling pool.

configurations, the same CFR 100, CFR $100 \mathrm{~S}$, CFR 100 SC, and CFR 100 SCA cases were considered. The same assumption regarding primary containment leak was used for all cases $0.5 \% / \mathrm{d}$. Only the base case has a secondary containment; its leak rate is $10 \% / \mathrm{d}$, and all secondary containment effluent is filtered.

For calculational convenience, all the single containment cases are assumed to have a filtration system of efficiency equal to that of the secondary containment filtration system of the base case. In real life, this would not be possible because there would be no way to collect the leakage and direct it through the filtration system without changing the basic containment concept to a so-called confinement system. Primary containment leakage comprises the total of all the very small leakage flows from containment penetrations and airlocks. Without a secondary containment, the only way to collect and filter the primary containment leakage $\checkmark$ id be to maintain the primary containment building at a slight vacuum by constantly running fans whose exhaust is filtered. The disadvantage of this type of containment concept is that the total exhaust rate would increase from the $0.5 \% / \mathrm{d}$ maximum value to $10 \% / \mathrm{d}$ or more. While reading the following discussion, remember that the single containment results would actually be even worse than shown.

Initial comparison of radionuclide escape to the environment revealed that the source terms for CFR 100 SC and CFR 100 SCA cases were similar to, but bounded by, the source terms of the CFR $100 \mathrm{~S}$ case. Therefore, in-depth comparison is performed only between the base case and the CFR $100 \mathrm{~S}$ case. A previously developed, detailed MACCS code ${ }^{52}$ model for the ANS site was used. While conducting MACCS evaluations for this study, relocation, sheltering, and evacuation features were deactivated for conservatism (consistent with typical evaluations of radiological consequences per the 10 CFR 100 guidelines). Sample results of total population whole-body dose with distance at different confidence levels are displayed for the two cases in Fig. 4.6. As may be expected, the whole-body doses from the single containment configuration are larger by an order of magnitude than seen for the dual containment configuration. The disparity would have been even greater if efficient filtration had not been assumed, unrealistically, for single containment concepts compared. 


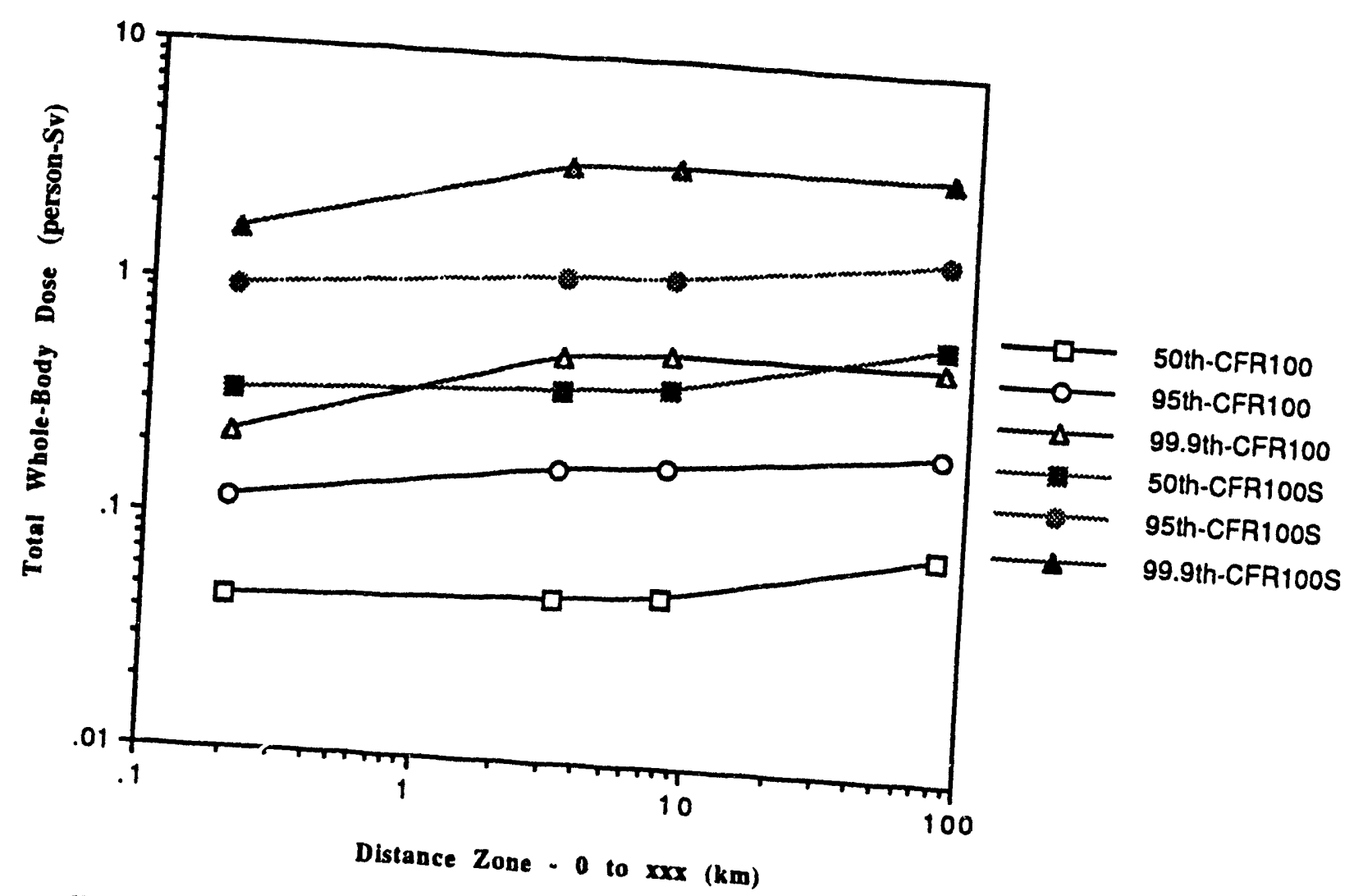

Fig. 4.6. Variation of whole-body dose for single and dual containments vs distance zone at various percentiles.

\subsubsection{Pressure Wave Calculations for Hypothetical Local $D_{2}$-Air Detonation
Events}

During the $\mathrm{D}_{2}$ combustion safety study discussed in 5 sct. 4.1, it was concluded that the very unlikely to assume a deuterium would be if released into asume a detonable configuration was desired to estirge open area. Nevertheless, it could generate loads whether a detonation event containment. This severe enough to damage performed to estimsection describes calculations pulses for a hypothetica detonation pressure upper bay and one in al detonation scenario in the floor. The magnitude and enclosure on the second suggests that a deto and duration of these loads would be unlikely to significe the reactor pool primary containely to significantly damage the relatively small ent steel shell, but that one in a relatively small enclosure could have duration and amplitude sufficient to cause yielding of structural

Shock wave generation and transport modeling and analyses were conducted to evaluate regimpact of deuterium detonations in two region of the ANS containment, viz., in the dome second floor of bay and in an enclosure on the schematically in experiment room, as shown calculations was 10 . 4.7. The purpose of these dependent, spatially valuate best-estimate, timehydrogen detorion loads for

Considerable uns in the two critical regions. complex thermancertainties associated with stratification, and random, effect of obstructions on turbulence, detailed moccurring ignition sources make task Severeling of every stage a formidable made. A key assumption wamptions had to be air mixture in the rang was that any hydrogen- 


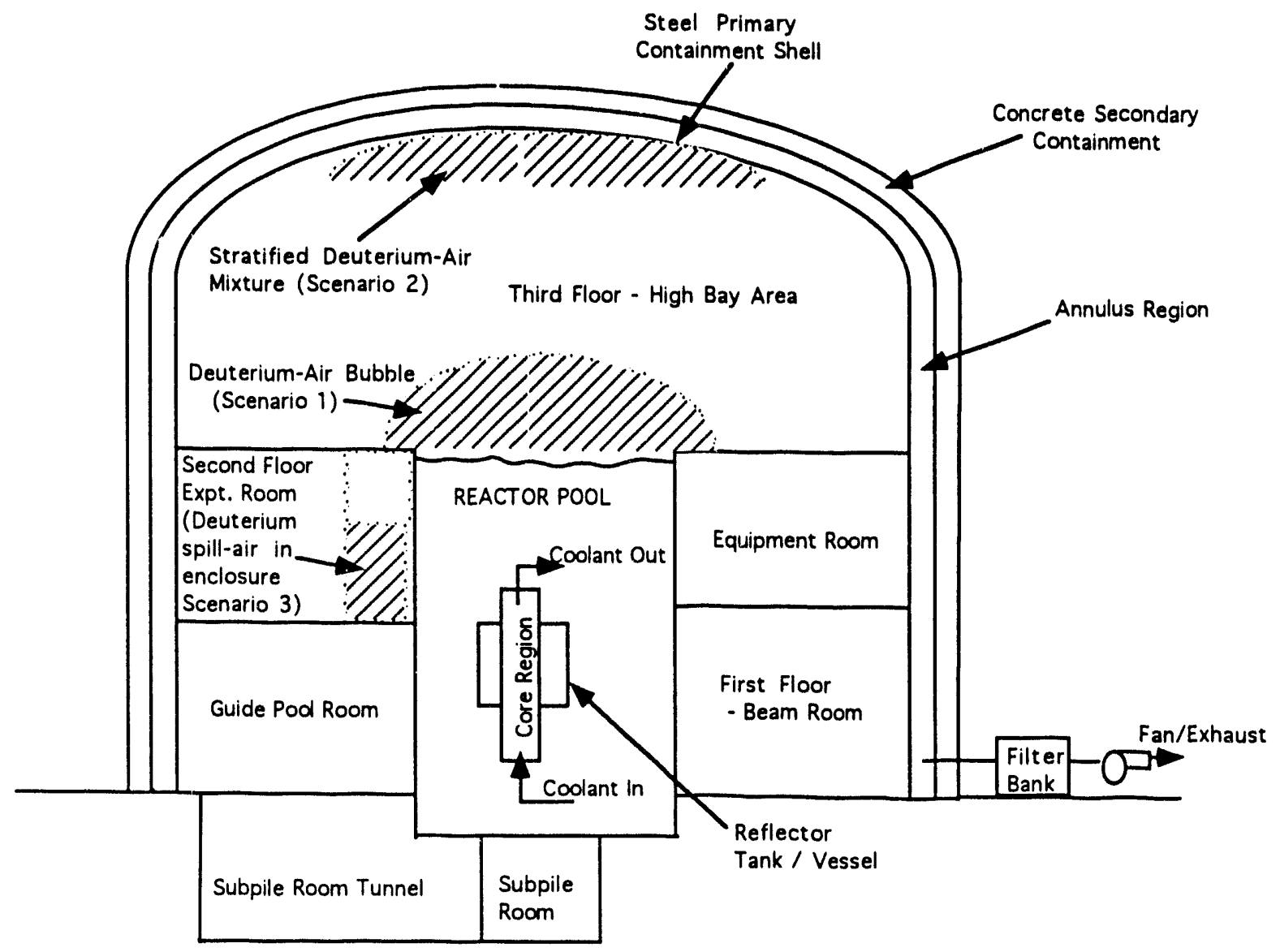

Fig. 4.7. Schematic representation of Advanced Neutron Source containment (showing deuterium-air mixture regions for detonation studies of scenarios 1,2 , and 3 ).

undergo a classical Chapman-Jouguet (C-J) detonation. A detonation would begin as a point source and propagate spherically outward. Volumetric heating to represent several ignition sources was also considered. Hydrogen-air mixtures were assumed to be uniform, and threedimensional effects were considered to be negligible. Further, model boundaries were assumed to be perfectly reflecting. It should be noted that such assumptions have also been utilized in the past for analysis ${ }^{53}$ of hydrogen detonations under power re $\omega_{\text {. }}$ : or severe accident conditions.

The principal tools utilized for the study were the $\mathrm{CTH}^{54}$ and CET89 $9^{55}$ computer codes. CTH is a highly sophisticated tool developed to evaluate shock wave physics, fluid-structure interactions, and missile penetration dynamics, along with multimaterial motion and response in one, two, and three dimensions. CET89 is a chemical equilibrium thermodynamics code developed to evaluate thermodynamics of reacting substances. For best-estimate e'valuations, CET89 results for various mixtures were utilized at the front end to set up appropriate shock-physics parameters associated with C-J detonations required as input to $\mathrm{CTH}$ for simulating a high explosive burning process. Specifically, CET89 was used to evaluate detonation parameters for three hydrogen-air volume fractions- $15 \mathrm{vol} \%, 29 \mathrm{vol} \%$. and 
58 vol \%-representing (in dry air) the lower detonation limit, the stoichiometric composition, and the upper detonation limit, respectively.

Three scenarios were postulated for this study. For scenario 1, it was conservatively assumed that the inventory of deuterium from both cold sources (totaling $40 \mathrm{~kg}$ of $\mathrm{D}_{2}$-equivalent to $20 \mathrm{~kg}$ of $\mathrm{H}_{2}$ ) is released into the reactor pool in conjunction with $20 \mathrm{~kg}$ of $\mathrm{D}_{2}$ postulated to be simultaneously released by a reactor severe accident with complete and rapid oxidation of all the aluminum in the reactor core. This $60-\mathrm{kg}$ inventory of $D_{2}$ is postulated to bubble out of the reactor pool (as seen in Fig. 4.7) and to mix with air in various proportions before undergoing a detonation event. Scenario 2 was modeled and analyzed for the situation wherein the $60 \mathrm{~kg}$ of $\mathrm{D}_{2}$ rises through the high bay volume and stratifies under the steel dome. Mixing and diffusion during transport were acknowledged for scenario 2 by assuming that the maximum hydrogen concentration would not exceed 15 vol \%. Scenario 3 involves the hypothetical escape of about $15 \mathrm{~kg}$ of deuterium liquid from a cryogenic component of one cold source onto the floor of the cold source cryogenic equipment room in the second floor experiment room. The $\mathrm{D}_{2}$ liquid is heated rapidly, evaporates, and mixes with surrounding air in various proportions before undergoing a detonation event.

An extensive series of one-dimensional spherical geometry simulations was first conducted before conducting two-dimensional model calculations for scenarios 1 and 2 . These onedimensional calculations were needed to conduct parametric studies to evaluate effects of nodalization, point ignition source versus volumetric heating, boundary effects, uncertainties in shock parameters such as detonation velocities, and detonation rate effects. Insights gained from these parametric studies were employed thereafter in conducting two-dimensional cylindrical geometry simulations for the dome region. Figure 4.8 provides a sample of pressurization results for regions right above the pool surface, at the intersection of the steel hemispherical shell and the high bay floor, and at the top of the hemispherical dome, respectively. Results are shown for scenarios 1 and 2 for 15 vol \% detonation events. As noted from Fig. 4.8, significant variations can be noted in shock pressure buildup as well as dissipation, underscoring the importance of multidimensional studies for such geometries. Further, it was found that the stoichiometric concentration case gives rise to largest loadings, followed by the $15 \mathrm{vol} \%$ case and, finally, by the $58 \mathrm{vol} \%$ case. The $58 \mathrm{vol} \%$ case results in incomplete combustion of hydrogen because of depletion of available oxygen

For scenario 3, a one-dimensional rectangular geometry model was developed and exercised for the three concentration values. Briefly, except for magnitude and duration of pressure pulses, the essential results are similar to those seen for the first two scenarios. Because of space considerations, results are not displayed for this scenario.

An important phenomenon for all scenarios deals with high temperatures calculated in the explosion zones. The impact of these flame temperatures on safety and nonsafety related equipment $v$ ill be addressed in future studies.

\subsubsection{Fission Product Chemistry Scoping Study}

Previous MELCOR models for radionuclide transport for steaming pool scenarios did not account for chemistry effects. MELCOR models radioiodine as being in an elemental form, wherein release of this important radionuclide from water pools is dependent on the vapor pressure curve alone. Effects of radiolysis, hydrolysis, and evaporation are not modeled in MELCOR. A computer program, tentatively designated CHEMANS-93, was developed at ORNL based upon mathematical models developed for the TRENDS code ${ }^{5 t}$ to describe the fission product chemistry behavior of iodine and noble gasses. The application of this code is for an event of a hypothetical severe accident in which the core inventory of fission products is uniformly dispersed 


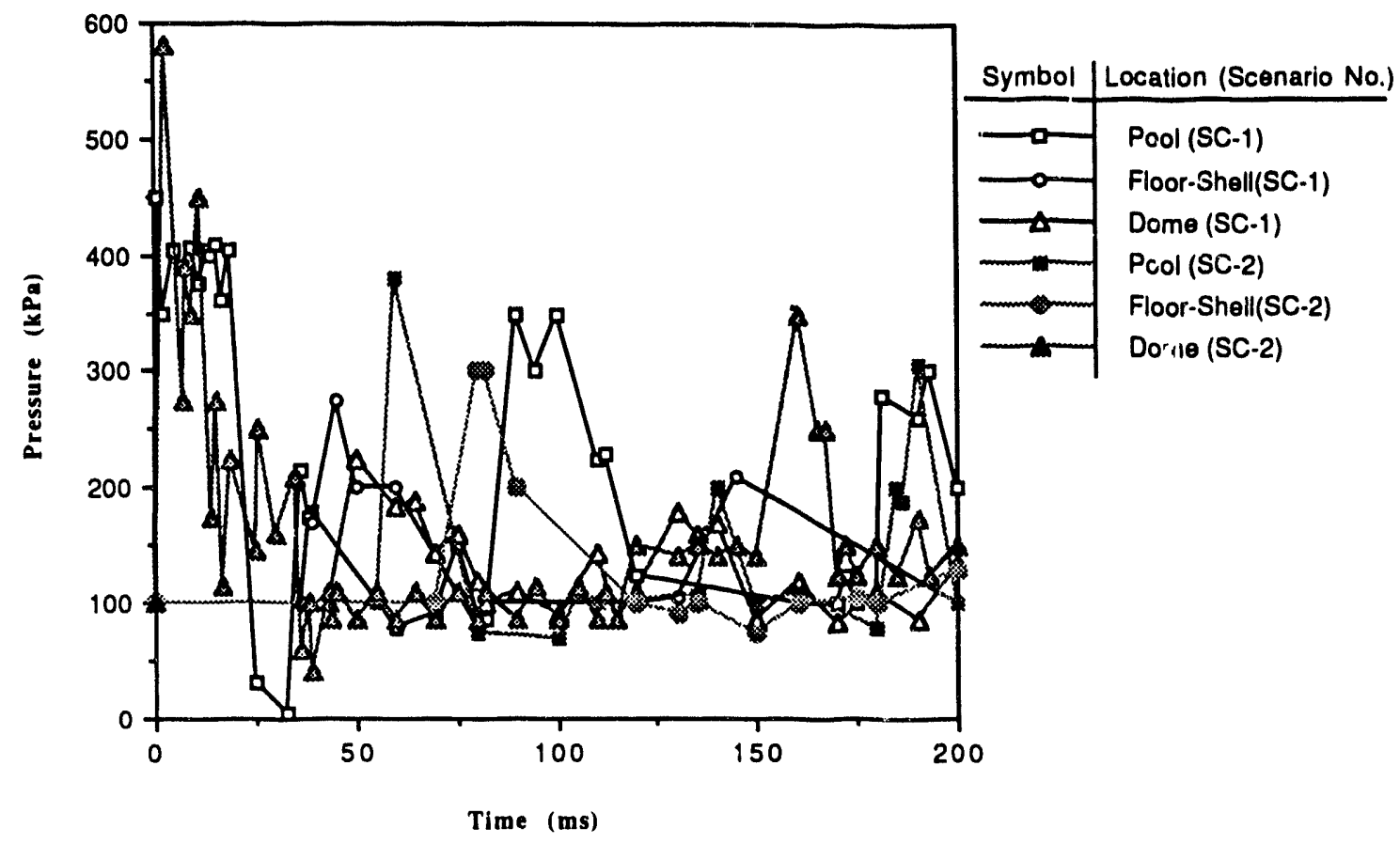

Fig. 4.8. Variation of pressure with time during hydrogen detonations in Advanced Neutron Source containment $(\mathrm{SC}-1$ = scenario $1 ;$ SC-2 = scenario 2$)$.

into the reactor pool. Behavior of iodine is assumed to be governed by radiolysis, hydrolysis, and evaporation, whereas behavior of noble gasses is assumed to be governeu oy evaporation only. Before conducting ANS-specific calculations, comprehensive parametric studies were conducted to note effects of pool $\mathrm{pH}$, temperature, and volume. Initial iodine sourced into the reactor pool was conservatively assumed to be molecular iodine, i.e., in its most volatile form. ANS-specific calculations indicated that the releases of iodine can be potentially in the $10 \%$ range for small pool volumes (i.e., $50 \mathrm{~m}^{3}$ ) and $\mathrm{h}$ igh temperatures $\left(98^{\circ} \mathrm{C}\right)$. Negligible $(<1 \%)$ releases were evaluated for larger pool volumes of $600 \mathrm{~m}^{3}$ combined with normal operating temperatures and buffered $\mathrm{pH}$ level of 6.0. It was found that the $\mathrm{pH}$ level has the strongest influence on iodine release. For example, iodine releases of $74 \%$ were evaluated for a $\mathrm{pH}$ level of 4.0 , and only about $10^{-3} \%$ for $\mathrm{pH}=7.1$. Noble gasses are released over short periods of time, depending on pool volume and temperature. The results of this scoping study provided valuable insights on key parametric variations. It provides conservative guidelines where applicable (e.g., when pool cooling equipment is functional) and will be used for planning further studies. 


\subsubsection{Severe Accident Experimentation and Related Analysis}

During FY 1993, detailed severe accident experiment planning began. Table 4.3 shows a list of the proposed severe accident experiments. As seen from Table 4.3, most of the experiments are separate-effects type of tests that endeavor to evaluate the key phenomena of interest on an individual basis to the extent possible. These experiments are needed to provide necessary insights for conducting mathematical modeling and simulation for risk evaluation and for assisting in validation of incorporated design features.

During FY 1993, significant progress was made in developing cooperative efforts at testing of ANS fuel plates under rapid energy deposition conditions in JAERI's NSRR. Specifically, two miniplates were fabricated, shipped to JAERI in Japan, and successfully subjected to power bursts in the NSRR. Valuable data have already been obtained at two energy deposition levels to evaluate onset of plate bowing, cracking, and melting, although the results are believed to be

Table 4.3. Matrix of severe accident studies-related experiments under study

\begin{tabular}{|c|c|c|}
\hline Number & Severe accident test & Need addressed/information desired \\
\hline 1 & FCI shock tube test & $\begin{array}{l}\text { Benchmarking data on triggerability, thermal-to-mechanical } \\
\text { conversion (with and without ignition) }\end{array}$ \\
\hline 2 & FCI small scale testing & Fundamentals of ANS fuel onset of ignition and dispersion \\
\hline 3 & Physical properties & $\begin{array}{l}\text { Additional physical properties for thermal-hydraulic severe } \\
\text { accident calculations }\end{array}$ \\
\hline 4 & Transient fuel performance & $\begin{array}{l}\text { Obtain design basis information on bowing, cracking, and } \\
\text { energy thresholds for disruptive behavior fuel-coolant } \\
\text { interaction energetics }\end{array}$ \\
\hline 5 & Debris-structure interaction & $\begin{array}{l}\text { Characterize fundamentals of interactions between ANS fuel } \\
\text { debris and structures }\end{array}$ \\
\hline 6 & Flow blockage/damage propagation & Evaluate damage initiation and propagation \\
\hline 7 & Fission product release/chemistry & $\begin{array}{l}\text { Obtain basic information related to fission product release and } \\
\text { chemistry of ANS silicide fuels in steam }\end{array}$ \\
\hline 8 & Debris coolability & $\begin{array}{l}\text { Evaluate what constitutes coolability (thermal-hydraulics of } \\
\text { cooling) }\end{array}$ \\
\hline 9 & Fuel melting/dispersion & $\begin{array}{l}\text { Determine how the fuel comes apart and disperses in flowing } \\
\text { medium essentially in intact mode }\end{array}$ \\
\hline 10 & $\begin{array}{l}\text { Core-concrete-interaction mitigation } \\
\text { confirmatory tests }\end{array}$ & $\begin{array}{l}\text { Similar to debris-structure interaction test but with a larger } \\
\text { scale apparatus and including water }\end{array}$ \\
\hline 11 & Containment thermal-hydraulics & $\begin{array}{l}\text { Evaluate natural convection heat transfer, transport of fission } \\
\text { products, flow patterns, holdup }\end{array}$ \\
\hline
\end{tabular}

Note: Tests $1-5$ have currently been determined to have a higher priority. 
conservative because the miniplates were much less homogeneous than the specifications for actual ANS fuel plates would permit. Efforts have been incorporated towards developing mathematical models for capturing the physics of these complex processes. Specifically, a threedimensional model has been developed with the HEATING-7 code ${ }^{57}$ and is being exercised. Initial results look promising. This model is being extended further to accommodate fuel meat inhomogeneities and boundary fluid behavior. We have also developed a first-cut two-dimensional structural dynamics model using the $\mathrm{CTH}$ code. This model is being tested. Once operational in three-dimensional format, this model should be capable, in principal, of providing details of material fracture, bowing, stretching, and dispersion. Because of the long computation time required for such problems, we have also introduced efforts to place CTH on a parallel virtual machine at ORNL. These efforts have been successful, in that CTH now operates on ORNL's
Kendall-Square Research parallel processing computer (although on a single processor) and may eventually be extended to multiple processors, if resources permit. Five additional NSRR tests under a variety of conditions are planned for $\mathrm{FY}$ 1994. $\mathrm{U}_{3} \mathrm{Si}_{2}-\mathrm{Al}$ droplet steam explosion tests at the University of Wisconsin were brought to a close, data having been obtained to characterize molten aluminum-water steam explosion behavior. The $\mathrm{Al}-\mathrm{H}_{2} \mathrm{O}$ interactions were analyzed using wavelet theory. Results of this exercise provided insights into fundamentals of fragmentation behavior. However, significant difficulties were encountered during testing with $\mathrm{U}_{3} \mathrm{Si}_{2}$-Al mixtures, which become highly viscous upon melting and eutectic formation. The mixtures were very difficult to drop coherently into a water chamber because of the eutectic sticking to the sides of the crucible. It was clear that this mode of fuel mixture delivery would not provide necessary information on the propensity of molten ANS fuel to undergo a steam explosion event. 


\section{PUBLICATIONS FY 1993}

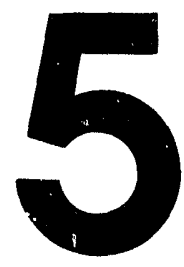

R. E. Battle and G. T. Alley, "Issues of Verification and Validation of Application-Specific Integrated Circuits in Reactor Trip Systems," Proceedings American Nuclear Society Topical Meeting on Nuclear Plant Instrumentation, Control, and Man-Machine Interface Technologies, American Nuclear Society, Oak Ridge, April 1993.

N. C. J. Chen, "Loss-of-Coolant Accident Mitigation for the Advanced Neutron Source Reactor," Proceedings 29th ASME/AIChE/ANS/AIAA National Heat Transfer Conference, Atlanta, August 1993.

J. E. Cleaves, “Advanced Neutron Source Main Control Complex Video,” videotape, April 1993.

J. E. Cleaves and W. M. Fletcher, "ANS Main Control Complex Three-Dimensional Computer Model Development," Proceedings American Nuclear Society Topical Meeting on Nuclear Plant Instrumentation, Control, and Man-Machine Interface Technologies, American Nuclear Society, Oak Ridge, April 1993.

A. Crabtree and M. Siman-Tov, Thermophysical Properties of Saturated Light and Heavy Water for Advanced Neutron Source Applications, ORNL/TM-12322, May 1993.

V. Georgevich, R. P. Taleyarkhan, and C. Nestor, "Modeling and Analysis of Steam Explosion Energetics in Uranium-A.luminum Fueled Reactors," Proceedings International Topical Meeting on Probabilistic Safety Assessment (PSA '93), Clearwater, Florida, January 1993.

V. Georgevich et al., "Modeling and Analysis of Recriticality-Induced Severe Accidents During Refueling for the Advanced Neutron Source Reactor at Oak Ridge National Laboratory," Proceedings Second International Conference on Nuclear Engineering (ICONE-2), San Francisco, March 1993.

M. L. Gildner, ANS Quality Assurance Plan, Rev. 2, ORNL/TM-11446, June 1993.

R. M. Harrington and C. D. West, "Designing for Safety in the Conceptual Design of the Advanced Neutron Source," Proceedings Eleventh International System Safety Conference, University of Cincinnati, July 1993.

J. B. Hayter, "New Techniques in Neutron Scattering," Proceedings Fifth International Symposium on Advanced Nuclear Energy Research, Mito, Ibaraki, Japan, March 1993.

J. B. Hayter, “A Self-Consistent Theory of Dressed Micelles," Langmuir 1992 8, 2873. 
M. M. Houser, "Advanced Neutron Source Operating Philosophy," Proceedings American Nuclear Society Topical Meeting on Nuclear Plant Instrumentation, Control, and Man-Machine Interface Technologies, American Nuclear Society, Oak Ridge, April 1993.

S. H. Kim, R. P. Taleyarkhan, and V. Georgevich, "Containment Performance Analyses of the Advanced Neutron Source Reactor at the Oak Ridge National Laboratory," Proceedings International Topical Meeting on Probabilistic Safety Assessment (PSA '93), Clearwater, Florida, January 1993.

S. H. Kim et al., "Modeling and Analysis of Core Debris Recriticality During Hypothetical Severe Accidents in the Advanced Neutron Source Reactor," Proceedings Second International Conference on Nuclear Engineering (ICONE-2), San Francisco, March 199?

S. H. Kim and R. P. Taleyarkhan, Source Term and Radiolngical Consequence Evaluation for the AG'vanced Neutron Source Conceptual Safety Report, ORNL/TM-12301, September 1993.

K. Morsk, An Investigation of Scramming the Outer Shutdown Rods of the ANS with No Reversal of Flow' in the Marifold Inlet Lines, ORNL/M-2259, October 1992.

R. E. Pawel et al., "The Corrosion Behavior of 8001 Al Under Heat-Transfer Conditions in an Aqueous Loop System," Proceedings National Association of Corrosion Engineers Annual Meeting, New Orleans, March 1993.

R. E. Pawel et al., The Corrosion Behavior of 8001 Al Under Heat-Transfer Conditions in an Aqueous Loop System, ORNL/NPR-92/65, April 1993.

R. E. Pawel, D. K. Felde, and M. T. McFee, "The Development of an Improved Correlation for Corrosion Product Growth on Aluminum Alloy Fuel Cladding for the Advanced Neutron Source," Proceedings TMS/NACE/ANS 6th International Symposium on Environmental Degradation of Materials in Nuclear Systems, San Diego, August 1993.

F. J. Peretz, Summary Report of the ANS Containment Workshop, CONF-9008150, September 1993.

W. K. Sartory, Nonlinear Analysis of Hydraulic Buckling Instability of ANS Involute Fuel Plates, ORNL /TM-12319, April 1993.

L. W. Scarbrough, Department of Energy, Advanced Neutron Source Fact Sheet, ORNL/M-2828, May 1993.

L. W. Scarbrough, The Advanced Neutron Source Briefing Manual, ORNL/M-2910, June 1993.

D. L. Selby, The Research and Development Plan for the ANS, ORNL/TM-12249, September 1992.

D. L. Selby, R. M. Harrington, and P. B. Thompson, Advanced Neutron Source Project Progress Report. FY 1992, ORNL-6723, January 1993.

88 Advanced Neutron Source (ANS) Progress Report 
M. Siman-Tov et al., "Experimental Investigation of Thermal Limits in Parallel Plate Configuration for the ANS Recctor," Symposium Series Vol. 89, Proceedings 29th ASME/AIChE/ANS/AIAA National Heat Transfer Conference, Atlanta, August 1993.

I. K. Snook, Royal Melbourne Institute of Technology, and J. B. Hayter, Oak Ridge National Laboratory, "Static Structure of Strongly Interacting Colloidal Particles," Langmuir 1992 8, 2880-2884.

W. F. Swinson et al., "Fuel Plate Stability Experiments and Analysis for the Advanced Neutron Source," J. Pressure Vessel Tech., American Society of Mechanical Engineers, July 1993.

W. F. Swinson et al., Fuel Plate Stability Experiments and Analysis for the Advanced Neutron Source, ORNL/TM-12353, May 1993.

W. F. Swinson et al., "Structural Response of Reactor Fuel Plates to Coolant Flow," Pressure Vessels and Piping, Vol. 258, Flow Induced Vibration and Fluid-Structure Interaction, 21-33, American Society of Mechanical Engineers, 1993.

R. P. Taleyarkhan, S. H. Kim, and V. Georgevich, "Radiological Consequence Analyses of the Advanced Neutron Source Reactor at the Oak Ridge National Laboratory," Proceedings International Topical Meeting on Probabilistic Safety Assessment (PSA '93), Clearwater, Florida, January 1993.

R. P. Taleyarkhan et al., Core Debris Recriticality Modeling and Analysis Under Severe Accident Conditions for the ANS, ORNL/TM-12302, May 1993.

R. P. Taleyarkhan, "Overview of Severe Accident Modeling and Analysis Work for the Advanced Neutron Source Conceptual Safety Analysis Report," Proceedings Third International Workshop on Severe Accident Research, Tokyo, Japan, November 1992.

P. B. Thompson, Oak Ridge National Laboratory, and W. E. Meek, Gilbert/Commonwealth, Inc., "The Advanced Neutron Source (ANS) Project, A World-Class Research Reactor Facility," Proceeding.s 1993 Annual Meeting of the American Nuclear Society, San Diego, June 1993.

C. D. West, ed., IGORR News, Issue No. 4, March 1993 (newsletter).

C. D. West et al., ANS News Source, Issue No. 3, March 1993 (newsletter).

C. D. West, The Advanced Neutron Source Reactor Summary Description and Safety Features, May 1993 (pamphlet).

C. D. West, "International Group on Research Reactors (IGORR)," Neut. News, September 1993.

C. D. West, "A Status Report on the Advanced Neutron Source Project," Proceedings 3rd Meeting International Group on Research Reactors (IGORR-III), Naka-machi, Ibaraki-ken, Japan, October 1993. 
C. D. West, "Dosimetry Issues for an Ultra-High Flux Beam and Multipurpose Research Reactor Design," Proceedings Eighth ASTM-EURATOM Symposium on Reactor Dosimetry, Vail, Colorado, September 1993.

G. T. Yahr, "Fatigue Design Curves for 6061-T6 Aluminum," Pressure Vessels and Piping, Vol. 259, Changing Priorities for Codes and Standards, American Society of Mechanical Engineers, 1993.

90 Advanced Neutron Source (ANS) Progress Report 


\section{REFERENCES}

1. Basic Energy Sciences Advisory Committee, Neutron Sources for America's Future, DOE/ER0576P, U.S. Department of Energy, Office of Energy Research, Washington, January 1993.

2. U.S. Department of Energy, Order No. 5700-6C, Quality Assurance, August 1991.

3. K. Scharmer and H. G. Eckert, FOEHN: The Critical Experiment for the Franco-German High Flux Reactor, ORNL/TR-91/23, Martin Marietta Energy Systems, Inc., Oak Ridge Natl. Lab., 1991, translated from the German report KFK 1064 issued by Kernforschungszentrum, December 1971.

4. J. F. Breismeister, MCNP Version 3b, Monte Carlo Neutron and Photon Transport Code System, LA-7396-M, Rev. 2, Los Alamos National Laboratory, Los Alamos, New Mexico, September 1986.

5. A. M. Ougouag et al., Idaho National Engineering Laboratory, MCNP Analysis of the FOEHN Critical Experiment, ORNL/TM-12466, Martin Marietta Energy Systems, Inc., Oak Ridge Natl. Lab., October 1993.

6. A. E. Bergles and W. M. Rohsenow, Forced Convection Surface Boiling Heat Transfer and Burnout in Tubes of Small Diameter, DSR Report No. 8767-21, Department of Mechanical Engineering, Massachusetts Institute of Technology, Boston, 1962.

7. J. Rest and G. L. Hofman, "Kinetics of Recrystallization and Fission-Gas-Induced Swelling in High Burnup $\mathrm{UO}_{2}$ and $\mathrm{U}_{3} \mathrm{Si}_{2}$ Nuclear Fuels," Fundamental Aspects of Inert Gases in Solids, p. 443, F. E. Donnelly and J. H. Evans, eds., Plenum Press, New York, 1991.

8. D. L. Selby, R. M. Harrington, and F. J. Peretz, Advanced Neutron Source (ANS) Project Progress Report, ORNL-6574, Martin Marietta Energy Systems, Inc., Oak Ridge Natl. Lab., April 1990.

9. D. L. Selby, R. M. Harrington, and F. J. Peretz, Advanced Neutron Source (ANS) Project Progress Report, ORNL-6656, Martin Marietta Energy Systems, Inc., Oak Ridge Natl. Lab., February 1991.

10. D. L. Selby, R. M. Harrington, and P. B. Thompson, Advanced Neutron Source (ANS) Project Progress Report, FY 1991, ORNL-6696, Martin Marietta Energy Systems, Inc., Oak Ridge Natl. Lab., January 1992.

11. D. L. Selby, R. M. Harrington, and P. B. Thompson, Advanced Neutron Source (ANS) Project Progress Report, FY 1992, ORNL-6723, Martin Marietta Energy Systems, Inc., Oak Ridge Natl. Lab., January 1993. 
12. R. E. Pawel et al., The Development of a Preliminary Correlation of Data on Oxide Growth on 6061 Aluminum under ANS Thermal-Hydraulic Conditions, ORNL/TM-11517, Martin Marietta Energy Systems, Inc., Oak Ridge Natl. Lab., June 1990.

13. R. E. Pawel et al., Th:- Corrosion Behavior of 8001 Al Under Heat-Transfer Conditions in an Aqueous Loop System, ORNL/NPR-92/65, Martin Marietta Energy Systems, Inc., Oak Ridge Natl. Lab., April 1993.

14. R. E. Pawel et al., "Fuel Cladding Corrosion Studies for the Advanced Neutron Source," Trans. Am. Nuc. Soc. 61, 388 (1990).

15. R. E. Pawel et al., "The Corrosion of 6061 Aluminum under Heat Transfer Conditions in the ANS Corrosion Test Loop," Oxid. Met. 36 (1/2), 175 (1991).

16. G. L. Yoder et al., "The Effect of Aluminum Corrosion on the Advanced Neutron Source Fuel Design," Nucl. Eng. Design 136, 401 (1992).

17. R. E. Pawel et al., "The Corrosion Behavior of 8001 Al Under Heat Transfer Conditions in an Aqueous Loop System," NACE CORROSION '93, Paper No. 188, New Orleans, March 1993.

18. R. E. Pawel, D. K. Felde, and M. T. McFee, "The Development of an Improved Correlation for Corrosion Product Growth on Aluminum Alloy Fuel Cladding for the Advanced Neutron Source," Proceedings 6th International Symposium on Environmental Degradation of Materials in Nuclear Power Systems, TMS/NACE/ANS, San Diego, August 1993.

19. M. Leddineg, "Unstabilitact der Stroemung bei natuerlichem und Zwangumlauf," die Warme 61(48), 891-898 (1938).

20. M. Leddineg, "Flow Distribution in Forced-Circulation Boilers," Eng. Digest 10, 85-89 (1949).

21. D. K. Felde, G. L. Yoder, and D. Skrzycke, "The Advanced Neutron Source Thermal Hydraulic Test Loop," Proceedings 8th Power Plant Dynamics, Control, and Testing Symposium, Knoxville, Tennessee, May 1992.

22. M. Siman-Tov et al., "Experimental Investigation of Thermal Limits in Parallel-Plate Configuration for the Advanced Neutron Source Reactor," AIChE Symposium Series, Vol. 89 , Proceedings 29th National Heat Transfer Conference, Atlanta, August 1993.

23. R. B. Duffey and E. D. Hughes, "Static Flow Instability Onset in Tubes, Channels, Annuli, and Rod Bundles," ASME HTD-Vol. 150, Proceedings ASME Winter Annual Meeting, Dallas, November 1990.

24. S. C. Lee and S. G. Bankoff, "Prediction of the Onset of Significant Void in Down Flow Subcooled Nucleate Boiling," ASME HTD-Vol. 197, Proceedings 28th National Heat Transfer Conference and Exhibition, San Diego, August 199?. 
25. J. T. Rogers and J. Li, "Prediction of the Onset of Significant Void in Flow Boiling of Water," ASME HTD-Vol. 217, Proceedings ASME Winter Annual Meeting, Anaheim, California, November 1992.

26. E. D. Waters, Heat Transfer Experiments for Advanced Test Reactor, BNWL-216, UC-80 (TID4500), Battelle Northwest Laboratory, Richland, Washington, May 1966.

27. J. Costa, Measurement of the Momentum Pressure Drop and Study of the Appearance of Vapor and Change in the Void Fraction in Subcooled Boiling at Low Pressure, ORNL/TR-90/21, Martin Marietta Energy Systems, Inc., Oak Ridge Natl. Lab., 1967.

28. R. H. Whittle and R. Forgan, "A Correlation for the Minima in the Pressure Drop vs Flow-Rate Curves for Subcooled Water Flowing in Narrow Heated Channels," Nucl. Eng. Design 6, 89-99 (1967).

29. P. Saha and N. Zuber, "Point of Net Vapor Generation and Vapor Void Fraction in Subcooled Boiling," Proceedings 5th International Heat Transfer Conference, Tokyo IV, 175-179 (1974).

30. D. R. Vondy, T. B. Fowler, and G. W. Cunningham, III, The Bold Venture Computation System for Nuclear Reactor Core Analysis, Version III, ORNL-5711, Martin Marietta Energy Systems, Inc., Oak Ridge Natl. Lab., November 1987.

31. J. C. Gehin, A Quasi-Static Polynomial Nodal Method for Nuclear Reactor Analysis, Ph.D Thesis, Department of Nuclear Engineering, Massachusetts Institute of Technology, Boston, August 1992.

32. W. K. Stromquist and O. Sisman, High Flux Reactor Fuel Assemblies Vibration and Water Flow, ORNL-50, Oak Ridge Natl. Lab., June 1948.

33. J. O. Johnson, ed., A User's Manual for MASH 1.0-A Monte Carlo Adjoint Code System, (see Chap. 3.0-GRTUNCL), ORNL/TM-1 1778, Martin Marietta Energy Systems, Inc., Oak Ridge Natl. Lab., March 1992.

34. W. A. Rhoades and R. L. Childs, "The DORT Two-Dimensional Discrete Ordinates Transport Code," Nucl. Sci. Eng. 99(1), 88-89 (May 1988).

35. E. P. Ficaro and D. K. Wehe, "Monte Carlo Simulations of the ${ }^{252} \mathrm{Cf}$-Source-Driven Noise Analysis Measurements for Determining Subcriticality," Procedures International Topical Meeting Advances in Mathematics, Computations, and Reactor Physics 1, 5.22.1-10 (1991).

36. J. March-Leuba and M. Ibn-Khayat, "Dynamic Modeling of the Advanced Neutron Source Reactor," Trans. Am. Nucl. Soc. 61, 386-388 (June 1990).

37. M. Ibn-Khayat, J. March-Leuba, and R. B. Perez, "LOCA Mitigation Studies for the Advanced Neutron Source: The Inertial Flow Diode Concept," Trans. Am. Nucl. Soc. 64, 305-306 (1991). 
38. V. H. Ransom et al., "RELAP5/MOD2 Code Manual, Vols. I-IV," NUREG/CR-4312, EGG-2396, August 1985.

39. R. S. Booth, ANS Configuration Management Plan, ORNL/ANS/INT-36/S2/RB, Martin Marietta Energy Systems, Inc., Oak Ridge Natl. Lab., June 1993.

40. Project Control Document (PCD), Preparation, Review, Approval, Revision, and Baseline Release, ANS-1201-93-2, Rev. 2, Advanced Neutron Source Project, Martin Marietta Energy Systems, Inc., Oak Ridge Natl. Lab., January 1993.

41. The Process Safety Institute Presents: BRAVO 2.0 $0^{\odot}$, A Windows 3.l Program for Quantitative Risk Assessment, JBF Associates, Inc., Knoxville, Tennessee, 1993.

42. PLG-0500, Data Base for Probabilistic Risk Assessment of Light Water Nuclear Power Plants, PLG, Inc., Newport Beach, California, November 1991.

43. FLUENT User's Guide, Addendum Version 4.2, FLUENT, Inc., Lebanon, New Hampshire, June 1993.

44. Flow-3D Theory, Flow Science, Inc., Los Alamos, New Mexico, 1991.

45. R. W. Shumway, Heat Transfer Smoothing in the RELAP5/MOD3 Code, EGG-NRE-10885, EG\&G Idaho, Idaho National Engineering Laboratory, Idaho Falls, Idaho, September 1993.

46. P. W. Dittus and L. M. K. Boelter, "Heat Transfer in Automobile Radiators of the Tubular Type," Univ. Calif. Pub. Eng. 2(13), 443-461 (1930), reprinted in Int. Comm. Heat Mass Transfer 12, 3-22 (1985).

47. J. C. Chen, "A Correlation for Boiling Heat Transfer to Saturated Fluids in Convective Flow," Proceedings 6th National Heat Transfer Conference, American Society of Mechanical Engineers, Boston, August 1963.

48. B. S. Petukhov, "Heat Transfer and Friction in Turbulent Pipe Flow with Variable Physical Properties," Advances in Heat Trans. 6, 528 (1970).

49. C. K. Youngdahl, C. A. Kot, and R. A. Valentin, Experimental Validation of PTA-I Computer Code for Pressure Transient Analysis Including the Effect of Pipe Plasticity, ANL-78-38, Argonne National Laboratory, Chicago, July 1978.

50. N. C. J. Chen et al., Validation and Verification of RELAP5 for Advanced Neutron Source Accident Analysis: Part I, Comparisons to ANSDM and PRSDYN Codes, ORNL/TM-12418/V1, Martin Marietta Energy Systems, Inc., Oak Ridge Natl. Lab., November 1993.

51. R. M. Summers et al., "MELCOR 1.8.0: A Computer Code for Nuclear Reactor Severe Accident Source Terms and Risk Assessment Analyses," NUREG/CR-553I, January 1991.

94 Advanced Neutron Source (ANS) Progress Report 
52. D. Chanin et al., "MELCOR Accident Consequence Code System-MACCS Version 1.5," NUREG/CR-4691 (1990).

53. R. K. Byers, "CSQ Calculations of $\mathrm{H}_{2}$ Detonations in the Zion and Sequoyah Nuclear Plants," NUREG/CR-2385, July 1982.

54. J. M. McGlaun and S. L. Thompson, "CTH: A Three-Dimensional Shock Wave Physics Code," Intl. J. Impact Eng. 10, 251-360 (1990).

55. S. Gordon and B. J. McBride, Computer Program for Calculation of Complex Chemical Equilibrium Compositions, Rocket Performance, Incident and Reflected Shocks, and ChapmanJouquet Detonations, NASA SP-273, National Aeronautics and Space Administration, Lewis Research Center, Cleveland, Ohio, March 1976.

56. C. F. Weber, E. C. Beahm, and T. S. Kress, Models of Iodine Behavior in Reactor Containments, ORNL/TM-12202, Martin Marietta Energy Systems, Inc., Oak Ridge Natl. Lab., October 1992.

57. K. W. Childs, HEATING-7.2 User's Manual, ORNL/TM-12262, Martin Marietta Energy Systems, Inc., Oak Ridge Natl. Lab., February 1993. 


\section{INTERNAL DISTRIBU'TION}

1. C. W. Alexander

2. D. J. Alexander

3. R. R. Allen

4. R. G. Alsmiller

5. E. E. Alston

6. J. L. Anderson

7. B. R. Appleton

8. J. W. Baker

9. R. E. Battle

10. J. E. Bigelow

11. E. E. Bloom

12. R.S. Booth

13. W. W. Bowman

14. R. A. Brown

15. J. A. Bucholtz

16. G. J. Bunick

17-18. J. H. Campbell

19. R. M. Canon

20. P. F. Cento

21. N. C. J. Chen

22. R. D. Cheverton

23. K. K. Chipley

24. J. E. Cleaves

25. J. T. Cleveland

26. G. L. Copeland

27. J. A. Crabtree

28. W. G. Craddick

29. D. F. Craig

30. J. R. DeVore

31. J. R. Dixon

32. H. L. Dodds

33. F. F. Dyer

34. W. W. Engle

35. G. Farquerson

36. D. K. Felde

37. R. E. Fenstermaker

38. G. F. Flanagan

39. J. C. Gehin

40. R. K. Genung
41. V. Georgevich

42-43. M. L. Gildner

44. G. E. Giles

45. R. W. Glass

46. H. A. Glovier

47. D. C. Haberkost

48-49. R. M. Harrington

50-51. J. B. Hayter

52. W. R. Hendrich

53. S. E. Holliman

54. L. L. Horton

55. R. O. Hussung

56. M. Z. Ibn-Khayat

57. D. T. Ingersoll

58-61. R. L. Johnson

62. J. E. Jones, Jr.

63. M. J. Kania

64. H. T. Kerr

65. S. H. Kim

66. W. E. Kohn

67. R. A. Lillie

68. M. A. Linn

69. P. S. Litherland

70. A. T. Lucas

71. L. K. Mansur

72. J. A. March-Leuba

73. M. F. Marchbanks

74-75. B. S. Maxon

76. G. T. Mays

77. M. T. McFee

78. S. V. McGrath

79. T. J. McManamy

80. G. R. McNutt

81. J. T. Mihalczo

82. H. A. Mook

83. R. M. Moon

84. D. G. Morris

85. M. D. Muhlheim

86. J.A. Murray 
87. R. K. Nanstad

88. W. R. Nelson

89. T. F. Orlin

90. J. Park

91. F. S. Patton

92. R. E. Pawel

93. H. R. Payne

94-95. F. J. Peretz

96. A. B. Poole

97. G. M. Powers

98. C. C. Queen

99. S. Raman

100. C. T. Ramsey

101. J. S. Rayside

102. W. R. Reed

103. J. P. Renier

104. J. B. Richard

105. J. B. Roberto

106. J. J. Robinson

107. R. Rothrock

108. T. L. Ryan

109. R. E. Saylor

110. J. P. Schubert

111. J. D. Sease

112-113. D. L. Selby

114. H. B. Shapira

115. W. D. Shults

116. M. Siman-Tov
117. B. R. Smith

118. J. O. Stiegler

119. N. E. Stone

120. T. K. Stovall

121. C. Sulfridge

122. W. F. Swinson

123. R. P. Taleyarkhan

124. D. W. Theisen

125-126. P. B. Thompson

127. K.R. Thoms

128. S. R. Tompkins

129. A. W. Trivelpiece

130. B. D. Warnick

131. M. W. Wendel

132-133. C. D. West

134. J. L. Westbrook

135. D. M. Williams

136. B. A. Worley

137. A. L. Wright

138. G. T Yahr

139. G. L. Yoder

140. ORNL Patent Office

141. Central Research Library

142. Document Reference Section

143. Y-12 Technical Library

144-145. Laboratory Records Dept.

146. Laboratory Records (RC)

\section{EXTERNAL DISTRIBUTION}

147. G. Aeppli, AT\&T Bell Laboratories, 600 Mountain Avenue, Murray Hill, NJ 07974

148. P. Ageron, Institut Laue Langevin, 156X 38042, Grenoble Cedex, France

149. J. Ahlf, Joint Research Center, Institute for Advanced Materials, 1755 ZG Petten, P.O. Box 2, The Netherlands

150. P. Armbruster, Institut Laue Langevin, 156X 38042, Grenoble Cedex, France

151. T. Asaoka, Deputy Director General, Tokai Research Establishment, Japan Atomic Energy Research Institute, Tokai-mura, Naka-gun, Ibaraki-ken, Tokyo 319-11, Japan

152. R. Awan, Division of Energy Research Reactors, Office of Nuclear Energy, Department of Energy, NE-473, Washington, DC 20585

153. J. Axe, Brookhaven National Laboratory, Building 510A, Upton, NY 11973

154. A. Axmann, Hahn-Meitner Institute Berlin, N3, Glienicker Str. 100, D-1000 Berlin 39 , Germany

155. F. Bates, Department of Chemical Engineering and Material Science, University of Minnesota, 151 Amundson Hall, 421 Washington Avenue, SE, Minneapolis, MN 55455 
156. G. S. Bauer, Paul Scherrer Institute, CH-5234 Villigen, Switzerland

157. J. M. Baugnet, Nuclear Services Program, S.C.K./C.E.N., Boeretang 200, B2400 Mol, Belgium

158. M. Bieth, High Flux Reactor Division, Institute for Advanced Materials, J.R.C. Petten, P.O. Box 2, 755 ZG Petten, The Netherlands

159. R. J. Birgeneau, Dean of Science, Building 6, Room 123, Massachusetts Institute of Technology, Cambridge, MA 02139

160. R. C. Birtcher, Argonne National Laboratory, 9700 S. Cass Avenue, Argonne, IL 60439

161. K. Böning, Fakultät für Physik E21, Technische Universität München, D-8046 Garching, Germany

162. R. L. Boyd, 17742 December Pine, Spring, TX 77379

163. P. Breant, CEN Saclay, SPS ORPHEE, 91191 Gif-sur-Yvette Cedex, France

164. R. Burns, Gilbert/Commonwealth, Inc., GH2-3597, P.O. Box 1498, Reading, PA 19603-1498

165. H. A. Capote, Burns \& Roe, 800 Kinderkamack Road, Oradell, NJ 07649

166. C. S. Cargill, III, IBM, T. J. Watson Research Center, P. O. Box 218, Yorktown Heights, NY 10598

167. G. K. Carlough, DRS/Hundley Kling Gmitter, Architects-Planners, One Gateway Center, Pittsburgh, PA 15222

168. J. M. Carpenter, Building 360, Argonne National Laboratory, 9700 S. Cass Avenue, Argonne, IL 60439

169. K. N. Clausen, RISO National Laboratory, Physics Department Postbox 49, DK-4000 Roskilde, Denmark

170. K. K. Conway, Laboratory Facilities Branch, U.S. Department of Energy, Oak Ridge Operations Office, CE-523, P. O. Box 2001, Oak Ridge, TN 37831-2001

171. R. S. Denning, Sr. Research Leader for Nuclear Safety, Battelle Memorial Institute, 505 King Avenue, Columbus, $\mathrm{OH} 43201$

172. C. Desandre, Technicatome, Centre d'Etudes Nucleaires de Saclay, BP17, 92291 Gif-surYvette Cedex, France

173. G. J. Earhardt, Missouri University Research Reactor, University of Missouri, Columbia, MO 65211

174. Y. Elkassabgi, Texas A\&I University, Department of Mechanical Engineering, Kingsville, TX 78363

175. W. C. Etter, Project Manager, Stone \& Webster Engineering Corporation, 702 S. Illinois Ave., Suite B-104, Oak Ridge, TN 37831

176. Y. Fanjas, MTR Fuel Technical and Project Manager, CERCA, BP 1114, 26104 Romans Cedex, France

177. B. Farnoux, CEN Saclay, Laboratoire Leon Brillouin, 91191 Gif-sur-Yvette Cedex, France

178. R. F. Fleming, Michigan Memorial Phoenix Project, 3034 Phoenix Memorial Laboratory, University of Michigan, North Campus, Ann Arbor, MI 48109-2100

179. C. D. Fletcher, Idaho National Engineering Laboratory, P.O. Box 1625, Idaho Falls, ID 83415

180. R. R. Fullwood, Building 130, Brookhaven National Laboratory, Upton, NY 11973

181. W. R. Gambill, Route 5, Box 220, Clinton, TN 37716

182. W. Glaser, Fakultät für Physik, Technische Universität München, D-8046 Garching, Germany

183. A. N. Goland, Department of Applied Science, Brookhaven National Laboratory, Upton, NY 11973

184. H. N. Goldstein, Gilbert/Commonwealth, Inc., P.O. Box 1498, Reading, PA 19603-1498

185. G. L. Greene, Room A141, Building 221, National Institute of Standards and Technology, Gaithersburg, MD 20899 
186. B. Gupta, AECL Technologies, 1155 Metcalfe Street, 8th Floor, Montreal, Quebec, H3B 2V6 Canada

187. O. K. Harling, Massachusetts Institute of Technology, 77 Massachusetts Avenue, Cambridge, MA 02139

188. H. L. Harlow, Central Research and Development Experimental Station, E. I. duPont de Nemours and Co., Inc., Wilmington, DL 19898

189. J. R. Harries, Embassy of Australia, 1601 Massachusetts Avenue, NW, Washington, DC 20036

190. D. Henderson, University of Wisconsin - Madison, Nuclear Engineering and Engineering Physics Department, 1500 Johnson Drive, Madison, WI 53706

191. A. F. Henry, Professor, Department of Nuclear Engineering, Massachusetts Institute of Technology, 77 Massachusetts Avenue, Cambridge, MA 02139

192. G. L. Hofman, Argonne National Laboratory, 9700 S. Cass Avenue, Argonne, IL 60439

193. D. Y. Hsia, P.O. Box 3, Lung-lan, Taoyuan, Taiwan, ROC

194. R. A. Hunter, Director, Office of Facilities, Fuel Cycle/Test Programs, Department of Energy, NE-47, Washington, DC 20585

195. L. C. Ianniello, Acting Associate Director, Office of Basic Energy Sciences, Office of Energy Research, U.S. Department of Energy, ER-10, Washington, DC 20585

196. M. Iizumi, Japan Atomic Energy Research Institute, Tokai Research Establishment, Tokaimura, Naka-gun, Ibaraki-ken 319-11, Tokyo, Japan

197. T. Iwasaki, Department of Nuclear Engineering, Tohuku University, Aoba, Aramari, Aobaku, Sendai-shi, Japan 980

198. S. N. Jahshan, Idaho National Engineering Laboratory, P.O. Box 1625, Idaho Falls, ID 83415

199. J. D. Jorgensen, Materials Science Division, Argonne National Laboratory, Argonne, IL 60439

200. A. Jostsons, Director, Advanced Materials Program, Australian Nuclear Science \& Technology Organization, New Illawarra Road, Lucas Heights, NSW, Australia

201. E. W. Kaler, Chemical Engineering Department, University of Delaware, Newark, DL 19716

202. M. Kaminaga, Department of Research Reactor Operations, Japan Atomic Energy Research Institute, Tokai-mura, Naka-gun, Ibaraki-ken 319-11, Tokyo, Japan

203. K. Kanda, Research Reactor Institute, Kyoto University, Kumatori-cho, Sennan-gun, Osaka 590-04, Japan

204. T. W. Kerlin, University of Tennessee, Department of Nuclear Engineering, 315 Pasqua Engineering Building, Knoxville, TN 37996-2300

205. J. D. Kling, DRS Hundley Kling Gmitter, Architects-Planners, One Gateway Center, Pittsburgh, PA 15222

206. E. Koonen, BR2 Department, CEN/ SCK, Boeretang 200, B-2400 MOL, Belgium

207. W. Krull, GKSS, Postfach 1160 , D-2054 Geesthacht, Germany

208. N. Kunitomi, Osaka University, 1-1 Yamadaoka, Fuita-Shi, Osaka 565, Japan

209. K. S. Kwok, Massachusetts Institute of Technology, Nuclear Reactor Laboratory, 138 Albany Street, Cambridge, MA 02139

210. R. T. Lahey, Jr., Department of Nuclear Engineering and Engineering Physics, Jonsson Engineering Center, Rensselaer Polytechnic Institute, Troy, NY 12180-3590

211. J. A. Lake, Manager, Nuclear Engineering and Reactor Design, Idaho National Engineering Laboratory, P.O. Box 1625, Idaho Falls, ID 83415

212. D. Lancaster, Georgia Institute of Technology, Atlanta, GA 30332 
213. A. G. Lee, Atomic Energy of Canada, Ltd., Whiteshell Nuclear Research Establishment, Pinawa, Manitoba, ROE 1L0, Canada

214. L. LeSage, Argonne National Laboratory, 9700 S. Cass Avenie, Argonne, IL 60439

215. R. F. Lidstone, Atomic Energy of Canada, Ltd., Whiteshell Nuclear Research Establishment, Pinawa, Manitoba, ROE ILO, Canada

216. R. Lindstrom, Inorganic Analytical Research, Division (551), Building 245, National Institute of Standards and Technology, Gaithersburg, MD 20899

217. S. Matsuura, Japan Atomic Energy Research Institute, Tokai Research Establishment, Tokaimura, Naka-gun, Ibaraki-ken 319-11, Tokyo, Japan

218. J. Mays, Babcock \& Wilcox, Inc., P.O. Box 785, Lynchburg, VA 24505-0785

219. J. C. McKibben, Research Reactor Facility, University of Missouri-Columbia, Research Park, Columbia, MO 65211

220. G. McCormick, Babcock \& Wilcox, Inc., P.O. Box 785, Lynchburgh, VA 24505-0785

221. W. E. Meek, Project Manager, Gilbert/Commonwealth, Inc., P.O. Box 1498, Reading, PA 19603-1498

222. A. I. Miller, Manager Chemical Engineering, AECL Research, Chalk River Laboratories, Chalk River, Ontario, KOJ IJO Canada

223. B. H. Montgomery, 109 Miramar Circle, Oak Ridge, TN 37830

224. J. P. Mulkey, Division of Energy Research Reactors, Office of Nuclear Energy, U.S. Department of Energy, NE-473, Washington, DC 20585

225. H. Nakata, Project Engineering Division, Department of JMTR Project, Japan Atomic Energy Research Institute, Oarai Ibaraki-ken, Tokyo, Japan

226. G. R. Odette, Department of Chemical \& Nuclear Engineering, University of California, Santa Barbara, CA 93016

227. C. H. Oh, Idaho National Engineering Laboratory, P.O. Box 1625, Idaho Falls, ID 83415

228. J. Oliver, Office of Facilities, Fuel Cycle/Test Programs, U.S. Department of Energy, NE 473, Washington, DC 20585

229. W. T. Oosterhuis, Materials Science Division, Office of Basic Energy Sciences, Office of Energy Research, U.S. Department of Energy, ER-132, Washington, DC 20585

230. S. L. Ostrow, Ebasco Services, Inc., 2 World Trade Center, 89th Floor, New York, NY 10048

231. R. A. Page, Southwest Research Institute, 6220 Culebea Road, P. O. Drawer 28510, San Antonio, TX 78228-0510

232. M. P. Paidousis, McGill University, Department of Mechanical Engineering, 817 Sherbrooke Street W, Montreal, PQ Canada H3A2K6

233. D. Patterson, Tennessee Technology Foundation, 10915 Hardin Valley Road, Knoxville, TN 37932

234. Y. V. Petrov, Sanct-Petersburg Nuclear Physics Institute, Russian Academy of Science, 188350 Gatchina, Sanct-Petersburg District, Federal Republic of Russia

235. H. J. Prask, National Institute of Standards \& Technology, A-106 Reactor, Gaithersburg, MD 20899

236. R. Pynn, Director, LANSCE, Los Alamos National Laboratory, Los Alamos, NM 87545

237. T. J. Raney, Ebasco Services, Inc., 2 World Trade Center, 89th Floor, New York, NY 10048

238. J. Rest, Argonne National Laboratory, 9700 S. Cass Avenue, Argonne, IL 60439

239. H. Reutler, Siemens, Friedrich-Ebert-Strasse, D-5060 Bergisch-Gladbach 1, Germany

240. J. J. Rhyne, Missouri University Research Reactor, University of Missouri, Columbia, MO 65211 
241. H.-J. Roegler, Siemens, Friedrich-Ebert-Strasse, D-5060 Bergisch-Gladbach 1, Germany

242. M. Rowe, National Institute of Standards and Technology, Washington, DC 20234

243. A. E. Ruggles, University of Tennessee, Department of Nuclear Engineering, 315 Pasqua Engineering Building, Knoxville, TN 37996-2300

244. J. J. Rush, National Institute of Standards and Technology, Bldg. 235, Rm. E151, Gaithersburg, MD 20899

245. T. P. Russell, Almaden Research Center, IBM Research Laboratories K91/802, 650 Harry Road, San Jose, CA 95120

246. J. M. Ryskamp, Idaho National Engineering Laboratory, P.O. Box 1625, Idaho Falls, ID 83415

247. T. Shibata, Japan Atomic Energy Research Institute, Kinki University, Kowakae, HigashiOsaka, Osaka 577, Japan

248. P. J. Shipper, Gilbert/Commonwealth, Inc., P.O. Box 1498, Reading, PA 19603-1498

249. E. Shirai, Department of Research Reactor Operations, Japan Atomic Energy Research Institute, Tokai-mura, Naka-gun, Ibaraki-ken 319-11, Tokyo, Japan

250. C. Shuping, Director of Reactor Engineering Department, Institute of Atomic Energy, P.O. Box 275, Beijing PRC

251. S. K. Sinha, CR-SL, Exxon Research \& Engineering Co., Route 22E, Annandale, NJ 0880 I

252. J. B. Slater, AECL Research, Chalk River Nuclear Laboratories, Chalk River, Ontario, KOJ IJO Canada

253. J. L. Snelgrove, ANS Fuels Development Task Leader, Argonne National Laboratory, 9700 S. Cass Avenue, Argonne, IL 60439

254. E. Steichele, Physik-Department, der Technische Universität München, D 8046 Garching München, Germany

255. R. S. Stein, Polymer Research Institute, University of Massachusetts, Amherst, MA 01002

256. A. Steryl, University of Rhode Island, Physics Dept., Kingston, RI 028849

257. P. T. Talarico, Gilbert/Commonwealth, Inc., P.O. Box 1498, Reading, PA 19603-1498

258. T. G. Theofanous, Theofanous \& Company, Inc., 857 Sea Ranch Drive, Santa Barbara, CA 93109

259. I. L. Thomas, Director, Materials Science Division, Office of Energy Research, U.S. Department of Energy, ER-13, Washington, DC 20585

260. V. Tschinkel, Landers \& Parsons, 310 W. College Ave., Tallahasse, FL 3230I

261. B. R. Upadhyaya, Department of Nuclear Engineering, University of Tennessee, Knoxville, TN 37996-2300

262-266. U.S. Department of Energy, Oak Ridge Operations Office, FEDC, MS-8218, P.O. Box 2009, Oak Ridge, TN $37831-8218$

267. M. Utsuro, Research Reactor Institute, Kyoto University, Kumatori-cho, Sennan-gun, Osaka 59()-()4, Japan

268. J. Verdier, Centre d'Etudes Nucleaices, SBT, 85X, 38041 Grenoble Cedex, France

269. S. F. Wang, P.O. Box 3, Lung-tan, T toyuan, Taiwan, ROC

270. J. M. Warren, Gilbert/Commonweat/h, Inc., 1055 Commerce Park Drive, Suite 200, Oak Ridge, TN 37830

271. L. West, College of Engineering, Uriversity of Arkansas, Mechanical Engineering Building, Fayetteville, AR 72701

272. C. A. Wemple, Idaho National Engineering Laboratory, P.O. Box 1625, Idaho Falls, ID 83415

102 Advanced Neutron Source (ANS) Progress Report 
273. S. H. White, Department of Physiology and Biophysics, University of California School of Medicine, Irvine, CA 92717

274. W. L. Whittemore, Senior Scientific Advisor, TRIGA Group, General Atomics Technologies, Inc., P. O. Box 85608, San Diego, CA 92138

275. R. F. Wichman, AECL Research, Chalk River Nuclear Laboratories, Chalk River, Ontario, KOJ IJO Canada

276. T. C. Wiencek, Argonne National Laboratory, 9700 S. Cass Avenue, Argonne, IL 60439

277. R. Wilson, Department of Physics, Harvard University, Cambridge, MA 02138

278. P. W. Winkler, Air Products and Chemicals, Inc., 7201 Hamilton Boulevard, Allentown, PA 18195-1501

279. A. W'lodawer, NCl-FCRF, ABL-Basic Research Program, P.O. Box B, Frederick, MD 21701

280. H. G. Wood, III, Associate Professor, Department of Mechanical and Aerospace Engineering, Thornton Hall, University of Virginia, Charlottesville, VA 22901

281. Y. H. Yang, P.O. Box 3, Lung-tan, Taoyuan, Taiwan, ROC

282. A. Zucker, 103 Orange Lane, Oak Ridge, TN 37830

283. Office of Assistant Manager for Energy Research and Development, U.S. Department of Energy, Oak Ridge Operations Office, P.O. Box 2001, Oak Ridge, TN 37831-2001

284. Office of Honors and Awards, P. King, P.O. Box 2008, Building 2518, MS-6324, Oak Ridge, TN 37831-6324

285-286. Office of Scientific and Technical Information, P.O. Box 62, Oak Ridge. TN 37831 


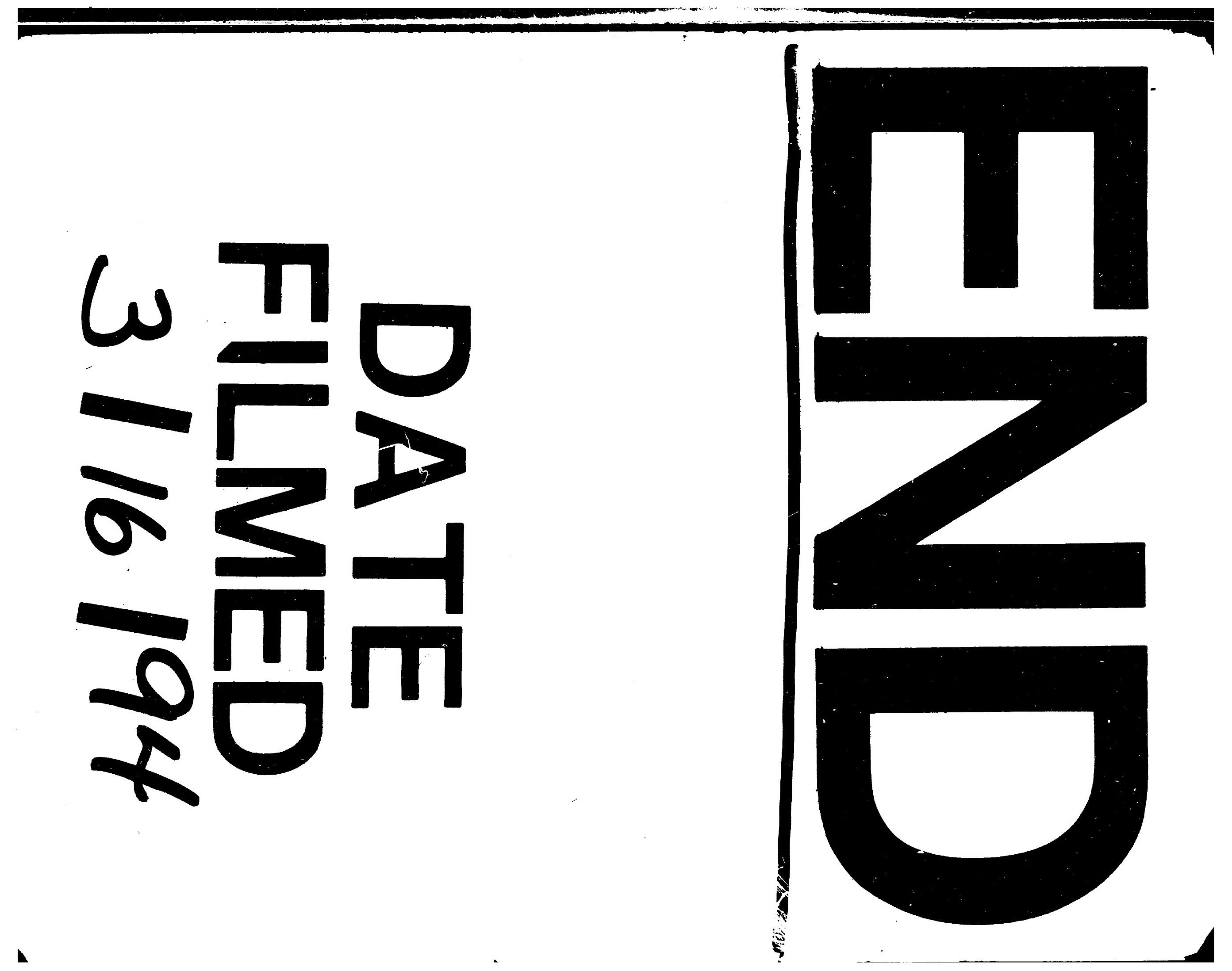


